\title{
Air quality in the eastern United States and Eastern Canada for 1990-2015: 25 years of change in response to emission reductions of $\mathrm{SO}_{2}$ and $\mathrm{NO}_{x}$ in the region
}

\author{
Jian Feng ${ }^{1}$, Elton Chan $^{2}$, and Robert Vet ${ }^{1, \hat{\zeta}}$ \\ ${ }^{1}$ Air Quality Measurement and Analysis Research Section, Atmospheric Science and Technology Directorate, \\ Environment and Climate Change Canada, Toronto, Canada \\ ${ }^{2}$ Measurements, Modelling and Interpretation Section, Atmospheric Science and Technology Directorate, \\ Environment and Climate Change Canada, Toronto, Canada \\ retired from Environment and Climate Change Canada in 2018.
}

Correspondence: Jian Feng (jian.feng@ canada.ca)

Received: 24 June 2019 - Discussion started: 15 August 2019

Revised: 6 February 2020 - Accepted: 11 February 2020 - Published: 16 March 2020

\begin{abstract}
SO}_{2}$ and $\mathrm{NO}_{x}$ are precursors to form sulfate, nitrate, and ammonium particles in the air, which account for more than $50 \%$ of $\mathrm{PM}_{2.5}$ mass in the eastern US (Bell et al., 2007) and are dominant components of $\mathrm{PM}_{2.5}$ during many smog events (Dabek-Zlotorzynska et al., 2011). $\mathrm{H}_{2} \mathrm{SO}_{4}$ and $\mathrm{HNO}_{3}$, formed from the oxidation of $\mathrm{SO}_{2}$ and $\mathrm{NO}_{x}$, respectively, are the main sources of acid deposition through wet and dry depositions. $\mathrm{NO}_{x}$ is also a precursor to the formation of tropospheric $\mathrm{O}_{3}$, which is an important atmospheric oxidant and is also essential for the formation of other atmospheric oxidants, such as $\mathrm{OH}$ and $\mathrm{H}_{2} \mathrm{O}_{2}$.

In the past 26 years from 1990 to 2015, emissions of $\mathrm{SO}_{2}$ and $\mathrm{NO}_{x}$ in the US were significantly reduced from 23.1 and 25.2 million $\mathrm{tyr}^{-1}$ in 1990 to 3.7 and 11.5 million $\mathrm{t} \mathrm{yr}^{-1}$ in 2015, respectively. In Canada, $\mathrm{SO}_{2}$ and $\mathrm{NO}_{x}$ were reduced by $63 \%$ and $33 \%$ from 1990 to 2014. In response to the significant reductions of $\mathrm{SO}_{2}$ and $\mathrm{NO}_{x}$ emissions, air quality in the eastern US and Eastern Canada improved tremendously during 1990-2015. In this study, we analyzed surface air concentrations of $\mathrm{SO}_{4}^{2-}, \mathrm{NO}_{3}^{-}, \mathrm{NH}_{4}^{+}$, $\mathrm{HNO}_{3}$, and $\mathrm{SO}_{2}$ measured weekly by the Clean Air Status and Trends Network (CASTNET) in the US and measured daily from the Canadian Air and Precipitation Monitoring Network (CAPMoN) in Canada to reveal the temporal and spatial changes in each species during the 25-year period. For the whole eastern US and Eastern Canada, the annual mean concentrations of $\mathrm{SO}_{4}^{2-}, \mathrm{NO}_{3}^{-}, \mathrm{NH}_{4}^{+}, \mathrm{HNO}_{3}, \mathrm{SO}_{2}$,
\end{abstract}

and $\mathrm{TNO}_{3}\left(\mathrm{NO}_{3}^{-}+\mathrm{HNO}_{3}\right.$, expressed as the mass of equivalent $\mathrm{NO}_{3}^{-}$) were reduced by $73.3 \%, 29.1 \%, 67.4 \%, 65.8 \%$, $87.6 \%$, and $52.6 \%$, respectively, from 1990 to 2015 . In terms of percentage, the reductions of all species except $\mathrm{NO}_{3}^{-}$were spatially uniform. The reductions of $\mathrm{SO}_{2}$ and $\mathrm{HNO}_{3}$ were similar in the warm season (May-October) and the cold season (November-April), and the reductions of $\mathrm{SO}_{4}^{2-}, \mathrm{NO}_{3}^{-}$, and $\mathrm{NH}_{4}^{+}$were more significant in the warm season than in the cold season. The reductions of $\mathrm{SO}_{4}^{2-}$ and $\mathrm{SO}_{2}$ mainly occurred in 1990-1995 and 2007-2015 during the warm season and in 1990-1995 and 2005-2015 during the cold season. The reduction of $\mathrm{NO}_{3}^{-}$mainly occurred in the Midwest after 2000. Other than in the Midwest, $\mathrm{NO}_{3}^{-}$exhibited very little change during the cold season for the period. The reduction of $\mathrm{NH}_{4}^{+}$generally followed the reduction trend of $\mathrm{SO}_{4}^{2-}$; especially after 2000 , the temporal trend of $\mathrm{NH}_{4}^{+}$was almost identical to that of $\mathrm{SO}_{4}^{2-}$. The ratio of $\mathrm{S}$ in $\mathrm{SO}_{4}^{2-}$ to total $\mathrm{S}$ in $\mathrm{SO}_{4}^{2-}$ plus $\mathrm{SO}_{2}$, as well as the ratio of $\mathrm{NO}_{3}^{-}$to $\mathrm{TNO}_{3}$ increased by more than $50 \%$ during the period. This indicates that a notable change in regional chemistry took place from the beginning to the end of the period, with a higher percentage of $\mathrm{SO}_{2}$ being oxidized to $\mathrm{SO}_{4}^{2-}$ and a higher percentage of $\mathrm{HNO}_{3}$ being neutralized to $\mathrm{NH}_{4} \mathrm{NO}_{3}$ near the end of the period. 


\section{Introduction}

Gases and particulate matter released into the air through anthropogenic activities can pollute the air and deteriorate the air quality locally, regionally, and continentally. Air pollution, which can decrease lung function, causing the development of asthma, bronchitis, and lung cancer (Kunzli et al., 2000; Heroux et al., 2015; WHO, 2006), is considered a major environmental risk to human health by the World Health Organization (WHO). Air pollution is also linked to stroke and heart disease, and the improvement of air quality can significantly reduce the $\mathrm{PM}_{2.5}$ - and $\mathrm{O}_{3}$-related mortality burden (Zhang et al., 2018). When emitted gases and particulate matter or secondary pollutants formed in the air from emissions are brought to the Earth's surface through dry and/or wet deposition, they pose a risk to the established ecosystems through acid rain as well as excessive deposition of nitrogen and sulfur. Air pollution also affects long-term climate through scattering and absorption of solar radiation by directly emitted or secondarily formed aerosols in the air (Haywood and Shine, 1995; Yu et al., 2006). In some heavily polluted regions, even local weather can be affected due to the change in energy budgets in the atmosphere and at the Earth's surface (Kajino et al., 2017).

In order to control air pollution, the US passed the Clean Air Act (CAA) of 1963 (Kuklinska et al., 2015). Major amendments to the law were passed in 1970, 1977, and 1990 (Kuklinska et al., 2015). The amendments to the CAA of 1990 addressed acid deposition, ozone depletion, and toxic air pollution (CAA, 1990). Specifically, Title IV of the 1990 amendments to the CAA, also known as acid deposition control, targeted emission reductions of two acid deposition precursors, $\mathrm{SO}_{2}$ and $\mathrm{NO}_{x}$, which along with $\mathrm{CO}, \mathrm{O}_{3}$, $\mathrm{Pb}$, and particulate matter are among the six species designated as criteria pollutants by United States Environmental Protection Agency (US EPA). $\mathrm{SO}_{2}$ and $\mathrm{NO}_{x}$ in the air can be oxidized to form acid $\mathrm{H}_{2} \mathrm{SO}_{4}$ and $\mathrm{HNO}_{3}$, which in turn can react with $\mathrm{NH}_{3}$ to form fine particulate matter $\left(\mathrm{PM}_{2.5}\right)$ and with crustal material or sea salts to form coarse particles (Yoshizumi and Hoshi, 1985; Zhuang et al., 1999). $\mathrm{NO}_{x}$, together with volatile organic compounds (VOCs), also participates in the formation of tropospheric $\mathrm{O}_{3}$, which is another criteria pollutant and an important atmospheric oxidant. Title IV of the Clean Air Act 1990 specifically targets $\mathrm{SO}_{2}$ and $\mathrm{NO}_{x}$ emissions from stationary fuel combustion facilities. The first phase of Title IV of the 1990 CAA amendment, which was implemented on 1 January 1995, requires 110 power plants to reduce $\mathrm{SO}_{2}$ emissions to a level calculated as the product of an emissions rate of $2.5 \mathrm{lbs}(1 \mathrm{lb}$ is equal to $0.4636 \mathrm{~kg}$ ) of $\mathrm{SO}_{2}$ per million British thermal units (Btu; $1 \mathrm{Btu}$ is equal to $1055.056 \mathrm{~J}$ ) multiplied by an average of their 1985-1987 fuel use (Lee, 1991). The second phase, which took effect on 1 January 2000, requires approximately 2000 utilities to reduce $\mathrm{SO}_{2}$ emissions to a level of $1.2 \mathrm{lbs}$ of $\mathrm{SO}_{2}$ per million British thermal units multiplied by the aver- age of their 1985-1997 fuel use (Lee, 1991). Since 1990, the national emissions of $\mathrm{SO}_{2}$ in the US have decreased steadily from 23.1 million tons in 1990 to 21.3 million tons in 1994 and dropped significantly to 18.6 million tons in 1995 due to the first phase implementation of Title IV of the 1990 CAA amendments (EPA, 2016, 2019). The $\mathrm{SO}_{2}$ emissions underwent a small increase during 1996-1998, to 18.9 million tons in 1998, and then continued the steady decrease to 14.5 million tons in 2005. From 2005 to 2012, the decrease in the emissions was accelerated with an annual reduction

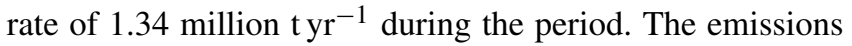
of $\mathrm{SO}_{2}$ leveled off during 2012-2015. In 1990, 87.9\% of $\mathrm{SO}_{2}$ emissions was from stationary fuel combustion facilities, $2 \%$ from on-road vehicles, and $2 \%$ from off-road mobile sources. By 2007, $\mathrm{SO}_{2}$ emissions from on-road vehicles were totally eliminated due to cleaner gasoline. In 2014, of the 4.9 million tons of total $\mathrm{SO}_{2}$ emissions, stationary fuel combustion, off-road mobile, and industrial and other processes contributed 4.1, 0.1 , and 0.7 million tons, respectively (EPA, 2016).

$\mathrm{NO}_{x}$ forms in the air when nitrogen reacts with oxygen under high temperature. Anthropogenic emissions of $\mathrm{NO}_{x}$ are mainly due to stationary fuel combustion, on-road vehicles, and off-road mobile operations. Nationwide in the US, they contributed 10.9, 9.6, and 3.8 million tons of the total 25.2 million tons of $\mathrm{NO}_{x}$ in 1990 (EPA, 2016). Changes in $\mathrm{NO}_{x}$ emissions during the 1990s were relatively small (Butler et al., 2003). Total $\mathrm{NO}_{x}$ emissions remained generally constant from 1990 to 1998 . From 1999 there was a decrease in $\mathrm{NO}_{x}$ emissions from stationary fuel combustion due to the implementation of Title IV of the 1990 CAA amendment as well as the implementation of the $\mathrm{NO}_{x}$ Budget Trading Program (NBP). Title IV of the 1990 CAA amendment not only required the reduction of $\mathrm{SO}_{2}$, but also stipulated the reduction of $\mathrm{NO}_{x}$ emissions from power plants, and it took effect in 1996. The NBP started in 2003 and was created to reduce $\mathrm{NO}_{x}$ emissions from power plants and other large combustion sources in the eastern US during warm months (https:// www.epa.gov/airmarkets/nox-budget-trading-program, last access: 13 November 2019). The NBP was replaced by the ozone season $\mathrm{NO}_{x}$ program under the Clean Air Interstate Rule in 2009. The $\mathrm{NO}_{x}$ emissions from stationary combustion facilities decreased steadily from 10.4 million tons in 1998 to 3.6 million tons in 2012, then remained relatively unchanged thereafter (EPA, 2016). Emissions of $\mathrm{NO}_{x}$ from on-road vehicles declined slowly from 1990 until 2001. After 2002, on-road emissions of $\mathrm{NO}_{x}$ decreased continuously and steadily. The trend of $\mathrm{NO}_{x}$ emissions from off-road mobile operations generally increased during the period 19902002 , up from 3.8 to $4.9 \mathrm{t}$, but after that it was reduced gradually to $2.7 \mathrm{t}$ in 2014 . Combining the emissions from stationary fuel combustion, on-road vehicles, and off-road mobile operations, the nationwide emissions of $\mathrm{NO}_{x}$ in the US changed little during 1990-1998 and decreased during 19982001. After 2002, they decreased steeply up to recent years. 
Note that there was a change in $\mathrm{NO}_{x}$ measurement methodology from 2001 to 2002, and it caused a sharp increase in the reported $\mathrm{NO}_{x}$ emissions in the US from 2001 to 2002 (EPA, 2019)

In Canada, similar measures were adopted to reduce air pollutant emissions. $\mathrm{SO}_{2}$ emissions in Canada were mainly from three major sectors: ore and mineral industries, the oil and gas industry, and electric utilities. For each sector, the annual $\mathrm{SO}_{2}$ emissions were reduced from $1.5,0.53$, and 0.62 million tons in 1990 to $0.47,0.28$, and 0.27 million tons in 2015 (ECCC, 2019). Nationally, annual $\mathrm{SO}_{2}$ emissions were reduced from 3.1 million tons in 1990 to 1.1 million tons in 2015 (ECCC, 2019). In 1990, the annual emissions of $\mathrm{SO}_{2}$ from Eastern Canada accounted for $59 \%$ of the national annual emissions. $\mathrm{NO}_{x}$ emissions in Canada were mainly from transportation (43\%) and oil and gas industries $(14 \%)$ (ECCC, 2019). Nationally, annual emissions of $\mathrm{NO}_{x}$ were reduced by $25 \%$, from 2.4 million tons in 1990 to 1.8 million tons in 2015. Specifically, annual emissions of $\mathrm{NO}_{x}$ in Eastern Canada were reduced by close to $50 \%$, from 1.2 million tons to 0.64 million tons.

Air quality trends during the past few decades, especially since 1990, are of great interest for both scientific communities and the general public. For the eastern part of the US and Canada, trends of air quality after 1990 have been reported in previous studies for $\mathrm{O}_{3}$ (Chan and Vet, 2010), $\mathrm{O}_{3}$ and nitrate (Butler et al., 2011), particulate $\mathrm{SO}_{4}^{2-}$ (Hand et al., 2012), and air quality and atmospheric deposition (Sickles II and Shadwick, 2007; Sickles II and Shadwick, 2015; Cheng and Zhang, 2017). Sickles II and Shadwick (2007, 2015) compared the 5-year averages of air quality and atmospheric deposition in the eastern US for 1990-2004 and 1990-2009. Cheng and Zhang (2017) reported the temporal trends of the annual concentration of air pollutants from 31 Canadian rural locations, most of which were located in Eastern Canada. Aas et al. (2019) reported global and regional trends of atmospheric sulfur for 1990-2015 and found that North America and East Asia had the largest reductions of sulfur emissions during the late part of the period. In this study, we analyze the surface air concentration data measured weekly by the CASTNET network in the US and measured daily from the CAPMoN network in Canada to reveal the detailed temporal and spatial trends of air quality from 1990 to 2015 . These trends are not only important for the assessment of the improvement of air quality due to emissions reductions, but are also essential for the evaluation of chemical transportation models. The analysis will answer the following questions: (1) what are the trends of air pollutants over the eastern US and Eastern Canada following the significant reductions of $\mathrm{SO}_{2}$ and $\mathrm{NO}_{x}$ emissions during 1990-2015? (2) What are the physical and chemical mechanisms responsible for the trends? We will look at the air concentrations of gases $\mathrm{SO}_{2}$ and $\mathrm{HNO}_{3}$, as well as particulates $\mathrm{SO}_{4}^{2-}, \mathrm{NO}_{3}^{-}$, and $\mathrm{NH}_{4}^{+}$, which are either due to direct emissions of $\mathrm{SO}_{2}$ or due to the oxidation of $\mathrm{SO}_{2}$ and $\mathrm{NO}_{x}$, as well as the reaction of these oxidants with $\mathrm{NH}_{3}$.

\section{Data and methods}

\subsection{Networks of measurement: CASTNET and CAPMoN}

The monitoring of background- and regional-level ambient pollutants is essential for assessing regional air quality. In the US and Canada, this long-term monitoring of air quality in rural and remote areas is fulfilled by two monitoring networks: CASTNET and CAPMoN, respectively.

CASTNET is a monitoring network managed and operated by the US EPA in cooperation with several other federal, state, and local partners (Clarke et al., 1997; Bloomer et al, 2010). The network was established under the 1990 CAA to assess the trends of acidic deposition due to emission reduction programs. The network makes weekly integrated measurements of gases $\left(\mathrm{SO}_{2}\right.$ and $\left.\mathrm{HNO}_{3}\right)$ and particulates $\left(\mathrm{SO}_{4}^{2-}\right.$, $\mathrm{NO}_{3}^{-}, \mathrm{NH}_{4}^{+}, \mathrm{Mg}^{2+}, \mathrm{Ca}^{2+}, \mathrm{Na}^{+}$, and $\mathrm{Cl}^{-}$) using filter pack methods, as well as hourly measurements of $\mathrm{O}_{3}$. At selected sites, it also measures hourly concentrations of $\mathrm{NO}$, reactive nitrogen $\left(\mathrm{NO}_{y}\right), \mathrm{SO}_{2}$, and $\mathrm{CO}$.

CAPMoN is a monitoring network operated by Environment and Climate Change Canada (ECCC). The network began operation in 1983, although one of its two predecessor networks, the Air and Precipitation Network (APN), measured air concentrations as far back as 1978. The network measures $24 \mathrm{~h}$ integrated air concentrations of pollutants (from 08:00 to 08:00 LT, local time) through filter pack sampling and $24 \mathrm{~h}$ wet deposition by the collection of precipitation samples at the ground level. The daily air concentration measurements by CAPMoN also include gases $\left(\mathrm{SO}_{2}\right.$ and $\left.\mathrm{HNO}_{3}\right)$ and particulates $\left(\mathrm{SO}_{4}^{2-}, \mathrm{NO}_{3}^{-}, \mathrm{NH}_{4}^{+}, \mathrm{Mg}^{2+}, \mathrm{Ca}^{2+}\right.$, $\mathrm{Na}^{+}$, and $\mathrm{Cl}^{-}$), similar to CASTNET's weekly measurements. CAPMoN also measures hourly air concentrations of $\mathrm{O}_{3}, \mathrm{NO}_{y}$, and gaseous $\mathrm{Hg}$ at selected sites. More details about the CAPMoN dataset can be found in Cheng and Zhang (2017).

\subsection{Statistical analysis and methods}

As we focus on the long-term trends of air pollutants over the region, annual means for all seasons and seasonal means for the warm and cold seasons were derived for each site from the weekly measurements of CASTNET and daily measurements of CAPMoN. To be precise, the seasonal mean concentrations in this study refer to the mean concentrations calculated for the warm (May-October) and cold (NovemberApril) seasons for each year. In order to avoid the fluctuations of annual or seasonal mean concentrations due to meteorology, 3-year averages were used to represent the mean concentrations at the beginning or the end of a period in calculating changes for that period. 
The Mann-Kendall test (MKT) is a nonparametric test to detect the trend of a time series and it does not require the variable of the time series to follow a normal distribution (Mann, 1945; Du et al., 2014). In this study, the MKT was used to detect if an increasing or decreasing trend exists when a time series generally looks flat. The $p$ value and tau coefficient are the two statistical parameters of the MKT, indicating the statistical significance and significance of a monotonic trend, respectively.

To assess the changes in air pollutants in response to emission reductions of $\mathrm{SO}_{2}$ and $\mathrm{NO}_{x}$, we looked at the following for species of $\mathrm{SO}_{4}^{2-}, \mathrm{SO}_{2}, \mathrm{NH}_{4}^{+}, \mathrm{NO}_{3}^{-}, \mathrm{HNO}_{3}$, and $\mathrm{TNO}_{3}$ $\left(\mathrm{NO}_{3}^{-}+\mathrm{HNO}_{3}\right.$, expressed as equivalent $\left.\mathrm{NO}_{3}^{-}\right)$:

1. temporal and spatial trends in the eastern US and Eastern Canada;

2. 10-year and 25-year changes for the periods of 19902000 and 1990-2015;

3. differences in trends in cold and warm seasons;

4. time series of the yearly regional means during the warm and cold seasons; and

5. long-term trends derived from polynomial regressions.

We also looked at correlations between $\mathrm{SO}_{4}^{2-}$ and $\mathrm{SO}_{2}$, the ratio of sulfur $\left(\mathrm{RSO}_{4}\right)$ in $\mathrm{SO}_{4}^{2-}$ to total sulfur in $\mathrm{SO}_{4}^{2-}$ plus $\mathrm{SO}_{2}$ in the air, the ratio of nitrogen $\left(\mathrm{RNO}_{3}\right)$ in $\mathrm{NO}_{3}^{-}$to $\mathrm{TNO}_{3}$, and their changes during the period in order to explain the physical and chemical mechanisms responsible for the trends.

\subsection{Region clustering of CASTNET and CAPMoN sites in the eastern US and Eastern Canada}

In the eastern US (EUS) and Eastern Canada (EC), there are significant spatial differences in emissions of $\mathrm{SO}_{2}, \mathrm{NO}_{x}$, and $\mathrm{NH}_{3}$. This results in distinctive regional patterns of air concentrations of $\mathrm{SO}_{4}^{2-}, \mathrm{NO}_{3}^{-}, \mathrm{NH}_{4}^{+}, \mathrm{HNO}_{3}$, and $\mathrm{SO}_{2}$. In this study, we used the cold season (November to April) 3-year mean concentrations of $\mathrm{NO}_{3}^{-}$and $\mathrm{SO}_{2}$ of each site, supplemented with the ratio of $\mathrm{RNO}_{3}$, as the criteria to cluster the CASTNET and CAPMoN sites into four different regions. The reasons for selecting the cold season are the following: (1) $\mathrm{NO}_{3}^{-}$is mainly in the form of $\mathrm{NH}_{4} \mathrm{NO}_{3}$ (Zhang et al., 2008), and it is more thermodynamically stable in the cold season than in the warm season; (2) the oxidation rate of $\mathrm{SO}_{2}$ is much lower in the cold season than in the warm season, and therefore the air concentration of $\mathrm{SO}_{2}$ more reflects the $\mathrm{SO}_{2}$ emission rate of the region; (3) because $\mathrm{NH}_{4} \mathrm{NO}_{3}$ is much more thermodynamically stable and much less affected by ambient temperature, $\mathrm{RNO}_{3}$ is mainly determined by the availability of $\mathrm{NH}_{3}$ over the region, and therefore $\mathrm{RNO}_{3}$ during the cold season is an indicator of the abundance of $\mathrm{NH}_{3}$ to form $\mathrm{NH}_{4} \mathrm{NO}_{3}$. The mean concentrations at the beginning of the period were used to cluster the sites as the emission rate of $\mathrm{SO}_{2}$ was the highest.

Based on the spatial patterns of the mean air concentration of $\mathrm{NO}_{3}^{-}, \mathrm{SO}_{2}$, and $\mathrm{RNO}_{3}$ during the cold season of 19891991, which are shown in Table S1b and Fig. S1b in the Supplement, four regions in the EUS and EC were clustered.

- Region 1: sites located north of latitude $40^{\circ}$ and with a concentration of $\mathrm{SO}_{2}$ less than $6.4 \mu \mathrm{g} \mathrm{m}^{-3}$ in the cold season.

- Region 2: sites with a mean concentration of $\mathrm{NO}_{3}^{-}$ greater than $2.5 \mu \mathrm{g} \mathrm{m}^{-3}$. Except for site ARE128 at $2.1 \mathrm{\mu g} \mathrm{m}^{-3}$, the highest air concentration of $\mathrm{NO}_{3}^{-}$of all other sites was $1.9 \mu \mathrm{g} \mathrm{m}^{-3}$. For sites in region 2, $\mathrm{RNO}_{3}$ was greater than $54 \%$, which was higher than any CASTNET and CAPMoN sites in other regions.

- Region 3: sites excluded from regions 1 and 2 and with an air concentration of $\mathrm{SO}_{2}$ greater than $15.0 \mu \mathrm{g} \mathrm{m}^{-3}$ during the cold season.

- Region 4: all other sites excluded from regions 1, 2, and 3. The highest mean $\mathrm{SO}_{2}$ of sites in region 4 during the cold season was less than $11.7 \mu \mathrm{g} \mathrm{m}^{-3}$.

The clustering of sites is shown in Fig. 1 with site names. Regions 2, 3, and 4 roughly correspond to the Midwest, Mid-Atlantic, and Southeast regions participating in the NBP (Butler et al., 2011). The site SND152 had a characteristic of region 2, but it is geologically located in region 4; therefore the site SND152 was not included in the study. Characteristics of each region are listed in Table 1. After grouping the sites into each cluster appropriately, annual and seasonal mean concentrations of each species from each site within the cluster show high correlations with the averaged values of the cluster, as shown in Fig. S3 and Table S3. For example, as shown in Table S3 for region 2, the averaged correlation coefficients of the seasonal mean concentrations of each site vs. the averaged values of the cluster during the warm season are $0.98,0.95,0.98,0.97,0.98$, and 0.98 for $\mathrm{SO}_{4}^{2-}, \mathrm{NO}_{3}^{-}$, $\mathrm{NH}_{4}^{+}, \mathrm{HNO}_{3}, \mathrm{SO}_{2}$, and $\mathrm{TNO}_{3}$, respectively. For all seasons, the corresponding averaged correlation coefficients are $0.97-$ $0.99,0.59-0.91,0.93-0.98,0.94-0.99,0.96-0.99$, and 0.860.98 for regions $1-4$.

\section{Results}

\subsection{Air quality in the eastern US and Eastern Canada at the beginning of the study period: 1989-1991}

The 3-year averages of the air concentrations of $\mathrm{SO}_{4}^{2-}, \mathrm{NO}_{3}^{-}$, $\mathrm{NH}_{4}^{+}, \mathrm{HNO}_{3}, \mathrm{SO}_{2}$, and $\mathrm{TNO}_{3}$, as well as $\mathrm{RSO}_{4}$ and $\mathrm{RNO}_{3}$ for 1989-1991 are used to describe the air quality at the beginning of the study period and are shown in Table S1a and $b$ for the warm and cold seasons. Mapping of 3-year average for each species is also provided as Fig. S1. Among 


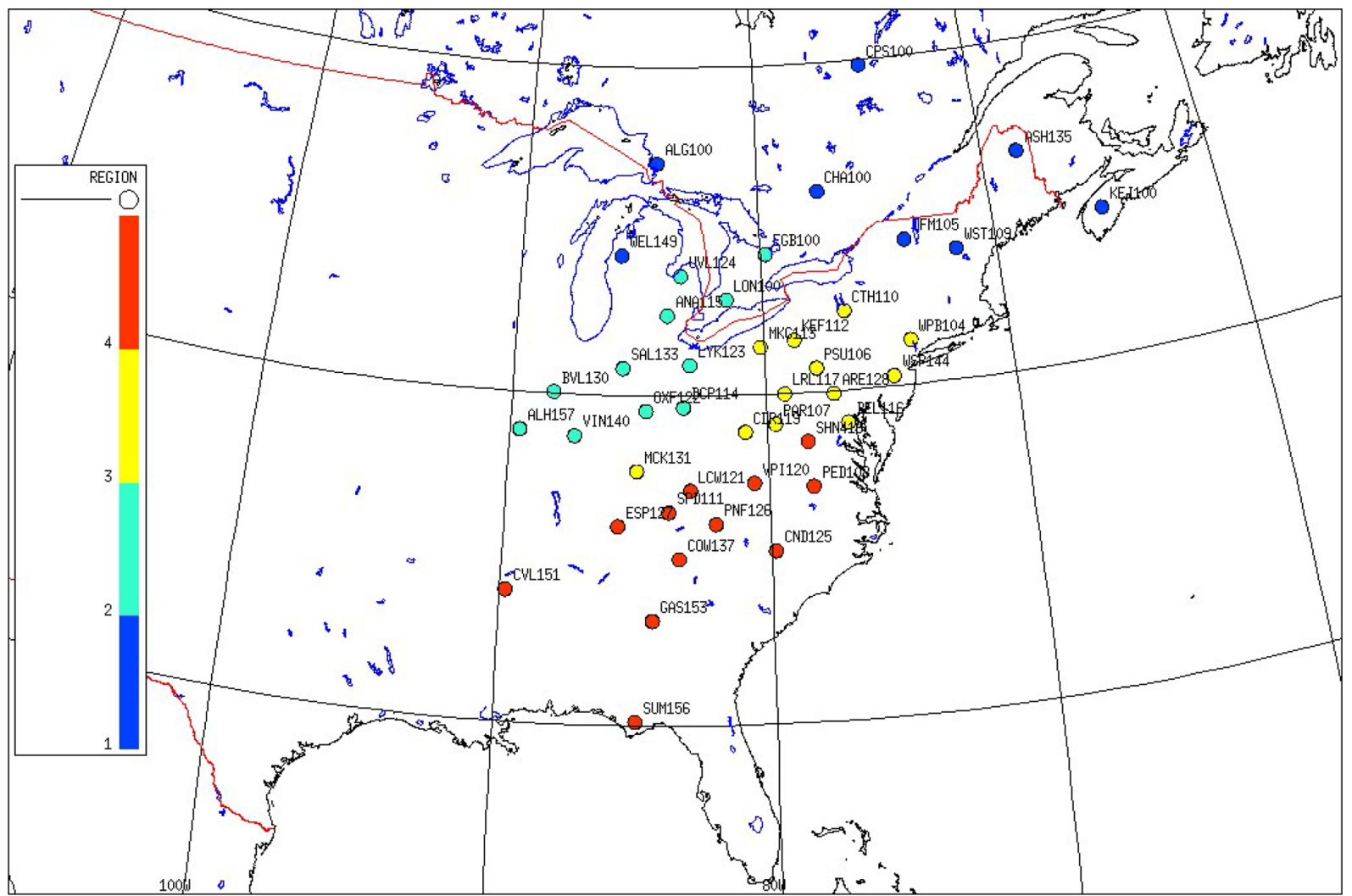

Figure 1. Clustered sites of CASTNET and CAPMoN in regions 1-4.

Table 1. Characteristics of four regions based on 3-year averages of 1989-1991 during the cold season.

\begin{tabular}{|c|c|}
\hline Region & Characteristics of region \\
\hline 1 & $\begin{array}{l}\mathrm{SO}_{2}<6.4 \mathrm{~g}^{-3} \text { for all sites; on average the region had the lowest seasonal } \\
\text { mean concentrations of } \mathrm{SO}_{4}^{2-}, \mathrm{NO}_{3}^{-}, \mathrm{NH}_{4}^{+}, \mathrm{HNO}_{3} \text {, and } \mathrm{SO}_{2} \text {. }\end{array}$ \\
\hline 2 & $\begin{array}{l}\mathrm{NO}_{3}^{-}>2.5 \mathrm{~g} \mathrm{~m}^{-3} \text { and } \mathrm{RNO}_{3}>54.0 \% \text { for all sites; } \mathrm{AVE} \_\mathrm{NO}_{3}^{-}=4.2 \mathrm{~g} \mathrm{~m}^{-3} ; \\
\mathrm{AVE}_{-} \mathrm{SO}_{2}=13.6 \mathrm{~g} \mathrm{~m}^{-3} ; \mathrm{AVE} \_\mathrm{RNO}_{3}=68.5 \% .\end{array}$ \\
\hline 3 & $\begin{array}{l}\mathrm{NO}_{3}^{-}<2.2 \mathrm{~g} \mathrm{~m}^{-3}, \mathrm{RNO}_{3}<47 \% \text {, and } \mathrm{SO}_{2}>15.2 \mathrm{~g} \mathrm{~m}^{-3} \text { for all sites; } \\
\mathrm{AVE}_{-} \mathrm{NO}_{3}^{-}=1.2 \mathrm{~g} \mathrm{~m}^{-3} ; \text { AVE_SO}{ }_{2}=19.2 \mathrm{~g} \mathrm{~m}^{-3} ; \mathrm{AVE}_{-} \mathrm{RNO}_{3}=32.3 \% .\end{array}$ \\
\hline 4 & $\begin{array}{l}\mathrm{SO}_{2}<11.7 \mathrm{~g} \mathrm{~m}^{-3} \text { and } \mathrm{NO}_{3}^{-}<0.7 \mathrm{~g} \mathrm{~m}^{-3} \text { for all sites; } \mathrm{AVE} \_\mathrm{NO}_{3}^{-}=0.6 \mathrm{~g} \mathrm{~m}^{-3} ; \\
\text { AVE_SO }{ }_{2}=7.2 \mathrm{~g} \mathrm{~m}^{-3} ; \mathrm{AVE}_{-} \mathrm{RNO}_{3}^{-}=28.3 \% .\end{array}$ \\
\hline
\end{tabular}

the four regions and both the warm and cold seasons, region 1 had the lowest air concentration of all species, with mean $\mathrm{NO}_{3}^{-}, \mathrm{HNO}_{3}$, and $\mathrm{NH}_{4}^{+}$concentrations of less than $1.0 \mu \mathrm{g} \mathrm{m}^{-3}$. The mean air concentration of $\mathrm{NO}_{3}^{-}$during the warm season was only $0.14 \mu \mathrm{g} \mathrm{m}^{-3}$. Mean $\mathrm{SO}_{4}^{2-}$ concentrations were 2.9 and $2.3 \mathrm{\mu g} \mathrm{m}^{-3}$ during the warm and cold seasons, respectively, and $\mathrm{SO}_{2}$ was 1.6 and $3.6 \mu \mathrm{g} \mathrm{m}^{-3}$ correspondingly.

For regions 2-4, $\mathrm{SO}_{4}^{2-}$ was highest in region 3 and lowest in region 4 for both seasons, varying from 7.6 to $8.2 \mu \mathrm{g} \mathrm{m}^{-3}$ during the warm season and 3.6 to $4.2 \mu \mathrm{g} \mathrm{m}^{-3}$ during the cold season. The difference in the regional mean of $\mathrm{SO}_{4}^{2-}$ between region 2 and 3 was less than $0.1 \mu \mathrm{g} \mathrm{m}^{-3}$ during the cold season. Generally, $\mathrm{SO}_{4}^{2-}$ in regions $2-4$ was spatially uniform. For each region, $\mathrm{SO}_{4}^{2-}$ during the warm season was about double that during the cold season. The same as $\mathrm{SO}_{4}^{2-}, \mathrm{SO}_{2}$ was also highest in region 3 and lowest in region 4 for regions $2-4$, but $\mathrm{SO}_{2}$ in region 3 was much higher and was about 2.5 times that in region $4 . \mathrm{SO}_{2}$ in regions 3 and 2 during the cold season, being 19.2 and $13.7 \mu \mathrm{g} \mathrm{m}^{-3}$, respectively, showed the two highest concentrations and the only two concentrations greater than $10.0 \mu \mathrm{g} \mathrm{m}^{-3}$ among all 
species in four regions and during the warm and cold seasons. The difference in $\mathrm{SO}_{2}$ between region 3 and 2 was less than $1.0 \mu \mathrm{g} \mathrm{m}^{-3}$ during the warm season but was more than $5.0 \mu \mathrm{g} \mathrm{m}^{-3}$ during the cold season. Despite significant differences in $\mathrm{SO}_{2}$ for regions 2-4, the corresponding differences in $\mathrm{SO}_{4}^{2-}$ were small. As an example, during the cold season, the seasonal mean concentration of $\mathrm{SO}_{2}$ in region 3 was higher than that in region 4 by $10.0 \mu \mathrm{g} \mathrm{m}^{-3}$, but the corresponding difference in $\mathrm{SO}_{4}^{2-}$ was only $0.7 \mu \mathrm{g} \mathrm{m}^{-3}$. This can be attributed to the fact that the lifetime of $\mathrm{SO}_{4}^{2-}(\sim 5-7 \mathrm{~d})$ in the air is much longer than that of $\mathrm{SO}_{2}(\sim 2 \mathrm{~d})$ (Penner et al., 2001; Pitari et al., 2016). Lee et al. (2011) estimated the mean $\mathrm{SO}_{2}$ lifetime in the eastern US to be $19 \pm 7 \mathrm{~h}$ in summer and $58 \pm 20 \mathrm{~h}$ in winter. Comparing $\mathrm{SO}_{2}$ in the cold season to that in the warm season, it was about 2 times higher in regions 3 and 4 and $59 \%$ higher in region 2 . In contrast to the pattern of $\mathrm{SO}_{4}^{2-}, \mathrm{NO}_{3}^{-}$in regions $2-4$ was significantly different from region to region. Region 2 had the highest concentration of $\mathrm{NO}_{3}^{-}$at $1.5 \mu \mathrm{g} \mathrm{m}^{-3}$ during the warm season and $3.6 \mu \mathrm{g} \mathrm{m}^{-3}$ during the cold season; these values were about triple the value in region 3, which was the second highest. Region 4 had the lowest $\mathrm{NO}_{3}^{-}$concentrations among regions $2-4$, being 0.3 and $0.6 \mu \mathrm{g} \mathrm{m}^{-3}$ for the warm and cold seasons, respectively. The lowest value for stations in region 2 during the cold season was $2.5 \mu \mathrm{g} \mathrm{m}^{-3}$ at ALH157, higher than the highest value of $2.1 \mu \mathrm{g} \mathrm{m}^{-3}$ at BEL116 in region 3. During the warm season, $\mathrm{HNO}_{3}$ ranged from $1.7 \mu \mathrm{g} \mathrm{m}^{-3}$ in region 4 to 2.8 and $2.9 \mu \mathrm{g} \mathrm{m}^{-3}$ in regions 3 and 2. During the cold season, the highest concentration of $\mathrm{HNO}_{3}$ was in region 3 and the lowest in region 2, with values of 2.3 and $1.8 \mathrm{\mu g} \mathrm{m}^{-3}$, respectively. Considering both seasons, region 3 had the highest concentration of $\mathrm{HNO}_{3}$ among the four regions. Region 2 had the lowest concentration of $\mathrm{HNO}_{3}$ among regions 2-4 during the cold season due to the fact that a large portion of $\mathrm{HNO}_{3}$ was neutralized by $\mathrm{NH}_{3}$ to form $\mathrm{NH}_{4} \mathrm{NO}_{3}$. For $\mathrm{TNO}_{3}$, in both seasons, region 2 had the highest concentration, being 4.3 and $5.3 \mu \mathrm{g} \mathrm{m}^{-3}$ in the warm and cold seasons, mainly because of the significantly higher concentration of $\mathrm{NO}_{3}^{-}$than other regions. $\mathrm{TNO}_{3}$ was 3.2 and $3.5 \mu \mathrm{g} \mathrm{m}^{-3}$ for region 3 and 2.0 and $2.3 \mu \mathrm{g} \mathrm{m}^{-3}$ for region 4 during the warm and cold seasons. $\mathrm{NH}_{4}^{+}$in regions $2-4$ varied from 1.9 to $2.7 \mu \mathrm{g} \mathrm{m}^{-3}$ during the warm season and 1.1 to $2.3 \mu \mathrm{g} \mathrm{m}^{-3}$ during the cold season, with the highest concentrations in region 2 and the lowest concentrations in region 4 for both seasons. $\mathrm{NH}_{4}^{+}$was higher in the warm season than in the cold season for all regions, as much more $\left(\mathrm{NH}_{4}\right)_{2} \mathrm{SO}_{4}$ formed in the warm season than in the cold season.

In general, region 1 had the lowest concentration of all species among the four regions, and region 4 had the second lowest except $\mathrm{HNO}_{3}$, which was slightly more than in region 2 during the cold season. Regions 2 and 3 were the two most polluted regions in the EUS and ECA. Region 3 had the highest regional concentration of $\mathrm{SO}_{2}$ in both seasons, more than double that in regions 1 and 4; region 2 had the highest concentration of $\mathrm{NO}_{3}^{-}$and $\mathrm{TNO}_{3}$. In both seasons, $\mathrm{NO}_{3}^{-}$in region 2 was more than 4 times higher than that in regions 1 and 4 , and $\mathrm{TNO}_{3}$ was more than double that in regions 1 and 4 .

\subsection{Time series of seasonal mean concentrations of $\mathrm{SO}_{4}^{2-}, \mathrm{SO}_{2}, \mathrm{NO}_{3}^{-}, \mathrm{HNO}_{3}, \mathrm{TNO}_{3}$, and $\mathrm{NH}_{4}^{+}$ during 1990-2015}

Time series of seasonal mean concentrations of $\mathrm{SO}_{4}^{2-}, \mathrm{SO}_{2}$, $\mathrm{NO}_{3}^{-}, \mathrm{HNO}_{3}, \mathrm{TNO}_{3}$, and $\mathrm{NH}_{4}^{+}$for each region as well as each site of the region are shown in Fig. S3a for the cold season and Fig. S3b for the warm season. As an example, time series of regional averaged seasonal mean concentrations in regions 2 and 4 are shown in Fig. $2 a$ and $b$ for the cold and warm seasons. Time series of regional averages for regions 1-4 normalized to the year 2000 are presented in Fig. 3a and b for the warm and cold seasons. The year 2000 was chosen for normalization because (1) emissions of $\mathrm{NO}_{x}$ changed little during the first 10 years, and (2) 10 and 25 years of change in annual and seasonal mean concentrations of each species will be discussed in Sect. 3.3. As shown in Fig. S3, the time series for the stations within each region were very highly correlated when the stations are properly grouped into four regions. The discussion in this section is based on the time series of seasonal mean concentrations presented in Fig. S3 as well as Fig. 3.

\subsection{1 $\mathrm{SO}_{4}^{2-}$ and $\mathrm{SO}_{2}$}

\section{$\mathrm{SO}_{4}^{2-}$ and $\mathrm{SO}_{2}$ during the cold season}

As seen from the time series of the seasonal mean concentrations in Fig. S3, $\mathrm{SO}_{4}^{2-}$ in region 1 had a steady decreasing trend from 1989 to 2000 , then a relatively slower decreasing trend from 2001 to $2016 . \mathrm{SO}_{4}^{2-}$ in region 2 had a decreasing trend during 1989-1995 and a slow decreasing trend during 1995-2005. From 2005 to 2016, there was a straight decreasing trend with only small increases in 2008 and 2014. $\mathrm{SO}_{4}^{2-}$ in region 3 generally decreased significantly for the period 1989-1999 and was followed by a slow decreasing period from 2000 to 2008. There was a smooth decreasing trend from 2008 to 2016, and the drop in the seasonal mean concentration was significant in 2008-2011 and 2014-2016. $\mathrm{SO}_{4}^{2-}$ in region 4 had a peak in 1989 for 1988-1990, which was followed by three relatively constant periods of 19901993, 1994-2001, and 2002-2007, with the averages of the seasonal mean concentrations of $\mathrm{SO}_{4}^{2-}$ during the periods being $3.4,3.1$, and $2.8 \mu \mathrm{g} \mathrm{m}^{-3}$, respectively. There were only two major drops between the periods, in 1994 and 2002. From 2007 to $2016, \mathrm{SO}_{4}^{2-}$ in region 4 had a steep drop, and the concentration was reduced from $2.7 \mu \mathrm{g} \mathrm{m}^{-3}$ in 2007 to $1.1 \mathrm{\mu g} \mathrm{m}^{-3}$ in 2016. In general, $\mathrm{SO}_{4}^{2-}$ in the EUS and EC during the cold season can be described by two fast decreasing periods of 1989-1995 and 2005-2016 and a slow decreas- 

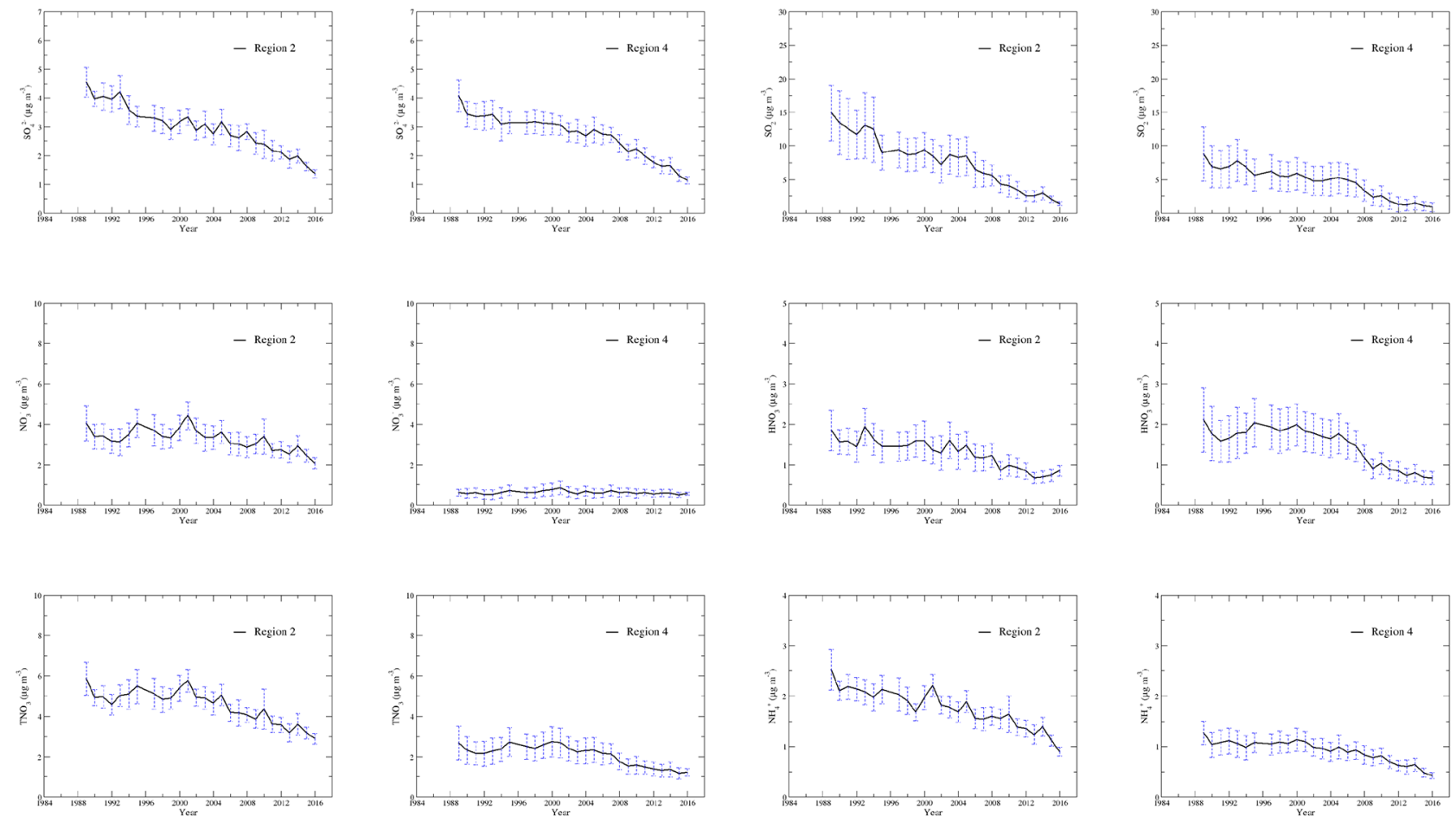

(a) Cold season

Figure 2.

ing period of 1995-2005. The annual reduction rates during the three periods were $0.14,0.03$, and $0.05 \mu \mathrm{g} \mathrm{m}^{-3} \mathrm{yr}^{-1}$ in region $1 ; 0.16,0.04$, and $0.13 \mu \mathrm{g} \mathrm{m}^{-3} \mathrm{yr}^{-1}$ in region $2 ; 0.15$, 0.05 , and $0.15 \mu \mathrm{g} \mathrm{m}^{-3} \mathrm{yr}^{-1}$ in region 3; and $0.10,0.04$, and $0.14 \mu \mathrm{g} \mathrm{m}^{-3} \mathrm{yr}^{-1}$ in region 4 . The decreasing rates in regions 2 and 3 were close. If all sites within regions $1-4$ were combined, the corresponding rates would be $0.14,0.04$, and $0.12 \mu \mathrm{g} \mathrm{m}^{-3} \mathrm{yr}^{-1}$ for the three periods.

$\mathrm{SO}_{2}$ in regions 2-4 during the cold season had a significant drop in 1989-1995, with a temporary increase in 1993 and 1994. From 1995 to 2005 the decreasing trend was slow, and then there was a very steep reduction from 2005 to 2012 . The trend from 2012 to 2016 was relatively flat. The trend of $\mathrm{SO}_{2}$ in region 1 was similar except that there was no obvious increase in 1993-1994.

$\mathrm{SO}_{2}$ exhibited an annual reduction rate of 0.28 , 0.06 , and $0.12 \mu \mathrm{g} \mathrm{m}^{-3} \mathrm{yr}^{-1}$ in region $1 ; 0.83,0.09$, and $0.73 \mu \mathrm{g} \mathrm{m}^{-3} \mathrm{yr}^{-1}$ in region $2 ; 1.13,0.22$, and $1.13 \mu \mathrm{g} \mathrm{m}^{-3} \mathrm{yr}^{-1}$ in region 3 ; and $0.32,0.08$, and $0.49 \mu \mathrm{g} \mathrm{m}^{-3} \mathrm{yr}^{-1}$ in region 4 for the periods of 19891995, 1995-2005, and 2005-2016. For regions 1-4 combined, the corresponding reduction rates were 0.72 , 0.16 , and $0.48 \mu \mathrm{g} \mathrm{m}^{-3} \mathrm{yr}^{-1}$. For the third period, if we only consider $2005-2012$, the annual reduction rate was $0.61 \mu \mathrm{g} \mathrm{m}^{-3} \mathrm{yr}^{-1}$. Although the trend of $\mathrm{SO}_{2}$ during 2012-
2016 was generally flat, the decrease in $\mathrm{SO}_{4}^{2-}$ during the period was still significant, especially in terms of percentage.

\section{$\mathrm{SO}_{4}^{2-}$ and $\mathrm{SO}_{2}$ during the warm season}

$\mathrm{SO}_{4}^{2-}$ in region 1 had a significant decrease from 1989 to 1996 , followed by a leveling-off until 2005 and a decreasing trend from 2005 to 2016. After a significant peak in 1989, $\mathrm{SO}_{4}^{2-}$ in region 2 had a large drop from 1989 to 1993 . There was a steady decreasing trend for 1994-2004, followed by a significant peak in 2005, which was captured by all measurement sites within the region. This was followed by a smooth decreasing trend for 2005-2016, with major drops in 20052006, 2007-2009, 2012, and 2013-2016. Unlike region 2, $\mathrm{SO}_{4}^{2-}$ in region 3 had no significant peak in 1989 and had a decreasing trend during 1989-1999. There was a levelingoff for 1999-2005, and it was followed by a significant decreasing trend for 2005-2016 with steep drops in 2005-2006, 2007-2009, and 2011-2016. $\mathrm{SO}_{4}^{2-}$ in region 4 had a decreasing trend in 1989-1994 and a slow decreasing trend in 1994-2000. After a drop in 2001, it had another levelingoff in 2001-2007 with a peak in 2005. There was a significant straight decreasing trend for 2007-2016 with a major drop during 2007-2009. $\mathrm{SO}_{4}^{2-}$ at all stations converged to the regional average after 2009. In general, the trend of $\mathrm{SO}_{4}^{2-}$ during the warm season can be characterized by two 

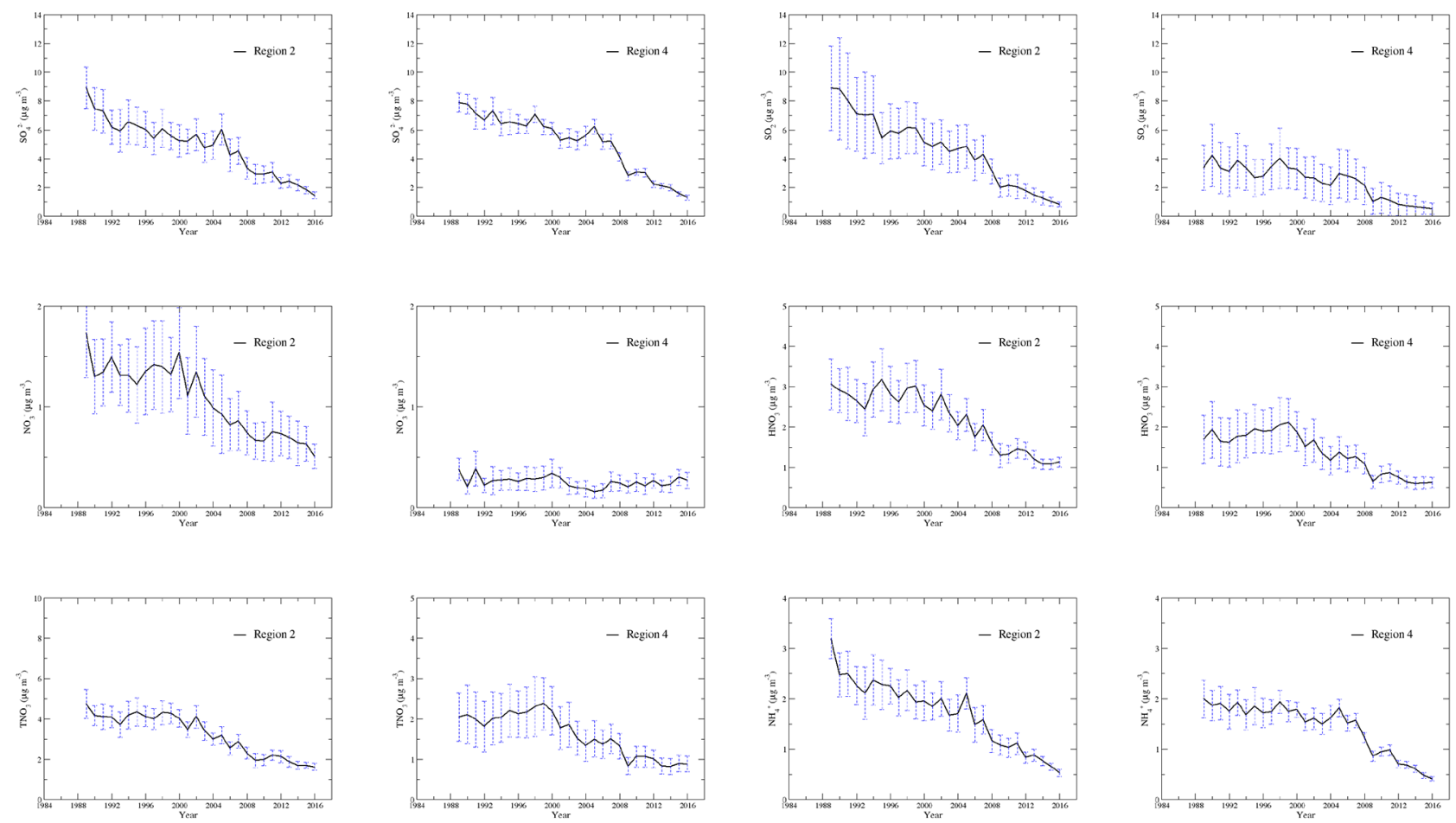

(b) Warm season

Figure 2. Time series of the regionally averaged seasonal mean concentrations during the cold (a) and warm (b) seasons for each species in region 2 (Midwest) and region 4 (Southeast). The vertical dashed line represents the standard deviation of the regionally averaged seasonal mean concentration. The regionally averaged seasonal mean concentrations in regions 2 and 4 during the cold season were not generated for 1996 because of an insufficient number of measurements.

Region 1
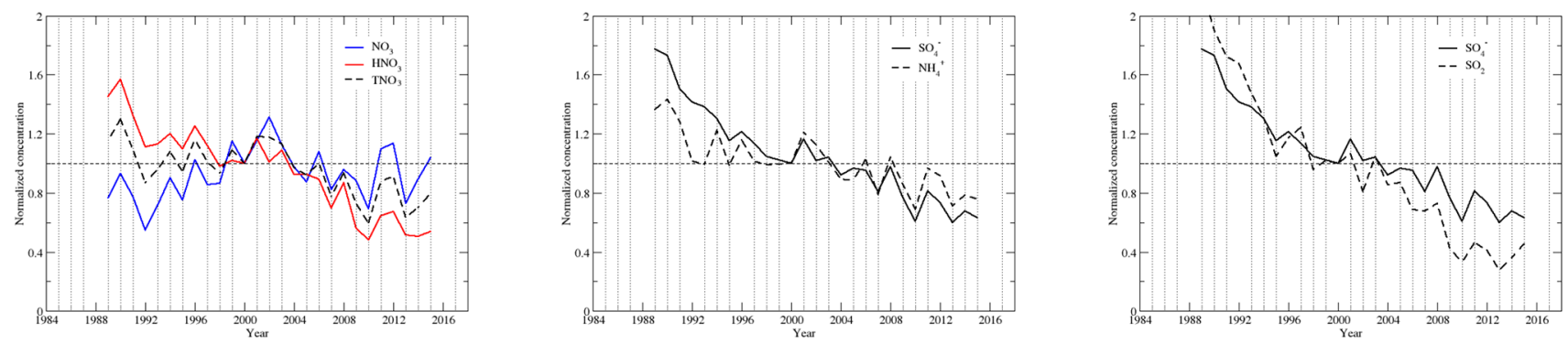

Region 2
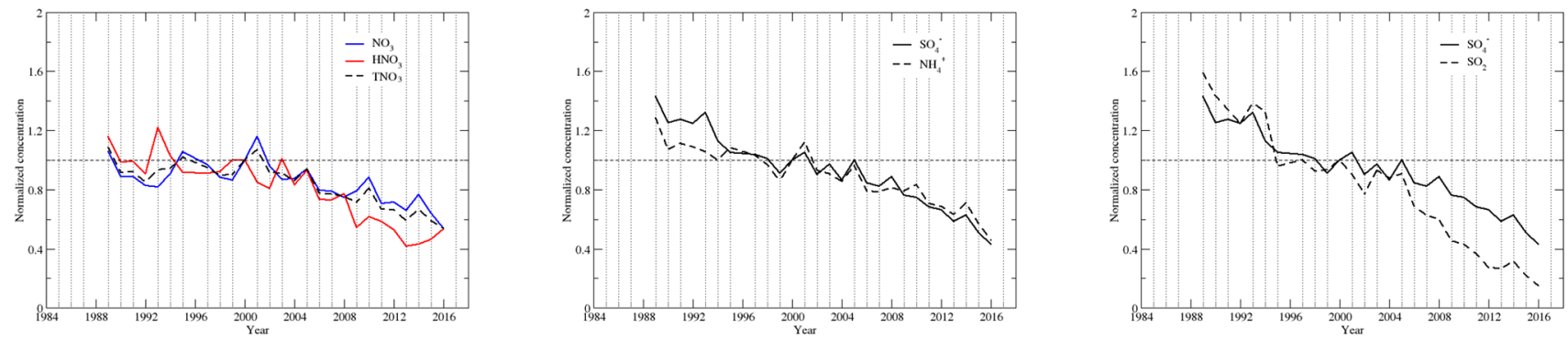

Figure 3. 
Region 3
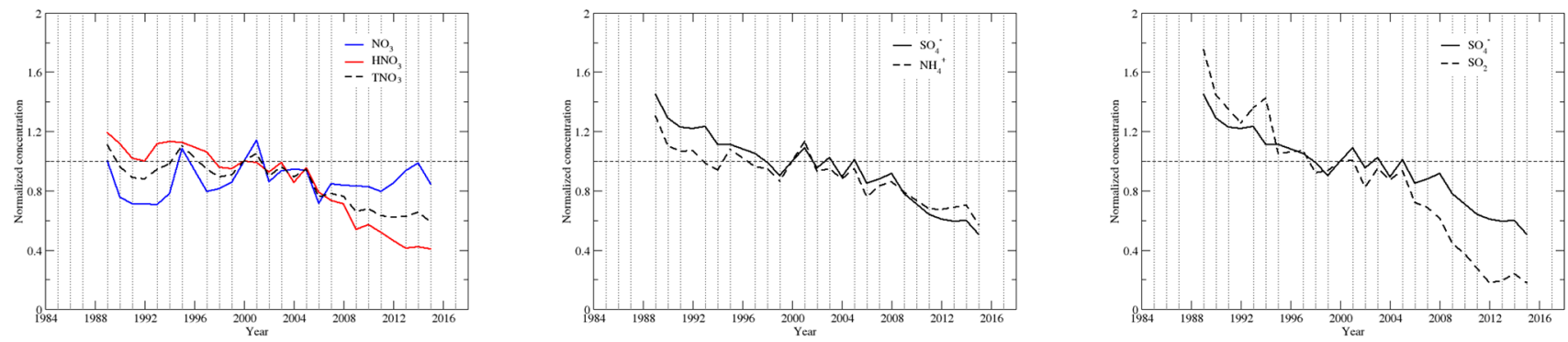

Region 4
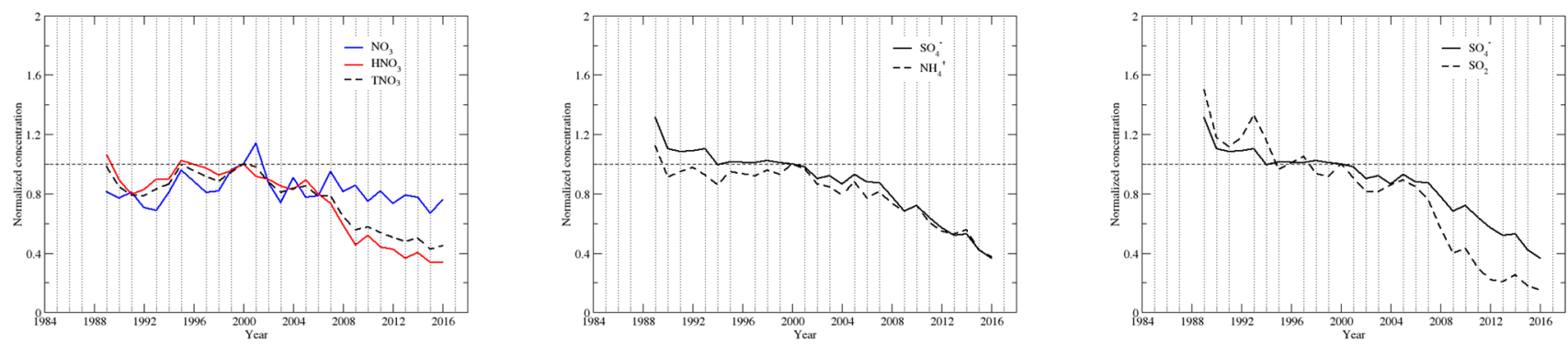

(a) Cold season

Figure 3.

Region 1
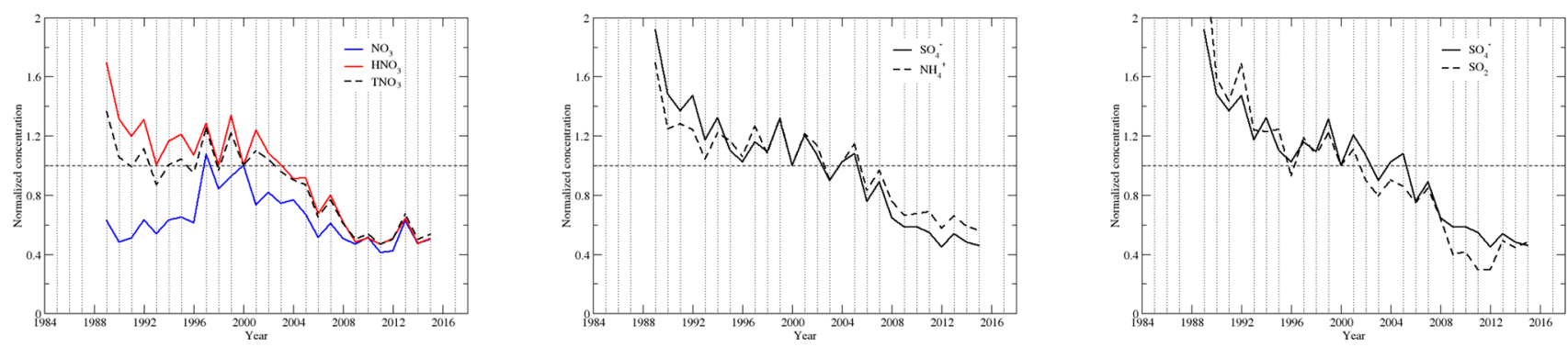

Region 2
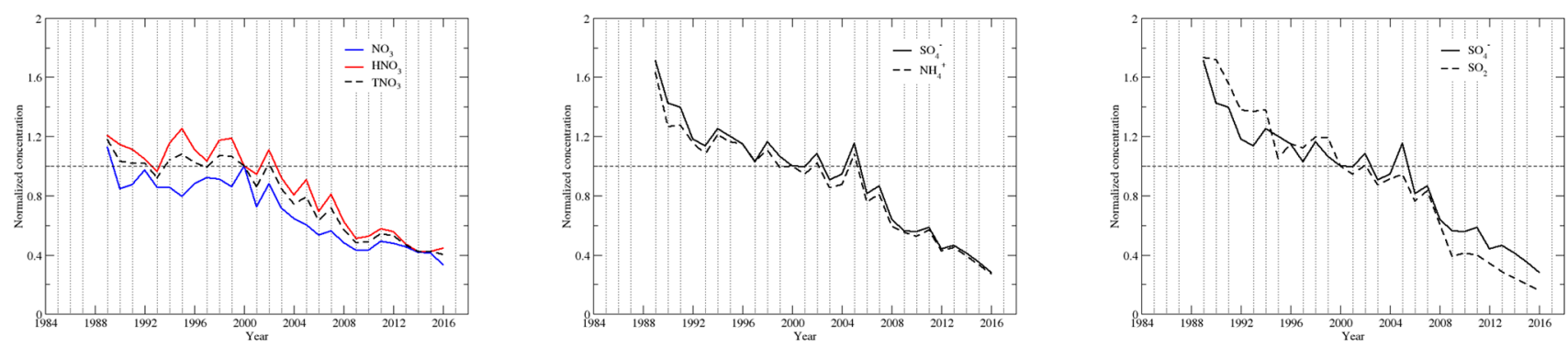

Figure 3. 
Region 3
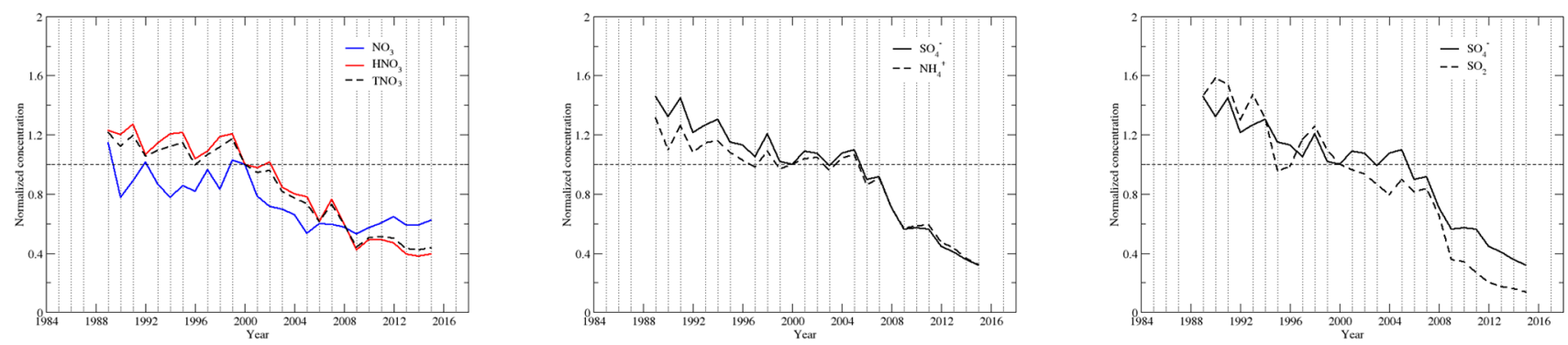

Region 4
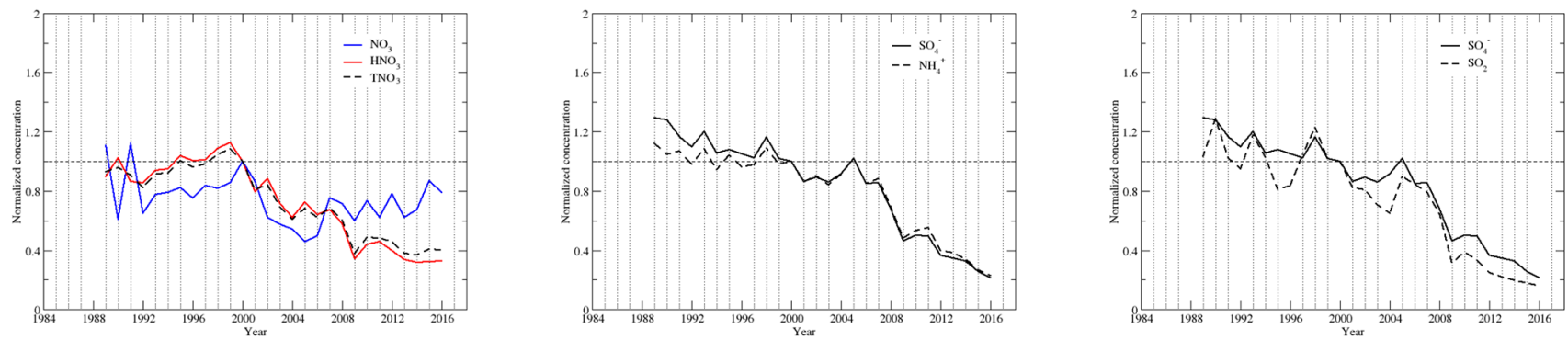

(b) Warm season

Figure 3. Time series of the regional seasonal mean concentrations normalized to the year 2000 for each species during the cold (a) and warm (b) seasons.

fast reduction periods of 1989-1995 and 2007-2016 and a slow period of 1995-2007. For the three periods, $\mathrm{SO}_{4}^{2-}$ had a reduction rate of $0.17,0.01$, and $0.14 \mu \mathrm{g} \mathrm{m}^{-3} \mathrm{yr}^{-1}$ for region $1 ; 0.39,0.03$, and $0.43 \mu \mathrm{g} \mathrm{m}^{-3} \mathrm{yr}^{-1}$ for region $2 ; 0.28$, 0.01 , and $0.52 \mu \mathrm{g} \mathrm{m}^{-3} \mathrm{yr}^{-1}$ for region 3 ; and $0.24,0.04$, and $0.50 \mu \mathrm{g} \mathrm{m}^{-3} \mathrm{yr}^{-1}$ for region 4 . For regions 3 and 4 , the most significant decrease occurred in 2007-2009.

$\mathrm{SO}_{2}$ concentrations during the warm season were quite low during 1990-2015 in region 1 . There was a slow decreasing trend from 1990 to 2007 , a relatively large decreasing trend in 2007-2009, and a level-off at a very low concentration $\left(<1.0 \mu \mathrm{g} \mathrm{m}^{-3}\right)$ in $2009-2016 . \mathrm{SO}_{2}$ during the warm season in regions 2-4 had similar trends: (1) a fast decreasing period of 1989-1995, with a leveling-off period of 19921994 in region 2 and a peak in 1993 in regions 3 and 4; (2) a slowly decreasing period of 1995-2007 with an initial slow increase in 1995-1999 in region 2 and an initial steep increase in 1996-1998 in region 3 and 4; (3) a fast decreasing period of 2007-2016 with very steep decreases in 2007-2009. For the three periods, $\mathrm{SO}_{2}$ had annual reduction rates of $0.12,0.03$, and $0.04 \mathrm{\mu g} \mathrm{m}^{-3} \mathrm{yr}^{-1}$ for region $1 ; 0.55,0.08$, and $0.43 \mu \mathrm{g} \mathrm{m}^{-3} \mathrm{yr}^{-1}$ for region $2 ; 0.46$, 0.11 , and $0.48 \mu \mathrm{g} \mathrm{m}^{-3} \mathrm{yr}^{-1}$ for region 3; and $0.13,0.05$, and $0.22 \mu \mathrm{g} \mathrm{m}^{-3} \mathrm{yr}^{-1}$ for region 4. For the whole region, the annual reduction rates during the warm season were 0.31 ,
0.04 , and $0.38 \mu \mathrm{g} \mathrm{m}^{-3} \mathrm{yr}^{-1}$ for $\mathrm{SO}_{4}^{2-}$ and $0.34,0.08$, and $0.30 \mu \mathrm{g} \mathrm{m}^{-3} \mathrm{yr}^{-1}$ for $\mathrm{SO}_{2}$ for the periods of 1989-1995, 1995-2007, and 2007-2016.

\subsection{2 $\mathrm{NO}_{3}^{-}, \mathrm{HNO}_{3}$, and $\mathrm{TNO}_{3}$}

\section{$\mathrm{NO}_{3}^{-}, \mathrm{HNO}_{3}$, and $\mathrm{TNO}_{3}$ during the cold season}

$\mathrm{NO}_{3}^{-}$in EUS and EC during the cold season was dominated by $\mathrm{NO}_{3}^{-}$in region 2 , which was much higher than $\mathrm{NO}_{3}^{-}$in other regions. As the trends of $\mathrm{NO}_{3}^{-}$during the cold season were not as obvious as other species, the MKT was applied to detect if a monotonic (increasing or decreasing) trend existed. The MKT indicated the following: (1) $\mathrm{NO}_{3}^{-}$in region 2 had no obvious trend in the period of 1989-2001 ( $p=0.45, \tau=0.18$ ), but there was a decreasing trend for the period 2001-2016 ( $p<0.001, \tau=-0.70)$; the trends of $\mathrm{NO}_{3}^{-}$in regions 1,3 , and 4 over the whole study period were pretty flat $(p=0.17-0.40,|\tau|<0.2)$.

Excluding a peak of $1.9 \mu \mathrm{g} \mathrm{m}^{-3}$ in 1993 , the trend of $\mathrm{HNO}_{3}$ in region 2 in the 1990s is flat. From 2003 to 2013, there was a decreasing trend, then a slow increasing trend for 2013-2016 in region $2 . \mathrm{HNO}_{3}$ in region 3 showed a general declining trend by $21.7 \%$ (2004-2005 vs. 19891990) during 1989-2005. The declining trend of $\mathrm{HNO}_{3}$ in the 1990 s was consistent with the increasing trend of $\mathrm{NO}_{3}^{-}$ 
during the period, as more $\mathrm{HNO}_{3}$ was neutralized by additional $\mathrm{NH}_{3}$ made available from decreasing $\mathrm{SO}_{4}^{2-} . \mathrm{HNO}_{3}$ decreased markedly from 2005 to 2009 in region 3 , then exhibited a slower decreasing trend for 2009-2016. $\mathrm{HNO}_{3}$ in region 4 had an initial decrease from 1989 to 1991, then an increasing trend of $21.1 \%$ (1999-2000 vs. 1991-1992) for 1991-2000. The region then showed a slow decrease in 2000-2005, a fast decrease in 2005-2009, and a slow decrease in 2009-2016.

$\mathrm{TNO}_{3}$ in the cold seasons over regions 2,3 , and 4 had similar trends. For 1990-2001, the general trend of $\mathrm{TNO}_{3}$ over the regions was from roughly constant to slowly increasing. This is consistent with the $\mathrm{NO}_{x}$ emission trend during the period. For 2001-2016, there was a significant decrease in $\mathrm{TNO}_{3}$ over the three regions. For region 3, it occurred mainly during the period 2001-2009.

\section{$\mathrm{NO}_{3}^{-}, \mathrm{HNO}_{3}$, and $\mathrm{TNO}_{3}$ during the warm season}

$\mathrm{NO}_{3}^{-}$in region 1 had an increasing trend in 1990-2000, a decreasing trend in 2000-2007, and a flat trend in 2007-2016. Linear regression of the $\mathrm{NO}_{3}^{-}$seasonal mean concentration in region 2 during the warm season from 1990 to 1999 showed a slow increasing trend for $\mathrm{NO}_{3}^{-}$in the 1990s. After 2002, there was a straight decline of the $\mathrm{NO}_{3}^{-}$concentration until 2009 and a steady decreasing from 2011 to 2016. Linear regression of $\mathrm{NO}_{3}^{-}$in region 3 shows a flat trend during 1989-2000 and a weakly increasing trend during 19901999. Between 2000 and 2005, $\mathrm{NO}_{3}^{-}$in region 3 exhibited a clearly declining trend. From 2005 to 2016, the trend was generally flat. The seasonal concentration of $\mathrm{NO}_{3}^{-}$in region 4 had a weakly increasing trend for 1992-2000, followed by a decreasing trend for 2000-2005 and a slow increasing trend for 2005-2016. In general, $\mathrm{NO}_{3}^{-}$during the warm season had a flat to weakly increasing trend for 1990-2000 and a strong decreasing trend for 2000-2005 for regions 2-4. For 20052016 , there was a decreasing trend for region 2 , a flat trend for region 3 , and a weakly increasing trend for region 4 .

$\mathrm{HNO}_{3}$ in region 1 was very low $\left(<1.0 \mu \mathrm{g} \mathrm{m}^{-3}\right)$ in general during the whole study period. There was flat trend in 1990 to 2001, a slow decreasing trend in 2001 to 2009, and a flat trend again in 2009 to $2016 . \mathrm{HNO}_{3}$ in regions $2-4$ can be characterized by three periods: a flat (regions 2 and 3 ) or a weak increasing (region 4) trend for 1989-1999, a significant decreasing trend for 1999-2009, and a generally flat trend for 2009-2016.

$\mathrm{HNO}_{3}$ dominated over $\mathrm{NO}_{3}^{-}$in $\mathrm{TNO}_{3}$ during the warm season for all regions, especially in regions 3 and 4 where the ratio of $\mathrm{NO}_{3}^{-}$to $\mathrm{TNO}_{3}$ was usually less than $20 \%$. Therefore, the trend of $\mathrm{TNO}_{3}$ generally followed that of $\mathrm{HNO}_{3}$ during the warm season. In the 1990s (1990-1999) the trend of $\mathrm{TNO}_{3}$ in the warm season over regions 2 and 3 was very flat, and there was a very weakly increasing trend over region 4 . The turning point of the trend was in 1999. For the period 1999-2009, all three regions showed significant de- creasing trends. For 2009-2016, the trends in the three regions were generally flat.

\subsection{3 $\mathrm{NH}_{4}^{+}$}

\section{$\mathrm{NH}_{4}^{+}$during the cold season}

$\mathrm{NH}_{4}^{+}$during the cold season in region 1 had a flat trend in 1990-1999 and a very slow decreasing trend in 19992009 , followed by a generally flat trend in 2009-2015. The trend of $\mathrm{NH}_{4}^{+}$in region 2 during the cold season was affected by both $\mathrm{SO}_{4}^{2-}$ and $\mathrm{NO}_{3}^{-}$. It had a near-linear decreasing trend from 1991 to 2009 and was followed by another steeper declining trend for 2009-2016. $\mathrm{NH}_{4}^{+}$in region 3 had a steep decrease in 1989-1994 and was followed by a weak decrease and a steep decrease in 1994-2009 and 2009-2016, respectively. $\mathrm{NH}_{4}^{+}$in region 4 remained unchanged during 19902001. After 2001, $\mathrm{NH}_{4}^{+}$decreased steadily until 2016.

\section{$\mathrm{NH}_{4}^{+}$during the warm season}

$\mathrm{NH}_{4}^{+}$in region 1 changed little in 1990-2005 and 2009-2015 during the warm season, but there was a decreasing trend in 2005-2009. Excluding the two significant peaks in 1989 and $2005, \mathrm{NH}_{4}^{+}$in region 2 showed a consistent and steady decreasing trend from 1990 to 2016. Figure 3 shows that the trend of $\mathrm{NH}_{4}^{+}$in region 3 generally followed that of $\mathrm{SO}_{4}^{2-}$ closely because $\mathrm{NH}_{4}^{+}$in region 3 was dominantly associated with $\mathrm{SO}_{4}^{2-}$ during the warm season. The two trends were almost identical after 2000. From 1995 to 2005, the trend of $\mathrm{NH}_{4}^{+}$in region 3 was almost flat. There was a major decrease in $\mathrm{NH}_{4}^{+}$in region 3 in 2005-2009 when it decreased by almost $50 \%$ in 4 years. $\mathrm{NH}_{4}^{+}$in region 4 changed little from 1990 to 2000 . Although during the same period $\mathrm{SO}_{4}^{2-}$ had an obvious decreasing trend, its impact on $\mathrm{NH}_{4}^{+}$was offset by the increasing trend of $\mathrm{NO}_{3}^{-}$during this period. After a drop in 2000-2001, $\mathrm{NH}_{4}^{+}$had a flat trend for 2001-2007, a dramatic decrease in 2007-2009, and a steady decreasing trend for 2010-2016.

\subsection{0 and 25 years of changes in ambient $\mathrm{SO}_{4}^{2-}, \mathrm{SO}_{2}$, $\mathrm{NH}_{4}^{+}, \mathrm{NO}_{3}^{-}, \mathrm{HNO}_{3}$, and $\mathrm{TNO}_{3}$ in the EUS and $\mathrm{EC}$ for 1990-2015}

As mentioned in Sect. 1, emissions of $\mathrm{NO}_{x}$ changed little during the 1990s in the EUS. Correspondingly, the time series of $\mathrm{TNO}_{3}$ in regions 2-4 during the 1990s did not decrease or even increased, as shown in Sect. 3.2. Also, some important metrics, such as $\mathrm{RSO}_{4}$ during the cold season and $\mathrm{RNO}_{3}$ during the warm and cold seasons, only started to have significant changes after the first 10 years. In order to capture how ambient air pollutants responded to emission reductions of $\mathrm{SO}_{2}$ and $\mathrm{NO}_{x}$ temporarily, 10 and 25 years of change in ambient $\mathrm{SO}_{4}^{2-}, \mathrm{SO}_{2}, \mathrm{NH}_{4}^{+}, \mathrm{NO}_{3}^{-}, \mathrm{HNO}_{3}$, and $\mathrm{TNO}_{3}$ during 1990-2015 are presented in Tables 2 and 3 and are sum- 
Table 2. Changes in the regionally averaged air concentrations of pollutants $\left(\mu \mathrm{g} \mathrm{m}^{-3}\right), \mathrm{RSO}_{4}(\%)$, and $\mathrm{RNO}_{3}(\%)$ between $1989-1991$ and 1999-2001 for regions 1-4.

\begin{tabular}{|c|c|c|c|c|c|c|c|c|c|}
\hline Region & & $\mathrm{SO}_{4}^{2-}$ & $\mathrm{NO}_{3}^{-}$ & $\mathrm{NH}_{4}^{+}$ & $\mathrm{HNO}_{3}$ & $\mathrm{SO}_{2}$ & $\mathrm{TNO}_{3}$ & $\mathrm{RSO}_{4}$ & $\mathrm{RNO}_{3}$ \\
\hline \multicolumn{10}{|c|}{ (a) Cold season } \\
\hline \multirow{4}{*}{1} & 1989-1991 & 2.29 & 0.37 & 0.57 & 0.74 & 3.62 & 1.1 & 31.13 & 32.53 \\
\hline & 1999-2001 & 1.46 & 0.49 & 0.44 & 0.54 & 1.91 & 1.01 & 35.7 & 48.58 \\
\hline & $\Delta$ & -0.83 & 0.12 & -0.13 & -0.2 & -1.71 & -0.09 & 4.57 & 16.05 \\
\hline & $\Delta \%$ & $-36.2 \%$ & $32.4 \%$ & $-22.8 \%$ & $-27.0 \%$ & $-47.2 \%$ & $-8.2 \%$ & $14.7 \%$ & $49.3 \%$ \\
\hline \multirow{4}{*}{2} & 1989-1991 & 4.19 & 3.62 & 2.27 & 1.66 & 13.65 & 5.25 & 17.92 & 68.49 \\
\hline & 1999-2001 & 3.14 & 3.86 & 1.95 & 1.51 & 8.87 & 5.35 & 19.77 & 71.93 \\
\hline & $\Delta$ & -1.05 & 0.24 & -0.32 & -0.15 & -4.78 & 0.1 & 1.85 & 3.44 \\
\hline & $\Delta \%$ & $-25.1 \%$ & $6.6 \%$ & $-14.1 \%$ & $-9.0 \%$ & $-35.0 \%$ & $1.9 \%$ & $10.3 \%$ & $5.0 \%$ \\
\hline \multirow{4}{*}{3} & 1989-1991 & 4.24 & 1.21 & 1.56 & 2.31 & 19.2 & 3.49 & 13.11 & 32.76 \\
\hline & 1999-2001 & 3.21 & 1.48 & 1.35 & 2.05 & 12.35 & 3.5 & 15.27 & 40.13 \\
\hline & $\Delta$ & -1.03 & 0.27 & -0.21 & -0.26 & -6.85 & 0.01 & 2.16 & 7.37 \\
\hline & $\Delta \%$ & $-24.3 \%$ & $22.3 \%$ & $-13.5 \%$ & $-11.3 \%$ & $-35.7 \%$ & $0.3 \%$ & $16.5 \%$ & $22.5 \%$ \\
\hline \multirow{4}{*}{4} & 1989-1991 & 3.57 & 0.55 & 1.09 & 1.81 & 7.24 & 2.33 & 28.29 & 25.14 \\
\hline & 1999-2001 & 3.09 & 0.77 & 1.1 & 1.9 & 5.52 & 2.66 & 30.36 & 28.31 \\
\hline & $\Delta$ & -0.48 & 0.22 & 0.01 & 0.09 & -1.72 & 0.33 & 2.07 & 3.17 \\
\hline & $\Delta \%$ & $-13.4 \%$ & $40.0 \%$ & $0.9 \%$ & $5.0 \%$ & $-23.8 \%$ & $14.2 \%$ & $7.3 \%$ & $12.6 \%$ \\
\hline \multicolumn{10}{|c|}{ (b) Warm season } \\
\hline \multirow{4}{*}{1} & 1989-1991 & 2.93 & 0.14 & 0.73 & 0.62 & 1.56 & 0.75 & 57.71 & 19 \\
\hline & 1999-2001 & 2.16 & 0.23 & 0.62 & 0.53 & 0.94 & 0.73 & 62.18 & 33.52 \\
\hline & $\Delta$ & -0.77 & 0.09 & -0.11 & -0.09 & -0.62 & -0.02 & 4.47 & 14.52 \\
\hline & $\Delta \%$ & $-26.3 \%$ & $64.3 \%$ & $-15.1 \%$ & $-14.5 \%$ & $-39.7 \%$ & $-2.7 \%$ & $7.7 \%$ & $76.4 \%$ \\
\hline \multirow{4}{*}{2} & 1989-1991 & 7.9 & 1.46 & 2.72 & 2.93 & 8.58 & 4.34 & 39.3 & 33.68 \\
\hline & 1999-2001 & 5.33 & 1.32 & 1.91 & 2.65 & 5.37 & 3.93 & 40.73 & 33.76 \\
\hline & $\Delta$ & -2.57 & -0.14 & -0.81 & -0.28 & -3.21 & -0.41 & 1.43 & 0.08 \\
\hline & $\Delta \%$ & $-32.5 \%$ & $-9.6 \%$ & $-29.8 \%$ & $-9.6 \%$ & $-37.4 \%$ & $-9.4 \%$ & $3.6 \%$ & $0.2 \%$ \\
\hline \multirow{4}{*}{3} & 1989-1991 & 8.2 & 0.47 & 2.33 & 2.79 & 9.11 & 3.22 & 37.98 & 13.91 \\
\hline & 1999-2001 & 6.04 & 0.48 & 1.91 & 2.4 & 6.06 & 2.84 & 40.7 & 15.74 \\
\hline & $\Delta$ & -2.16 & 0.01 & -0.42 & -0.39 & -3.05 & -0.38 & 2.72 & 1.83 \\
\hline & $\Delta \%$ & $-26.3 \%$ & $2.1 \%$ & $-18.0 \%$ & $-14.0 \%$ & $-33.5 \%$ & $-11.8 \%$ & $7.2 \%$ & $13.2 \%$ \\
\hline \multirow{4}{*}{4} & 1989-1991 & 7.61 & 0.32 & 1.92 & 1.74 & 3.67 & 2.04 & 60.76 & 16.99 \\
\hline & 1999-2001 & 5.85 & 0.31 & 1.69 & 1.84 & 3.1 & 2.12 & 58.29 & 15.22 \\
\hline & $\Delta$ & -1.76 & -0.01 & -0.23 & 0.1 & -0.57 & 0.08 & -2.47 & -1.77 \\
\hline & $\Delta \%$ & $-23.1 \%$ & $-3.1 \%$ & $-12.0 \%$ & $5.7 \%$ & $-15.5 \%$ & $3.9 \%$ & $-4.1 \%$ & $-10.4 \%$ \\
\hline
\end{tabular}

marized in Sect. 3.3.1 and 3.3.2. To avoid the fluctuation of annual ambient concentrations due to the variation of meteorology, the changes are calculated based on 3-year averages centered on 1990, 2000, and 2015.

\subsubsection{0 years of changes for the period 1990-2000}

During the 10-year period of 1990-2015, air quality in the EUS and EC underwent a number of major changes, which are summarized as follows.

1. During the first 10 years, $\mathrm{SO}_{2}$ concentrations declined in all regions and seasons by more than $25.0 \%$ except for region 4, which had a reduction of $15.5 \%$ during the warm season and $23.8 \%$ during the cold season.

2. $\mathrm{SO}_{4}^{2-}$ showed a similar but less significant decreasing trend as $\mathrm{SO}_{2}$. The reduction was more than $20 \%$ in all regions except for region 4 during the cold season. Region 4 during the warm season had a similar reduction rate as region 3 despite the significant difference in the reduction rates of $\mathrm{SO}_{2}$ in the two regions.

3. $\mathrm{NO}_{3}^{-}$increased between $6.6 \%$ and $40.0 \%$ during the cold season for regions $1-4$. Changes in $\mathrm{NO}_{3}^{-}$during 
Table 3. Changes in the regionally averaged air concentrations of air pollutants $\left(\mu \mathrm{g} \mathrm{m}^{-3}\right), \mathrm{RSO}_{4}(\%)$, and $\mathrm{RNO}_{3}(\%)$ between $1989-1991$ and 2014-2016 for the eastern US and Eastern Canada. Bold in (a) indicates the 3-year average concentrations still exceeding $1.0 \mu \mathrm{g} \mathrm{m}^{-3}$ in 2014-2016. Bold in (b) and (c) indicates reduction and increase rates exceeding $50 \%$.

\begin{tabular}{|c|c|c|c|c|c|c|c|c|c|}
\hline & & $\mathrm{SO}_{4}^{2-}$ & $\mathrm{NO}_{3}^{-}$ & $\mathrm{NH}_{4}^{+}$ & $\mathrm{HNO}_{3}$ & $\mathrm{SO}_{2}$ & $\mathrm{TNO}_{3}$ & $\mathrm{RSO}_{4}$ & $\mathrm{RNO}_{3}$ \\
\hline \multicolumn{10}{|c|}{ (a) All regions in the eastern US and Eastern Canada } \\
\hline \multirow{4}{*}{ All seasons } & 1989-1991 & 5.44 & 1.1 & 1.78 & 1.96 & 8.73 & 3.02 & 33.6 & 31.72 \\
\hline & 2014-2016 & 1.45 & 0.78 & 0.58 & 0.67 & 1.08 & 1.43 & 50.6 & 51.91 \\
\hline & $\Delta$ & -3.99 & -0.32 & -1.2 & -1.29 & -7.65 & -1.59 & 17 & 20.19 \\
\hline & $\Delta \%$ & $-73.3 \%$ & $-29.1 \%$ & $-67.4 \%$ & $-65.8 \%$ & $-87.6 \%$ & $-52.6 \%$ & $50.6 \%$ & $63.7 \%$ \\
\hline \multirow{4}{*}{ Cold season } & 1989-1991 & 3.73 & 1.58 & 1.49 & 1.76 & 11.71 & 3.31 & 21.41 & 40.98 \\
\hline & 2014-2016 & 1.4 & 1.21 & 0.68 & 0.66 & 1.5 & 1.86 & 42.33 & 61.04 \\
\hline & $\Delta$ & -2.33 & -0.37 & -0.81 & -1.1 & -10.21 & -1.45 & 20.92 & 20.06 \\
\hline & $\Delta \%$ & $-62.5 \%$ & $-23.4 \%$ & $-54.4 \%$ & $-62.5 \%$ & $-87.2 \%$ & $-43.8 \%$ & $97.7 \%$ & $49.0 \%$ \\
\hline \multirow{4}{*}{ Warm season } & 1989-1991 & 7.02 & 0.66 & 2.06 & 2.18 & 6.15 & 2.81 & 47.86 & 21.29 \\
\hline & 2014-2016 & 1.6 & 0.41 & 0.53 & 0.75 & 0.75 & 1.15 & 60.4 & 34.32 \\
\hline & $\Delta$ & -5.42 & -0.25 & -1.53 & -1.43 & -5.4 & -1.66 & 12.54 & 13.03 \\
\hline & $\Delta \%$ & $-77.2 \%$ & $-37.9 \%$ & $-74.3 \%$ & $-65.6 \%$ & $-87.8 \%$ & $-59.1 \%$ & $26.2 \%$ & $61.2 \%$ \\
\hline \multicolumn{10}{|c|}{ (b) Regions 1-4 during the warm season } \\
\hline \multirow{4}{*}{1} & 1989-1991 & 2.93 & 0.14 & 0.73 & 0.62 & 1.56 & 0.75 & 57.71 & 19.0 \\
\hline & 2014-2016 & 0.8 & 0.12 & 0.28 & 0.21 & 0.4 & 0.33 & 58.03 & 37.04 \\
\hline & $\Delta$ & -2.13 & -0.02 & -0.45 & -0.41 & -1.16 & -0.42 & 0.32 & 18.04 \\
\hline & $\Delta \%$ & $-72.7 \%$ & $-14.3 \%$ & $-61.6 \%$ & $-66.1 \%$ & $-74.4 \%$ & $-\mathbf{5 6 . 0} \%$ & $0.6 \%$ & $94.9 \%$ \\
\hline \multirow{4}{*}{2} & 1989-1991 & 7.9 & 1.46 & 2.72 & 2.93 & 8.58 & 4.34 & 39.3 & 33.68 \\
\hline & 2014-2016 & 1.83 & 0.62 & 0.66 & 1.08 & 1.03 & 1.68 & 54.85 & 36.38 \\
\hline & $\Delta$ & -6.07 & -0.84 & -2.06 & -1.85 & -7.55 & -2.66 & 15.55 & 2.7 \\
\hline & $\Delta \%$ & $-76.8 \%$ & $-\mathbf{5 7 . 5} \%$ & $-75.7 \%$ & $-63.1 \%$ & $-\mathbf{8 8 . 0} \%$ & $-61.3 \%$ & $39.6 \%$ & $8.0 \%$ \\
\hline \multirow{4}{*}{3} & 1989-1991 & 8.2 & 0.47 & 2.33 & 2.79 & 9.11 & 3.22 & 37.98 & 13.91 \\
\hline & 2014-2016 & 1.77 & 0.3 & 0.6 & 0.87 & 0.8 & 1.16 & 60.15 & 24.92 \\
\hline & $\Delta$ & -6.43 & -0.17 & -1.73 & -1.92 & -8.31 & -2.06 & 22.17 & 11.01 \\
\hline & $\Delta \%$ & $-78.4 \%$ & $-36.2 \%$ & $-74.2 \%$ & $-68.8 \%$ & $-91.2 \%$ & $-64.0 \%$ & $58.4 \%$ & $79.2 \%$ \\
\hline \multirow{4}{*}{4} & 1989-1991 & 7.61 & 0.32 & 1.92 & 1.74 & 3.67 & 2.04 & 60.76 & 16.99 \\
\hline & 2014-2016 & 1.62 & 0.27 & 0.5 & 0.61 & 0.59 & 0.86 & 68.29 & 30.8 \\
\hline & $\Delta$ & -5.99 & -0.05 & -1.42 & -1.13 & -3.08 & -1.18 & 7.53 & 13.81 \\
\hline & $\Delta \%$ & $-78.7 \%$ & $-15.6 \%$ & $-74.0 \%$ & $-64.9 \%$ & $-83.9 \%$ & $-\mathbf{5 7 . 8} \%$ & $12.4 \%$ & $\mathbf{8 1 . 3} \%$ \\
\hline \multicolumn{10}{|c|}{ (c) Regions 1-4 during the cold season } \\
\hline \multirow{4}{*}{1} & $1989-1991$ & 2.29 & 0.37 & 0.57 & 0.74 & 3.62 & 1.1 & 31.13 & 32.53 \\
\hline & 2014-2016 & 0.87 & 0.44 & 0.32 & 0.27 & 0.75 & 0.71 & 46.25 & 62.54 \\
\hline & $\Delta$ & -1.42 & 0.07 & -0.25 & -0.47 & -2.87 & -0.39 & 15.12 & 30.01 \\
\hline & $\Delta \%$ & $-\mathbf{6 2 . 0} \%$ & $18.9 \%$ & $-43.9 \%$ & $-63.5 \%$ & $-79.3 \%$ & $-35.5 \%$ & $48.6 \%$ & $\mathbf{9 2 . 3} \%$ \\
\hline \multirow{4}{*}{2} & 1989-1991 & 4.19 & 3.62 & 2.27 & 1.66 & 13.65 & 5.25 & 17.92 & 68.49 \\
\hline & 2014-2016 & 1.67 & 2.52 & 1.16 & 0.73 & 2.19 & 3.24 & 35.18 & 77.29 \\
\hline & $\Delta$ & -2.52 & -1.1 & -1.11 & -0.93 & -11.46 & -2.01 & 17.26 & 8.8 \\
\hline & $\Delta \%$ & $-60.1 \%$ & $-30.4 \%$ & $-48.9 \%$ & $-\mathbf{5 6 . 0} \%$ & $-84.0 \%$ & $-38.3 \%$ & $96.3 \%$ & $12.8 \%$ \\
\hline \multirow{4}{*}{3} & 1989-1991 & 4.24 & 1.21 & 1.56 & 2.31 & 19.2 & 3.49 & 13.11 & 32.76 \\
\hline & 2014-2016 & 1.59 & 1.25 & 0.77 & 0.86 & 2.17 & 2.09 & 34.91 & 57.95 \\
\hline & $\Delta$ & -2.65 & 0.04 & -0.79 & -1.45 & -17.03 & -1.4 & 21.8 & 25.19 \\
\hline & $\Delta \%$ & $-62.5 \%$ & $3.3 \%$ & $-50.6 \%$ & $-62.8 \%$ & $-\mathbf{8 8 . 7} \%$ & $-40.1 \%$ & $166.3 \%$ & $76.9 \%$ \\
\hline \multirow{4}{*}{4} & 1989-1991 & 3.57 & 0.55 & 1.09 & 1.81 & 7.24 & 2.33 & 28.29 & 25.14 \\
\hline & 2014-2016 & 1.36 & 0.55 & 0.51 & 0.71 & 1.13 & 1.25 & 48.53 & 43.71 \\
\hline & $\Delta$ & -2.21 & 0 & -0.58 & -1.1 & -6.11 & -1.08 & 20.24 & 18.57 \\
\hline & $\Delta \%$ & $-61.9 \%$ & $0.0 \%$ & $-53.2 \%$ & $-60.8 \%$ & $-84.4 \%$ & $-46.4 \%$ & $71.5 \%$ & $73.9 \%$ \\
\hline
\end{tabular}


the warm season in regions 3 and 4 were very small and only had a significant reduction of $9.6 \%$ in region 2 .

4. $\mathrm{TNO}_{3}$ increased little in region 1 , by 0.09 and $0.02 \mu \mathrm{g} \mathrm{m}^{-3}$ for the cold and warm seasons, respectively. $\mathrm{TNO}_{3}$ in regions 2 and 3 changed very little during the cold season and had a $9.4 \%$ and $11.8 \%$ reduction during the warm season. $\mathrm{TNO}_{3}$ in region 4 increased by $3.9 \%$ during the warm season and by $14.2 \%$ during the cold season.

5. Except for a negligible change in region $4, \mathrm{NH}_{4}^{+}$decreased by $13.5 \%$ to $22.8 \%$ for regions $1-3$ during the cold season; during warm season, it decreased by $12.0 \%$ to $29.8 \%$ for regions $1-4$.

6. In summary, over the first 10-year period of 1990-2010, $\mathrm{SO}_{2}, \mathrm{SO}_{4}^{2-}$, and $\mathrm{NH}_{4}^{+}$declined by $31.6 \%, 26.7 \%$, and $18.5 \%$, respectively, in the EUS and $\mathrm{EC} . \mathrm{HNO}_{3}$ was reduced in regions $1-3$. $\mathrm{NO}_{3}^{-}$increased in regions 1-4 during the cold season and changed very little $\left(<0.15 \mu \mathrm{g} \mathrm{m}^{-3}\right)$ during the warm season. Considering both seasons and all regions, $\mathrm{NO}_{3}^{-}$increased by $12.7 \%, \mathrm{HNO}_{3}$ declined by $5.6 \%$, and the change in $\mathrm{TNO}_{3}$ was negligible with the mean concentration being $3.02 \mu \mathrm{g} \mathrm{m}^{-3}$ for $1989-1990$ vs. $3.05 \mu \mathrm{g} \mathrm{m}^{-3}$ for $1999-$ 2001.

\subsubsection{5 years of changes for the period 1990-2015}

During the 25-year period of 1990-2015, air quality in the EUS and EC changed significantly and is summarized as follows.

1. Among all species, the most significant reduction during the period was for $\mathrm{SO}_{2}$. The reduction of $\mathrm{SO}_{2}$ in regions $2-4$ was similar in percentage, from $83.9 \%$ in the warm season for region 4 to $91.2 \%$ in the warm season for region 3. There were no major differences between the warm and cold seasons in terms of percentage reduction. In terms of absolute value, the biggest reduction was for $\mathrm{SO}_{2}$ in region 3 during the cold season, and the 3-year-averaged seasonal mean concentration was reduced from 19.2 to $2.2 \mu \mathrm{g} \mathrm{m}^{-3}$.

2. The reduction in $\mathrm{SO}_{4}^{2-}$ concentrations during the cold season was relatively uniform in terms of percentage, ranging from $60.1 \%$ in region 2 to $62.5 \%$ in region 3 . The reduction was more significant during the warm season than during the cold season, ranging from $72.7 \%$ in region 1 to $78.7 \%$ in region 4 . The reductions in regions 2,3 , and 4 were similar in terms of values in both seasons. The reduction of $\mathrm{SO}_{4}^{2-}$ in terms of percentage was much smaller than $\mathrm{SO}_{2}$ in all regions during both seasons except for $\mathrm{SO}_{4}^{2-}$ during the warm season in region 1.
3. During the warm season, the reduction of $\mathrm{NO}_{3}^{-}$was seen in all four regions, ranging from $14.3 \%$ and $15.6 \%$ in regions 1 and 4 to $36.2 \%$ and $57.5 \%$ in regions 3 and 2. The reduction of $\mathrm{NO}_{3}^{-}$during the cold season was only observed in region $2(30.4 \%)$. Although $\mathrm{TNO}_{3}$ was reduced during the cold season in regions 3 and 4 , a higher percentage of $\mathrm{HNO}_{3}$ was converted to $\mathrm{NO}_{3}^{-}$ as more excess $\mathrm{NH}_{3}$ was available to form $\mathrm{NH}_{4} \mathrm{NO}_{3}$ due to the reduction of $\mathrm{SO}_{4}^{2-}$. As a result, the trend of $\mathrm{NO}_{3}^{-}$in the two regions during the cold season changed very little. Unlike regions 3 and 4, region 2 did experience a significant reduction of $\mathrm{NO}_{3}^{-}$in the cold season, following a $38.3 \%$ reduction of $\mathrm{TNO}_{3}$. This can be explained as region 2 is an $\mathrm{NH}_{3}$-rich region. The formation of $\mathrm{NH}_{4} \mathrm{NO}_{3}$ during the cold season in the region is less sensitive to the excess $\mathrm{NH}_{3}$ made available from $\mathrm{SO}_{4}^{2-}$ reduction than in regions 3 and 4 . This can also be demonstrated by the least reduction of $\mathrm{HNO}_{3}$ (in terms of percentage) in region 2 during the cold season as well as the correlations of $\mathrm{RNO}_{3}$ vs. $\mathrm{SO}_{4}^{2-}$ shown in Sect. 5.4.

4. The reduction of $\mathrm{HNO}_{3}$ was similar in all four regions during the warm season, ranging from $63.1 \%$ to $68.8 \%$. During the cold season, region 2 had the lowest percentage reduction at $56.0 \%$, and region 1 had the highest at $63.5 \%$. The reduction of $\mathrm{HNO}_{3}$ can be through two paths: a reduction of $\mathrm{NO}_{x}$ emissions and an increased neutralization of $\mathrm{HNO}_{3}$ by more excess $\mathrm{NH}_{3}$ due to less formation of $\left(\mathrm{NH}_{4}\right)_{2} \mathrm{SO}_{4}$ and $\mathrm{NH}_{4} \mathrm{HSO}_{4}$. In terms of percentage, the reduction of $\mathrm{HNO}_{3}$ was more significant than $\mathrm{TNO}_{3}$ during the cold season, ranging from $14.4 \%$ more in region 4 to $28.0 \%$ more in region 1 .

5. $\mathrm{TNO}_{3}$ had a reduction rate ranging from $35.5 \%$ for the cold season in region 1 to $64 \%$ during the warm season in region 3. The reduction during the warm season was much greater than in the cold season, ranging from $11.4 \%$ higher in region 4 to $23.9 \%$ higher in region 3 . The difference was partially due to extra reductions of $\mathrm{NO}_{x}$ emissions from power plants and other large combustion sources during the ozone season (May-September) required by the NBP that began in 2003 and the Clean Air Interstate Rule that started in 2009 (Napolitano et al., 2007; Butler et al., 2011; Sickles II and Shadwick, 2015).

6. The reduction of $\mathrm{NH}_{4}^{+}$was similar in regions 2,3 , and 4 , ranging from $48.9 \%$ to $53.2 \%$ in the cold season and from $74.0 \%$ to $75.7 \%$ in the warm season. The reduction of $\mathrm{NH}_{4}^{+}$during the warm season was more significant than in the cold season, over $20 \%$ more in regions $2-4$. The reduction of $\mathrm{NH}_{4}^{+}$generally followed the trends of $\mathrm{SO}_{4}^{2-}$, but the reduction rate was much lower than that of $\mathrm{SO}_{4}^{2-}$ during the cold season because a certain percentage of $\mathrm{NH}_{4}^{+}$was associated with $\mathrm{NO}_{3}^{-}$and 
the reduction of $\mathrm{NO}_{3}^{-}$was not as significant as $\mathrm{SO}_{4}^{2-}$ during the cold season. Region 2 exhibited the largest reduction of $\mathrm{NH}_{4}^{+}(75.7 \%)$ during the warm season, contributed by a $76.8 \%$ reduction of $\mathrm{SO}_{4}^{2-}$ as well as a $57.5 \%$ reduction of $\mathrm{NO}_{3}^{-}$.

7. $\mathrm{RSO}_{4}$ increased the most in region 3 during the cold season at $166.3 \%$ and the least in region 1 during the warm season at $0.6 \%$. During the warm season, $\mathrm{RSO}_{4}$ increased by $54.9 \%$ and $58.4 \%$ in regions 2 and 3, respectively. The increase in $\mathrm{RSO}_{4}$ during the cold season was much higher than in the warm season in terms of percentage, ranging from $48.6 \%$ in region 1 to $166.3 \%$ in region 3.

8. $\mathrm{RNO}_{3}$ increased significantly in regions 1,3 , and 4 in both seasons, ranging from $73.9 \%$ to $94.9 \%$, but $\mathrm{RNO}_{3}$ only increased by $8.0 \%$ and $12.8 \%$ in the warm and cold seasons for region 2, which was rich in $\mathrm{NH}_{3}$.

9. As presented in Table 3, the following points apply for the whole region: (1) among the five species of $\mathrm{SO}_{4}^{2-}, \mathrm{NO}_{3}^{-}, \mathrm{NH}_{4}^{+}, \mathrm{HNO}_{3}$, and $\mathrm{SO}_{2}$, only $\mathrm{SO}_{4}^{2-}$ and $\mathrm{SO}_{2}$ still had regionally averaged annual mean concentrations exceeding $1.0 \mathrm{\mu g} \mathrm{m}^{-3}$ at the end of the study period. (2) $\mathrm{SO}_{4}^{2-}$ was reduced by $73.3 \%$ for the whole region during the study period, and it was reduced about $15 \%$ more in the warm season than in the cold season in terms of percentage; (3) $\mathrm{NH}_{4}^{+}$was reduced more in the warm season than in the cold season in terms of both percentage and absolute value; (4) $\mathrm{NO}_{3}^{-}$was reduced by $29.1 \%$ for the whole region. The reduction during the cold season occurred only in region 2 , and the reduction during the warm season mainly occurred in regions 2 and 3. The reduction of $\mathrm{NO}_{3}^{-}$for the whole region was mainly due to the reductions in region 2 during the warm and cold seasons; (5) $\mathrm{RSO}_{4}$ increased by $97.7 \%$ in the cold season, much higher than $26.2 \%$ in the warm season. $\mathrm{RSO}_{4}$ increased the most in region 3 during the cold season in terms of both absolute value and percentage.

\subsection{Air quality at the end of the study period: 2014-2016}

The 3-year-averaged air concentrations for 2014-2016 are used to describe the air quality at the end of the study period and are presented in Table S2 and Fig. S2. The air concentration mentioned in this section refers to the 3 -year-averaged air concentration for each species, either for the warm or the cold season.

As at the beginning of the period, region 1 had the cleanest air among all regions, with the lowest air concentrations of less than $1.0 \mu \mathrm{g} \mathrm{m}^{-3}$ for all species and for both the warm and cold seasons. Unlike at the beginning of the period when $\mathrm{SO}_{4}^{2-}$ during the warm season was about double that during the cold season in regions $2-4, \mathrm{SO}_{4}^{2-}$ at the end of the period had no significant differences between the two seasons. The air concentrations of $\mathrm{SO}_{4}^{2-}$ were less than $2.0 \mu \mathrm{g} \mathrm{m}{ }^{-3}$ in all regions and both seasons. For regions $2-4$ the regional averages ranged from 1.6 to $1.8 \mathrm{\mu g} \mathrm{m}^{-3}$ during the warm season and from 1.4 to $1.7 \mu \mathrm{g} \mathrm{m}^{-3}$ during the cold season. $\mathrm{SO}_{2}$ during the warm season was only from 0.6 to $1.0 \mu \mathrm{g} \mathrm{m}^{-3}$ for regions 2-4. In the cold season, $\mathrm{SO}_{2}$ in regions 2 and 3 was the same at $2.2 \mu \mathrm{g} \mathrm{m}^{-3}$ and was only $1.1 \mu \mathrm{g} \mathrm{m}^{-3}$ in region $4 . \mathrm{NH}_{4}^{+}$during the warm season varied from 0.5 to $0.7 \mu \mathrm{g} \mathrm{m}^{-3}$ for regions $2-4$. During the cold season, it was 0.5 and $0.8 \mu \mathrm{g} \mathrm{m}^{-3}$ in regions 4 and 3 , respectively, and it was much higher in region 2 with the value of $1.2 \mu \mathrm{g} \mathrm{m}^{-3}$. The air concentration of $\mathrm{NO}_{3}^{-}$during the warm season was very low in regions 3 and 4 , with values of $0.3 \mu \mathrm{g} \mathrm{m}^{-3}$, and it was doubled in region 2, being $0.6 \mu \mathrm{g} \mathrm{m}^{-3}$. During the cold season, $\mathrm{NO}_{3}^{-}$was much higher than during the warm season, being $2.5,1.3$, and $0.5 \mu \mathrm{g} \mathrm{m}^{-3}$ for regions 2,3 , and 4 , respectively. $\mathrm{HNO}_{3}$ in regions $2-4$ varied from $0.6 \mu \mathrm{g} \mathrm{m}^{-3}$ in region 4 to $1.1 \mu \mathrm{g} \mathrm{m}^{-3}$ in region 2 during the warm season and from $0.7 \mu \mathrm{g} \mathrm{m}^{-3}$ in region 4 to $0.9 \mu \mathrm{g} \mathrm{m}^{-3}$ in region 3 during the cold season. There was little difference between the warm and cold seasons in regions 3 and $4 . \mathrm{TNO}_{3}$ was the highest in region 2 in both seasons, being 1.7 and $3.2 \mu \mathrm{g} \mathrm{m}^{-3}$ for the warm and cold seasons, respectively. Region 3 had the second-highest $\mathrm{TNO}_{3}$ with values of 1.2 and $2.1 \mu \mathrm{g} \mathrm{m}^{-3}$ for the warm and cold seasons, and the corresponding values for region 4 were 0.9 and $1.3 \mu \mathrm{g} \mathrm{m}^{-3}$.

In summary, for species of $\mathrm{SO}_{4}^{2-}, \mathrm{NO}_{3}^{-}, \mathrm{NH}_{4}^{+}, \mathrm{HNO}_{3}$, and $\mathrm{SO}_{2}$, region 1 had air concentrations of less than $1.0 \mu \mathrm{g} \mathrm{m}^{-3}$ for all species in both seasons. For regions $2-4, \mathrm{NO}_{3}^{-}$was less than $1.0 \mu \mathrm{g} \mathrm{m}^{-3}$ for all regions and both seasons except regions 2 and 3 during the cold season, for which the air concentrations of $\mathrm{NO}_{3}^{-}$were 2.5 and $1.3 \mu \mathrm{g} \mathrm{m}^{-3}$, respectively; $\mathrm{HNO}_{3}$ was less than $1.0 \mu \mathrm{g} \mathrm{m}^{-3}$ except region 2 during the warm season with a value of $1.1 \mu \mathrm{g} \mathrm{m}^{-3} ; \mathrm{NH}_{4}^{+}$was less than $1.0 \mu \mathrm{g} \mathrm{m}^{-3}$ for all regions except region 2 during the cold season at $1.2 \mu \mathrm{g} \mathrm{m}^{-3} ; \mathrm{SO}_{4}^{2-}$ was greater than 1.0 but less than $2.0 \mu \mathrm{g} \mathrm{m}^{-3}$ for regions $2-4$ and both seasons; $\mathrm{SO}_{2}$ was greater than 1.0 but less than $2.5 \mu \mathrm{g} \mathrm{m}^{-3}$ for regions $2-4$ and both seasons, except regions 3 and 4 during the warm season, being 0.8 and $0.6 \mu \mathrm{g} \mathrm{m}^{-3}$. Among the four regions, region 2 had the highest air concentration for all species except $\mathrm{HNO}_{3}$ during the cold season. $\mathrm{NO}_{3}^{-}$in region 2 was especially high, double the second-highest value in region 3 in both seasons. Also, $\mathrm{NO}_{3}^{-}$in region 2 had the highest value (at $2.5 \mu \mathrm{g} \mathrm{m}^{-3}$ ) among all species in four regions and both seasons, although it significantly decreased from $3.6 \mu \mathrm{g} \mathrm{m}^{-3}$ at the beginning of the study period.

\subsection{The long-term trends derived with polynomial regressions}

Through trial and error, we found that polynomial regressions can reasonably describe the long-term trends of species 


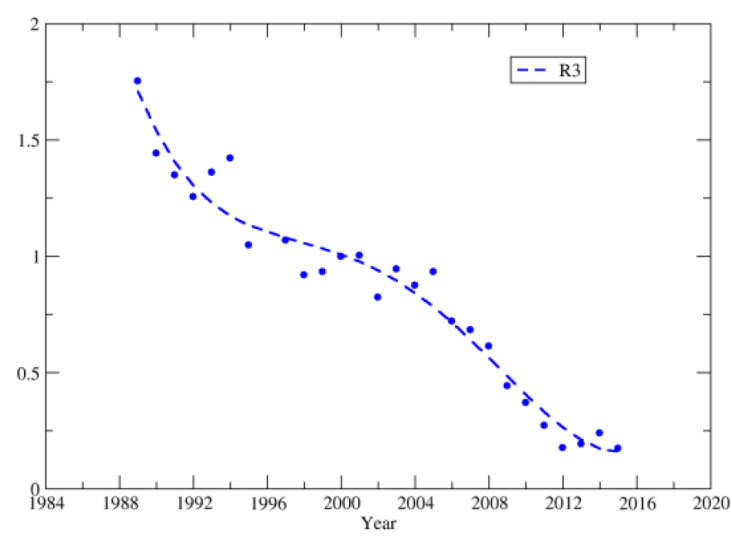

(a) $\mathrm{SO}_{2}$

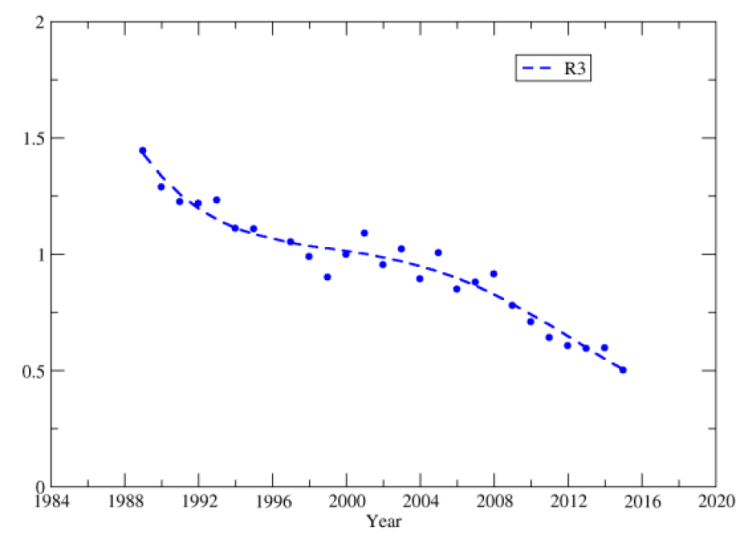

(b) $\mathrm{SO}_{4}{ }^{2-}$

Figure 4. Examples of fourth-order polynomial regressions of $\mathrm{SO}_{2}$ (a) and $\mathrm{SO}_{4}^{2-}$ (b) for region 3 during the cold season.

for the period. Through these regressions, we can eliminate the relatively short-term variations due to meteorology. Fourth-order polynomial regressions were applied to the normalized seasonal means of $\mathrm{SO}_{4}^{2-}, \mathrm{SO}_{2}$, and $\mathrm{NH}_{4}^{+}$during the cold and warm seasons. For $\mathrm{NO}_{3}^{-}, \mathrm{HNO}_{3}$, and $\mathrm{TNO}_{3}$, we applied fifth-order polynomial regressions to better capture the trends. The regressed trends are normalized to the regressed values of the year 2000 as this was the turning point for the trends of $\mathrm{NO}_{3}^{-}$. Examples of the regression for $\mathrm{SO}_{4}^{2-}$ and $\mathrm{SO}_{2}$ in region 3 during the cold season are shown in Fig. 4. Figure 5 shows comparisons between the normalized seasonal means during the cold season in region 3 and the corresponding regressed values.

The regressed trends for $\mathrm{SO}_{4}^{2-}, \mathrm{SO}_{2}, \mathrm{NH}_{4}^{+}, \mathrm{NO}_{3}^{-}, \mathrm{HNO}_{3}$, and $\mathrm{TNO}_{3}$ for the four regions during the cold and warm seasons are shown in Fig. 6a. The regressed trends for regions 1-4 clearly show that (1) the most significant reduction of all species was $\mathrm{SO}_{2}$, and (2) there were significant disparities in the reduction rates between $\mathrm{SO}_{4}^{2-}$ and $\mathrm{SO}_{2}$ during the cold season. There were also disparities during the warm season in regions $1-3$, but they were much less significant than the cold season; (3) among all species, the least significant reduction was for $\mathrm{NO}_{3}^{-}$during the period. Figure $6 \mathrm{~b}$ shows the regressed trends for each species during the cold and warm seasons for different regions. For $\mathrm{SO}_{4}^{2-}$ and $\mathrm{SO}_{2}$, there were large differences in the trends during 1990-2000 between regions 1 and 4 . The trends of $\mathrm{NH}_{4}^{+}$were different for the four regions during 1990-2000 in both seasons and during 2000-2016 in the cold season. In the warm season, the trends of $\mathrm{NO}_{3}^{-}$were similar for regions 2-4 during 19902000 but were different during 2000-2016. The trends of $\mathrm{HNO}_{3}$ and $\mathrm{TNO}_{3}$ were different for 1990-2000 during the warm season but were similar during 2000-2016.

\section{Discussion}

\section{1 $\mathrm{RSO}_{4}$ and correlations of $\mathrm{RSO}_{4}$ vs. $\mathrm{SO}_{2}$}

$\mathrm{RSO}_{4}$ is a metric describing how much sulfur in the air is oxidized from gas $\mathrm{SO}_{2}$ to particulate $\mathrm{SO}_{4}^{2-}$. A similar metric, the ratio of $\mathrm{SO}_{2}$ mass oxidized below $2 \mathrm{~km}$ to $\mathrm{SO}_{2}$ mass emitted, was used by Shah et al. (2018). $\mathrm{RSO}_{2}$, which is $1-\mathrm{RSO}_{4}$, was used by Sickles II and Shadwick (2015). $\mathrm{RSO}_{4}$ is also an indicator of the gas-particle partition ratio for sulfur in the air as $\mathrm{SO}_{2}$ and $\mathrm{SO}_{4}^{2-}$ exist in the air as a gas and particle, respectively. This metric depends on a number of factors: the oxidation capacity of the air, the local emission rate of $\mathrm{SO}_{2}$, the transportation of $\mathrm{SO}_{2}$ and $\mathrm{SO}_{4}^{2-}$ from upwind regions, and the time it takes to bring upwind $\mathrm{SO}_{2}$ and $\mathrm{SO}_{4}^{2-}$ to a local site. Generally, the longer it takes to transport an upwind air parcel, the higher the percentage of $\mathrm{SO}_{2}$ oxidized into $\mathrm{SO}_{4}^{2-}$, and more $\mathrm{SO}_{2}$ is dry-deposited than $\mathrm{SO}_{4}^{2-}$, so $\mathrm{RSO}_{4}$ is higher. Also, the lower the percentage of $\mathrm{SO}_{2}$ emitted locally and the higher the atmospheric oxidation capacity, the higher $\mathrm{RSO}_{4}$. $\mathrm{RSO}_{4}$ for 1989-1991 and 2014-2016, and the changes in $\mathrm{RSO}_{4}$ between 1989-1991 and 2014-2016 during the warm and cold seasons, are presented in Fig. S4. During the warm season, because more solar photons are available to produce $\mathrm{O}_{3}$ from $\mathrm{NO}_{x}$ and VOCs, $\mathrm{RSO}_{4}$ was much higher in the warm season than the cold season. At the beginning of the period, $\mathrm{RSO}_{4}$ in the warm season was about double that in the cold season in regions 1,2, and 4 and around triple in region 3. $\mathrm{RSO}_{4}$ was much higher in regions 4 and 1 than in regions 2 and 3 because the local emissions of $\mathrm{SO}_{2}$ were much higher in regions 2 and 3. The "freshly" emitted $\mathrm{SO}_{2}$ made $\mathrm{RSO}_{4}$ in regions 2 and 3 relatively smaller. $\mathrm{RSO}_{4}$ in region 3 during the cold season was only $13.1 \%$ in 1989 1991, indicating a very low sulfur gas-particle partitioning ratio. Figure $\mathrm{S} 4$ shows that during the cold season, $\mathrm{RSO}_{4}$ increased by more than $40 \%$ at all sites except for VPI120, 

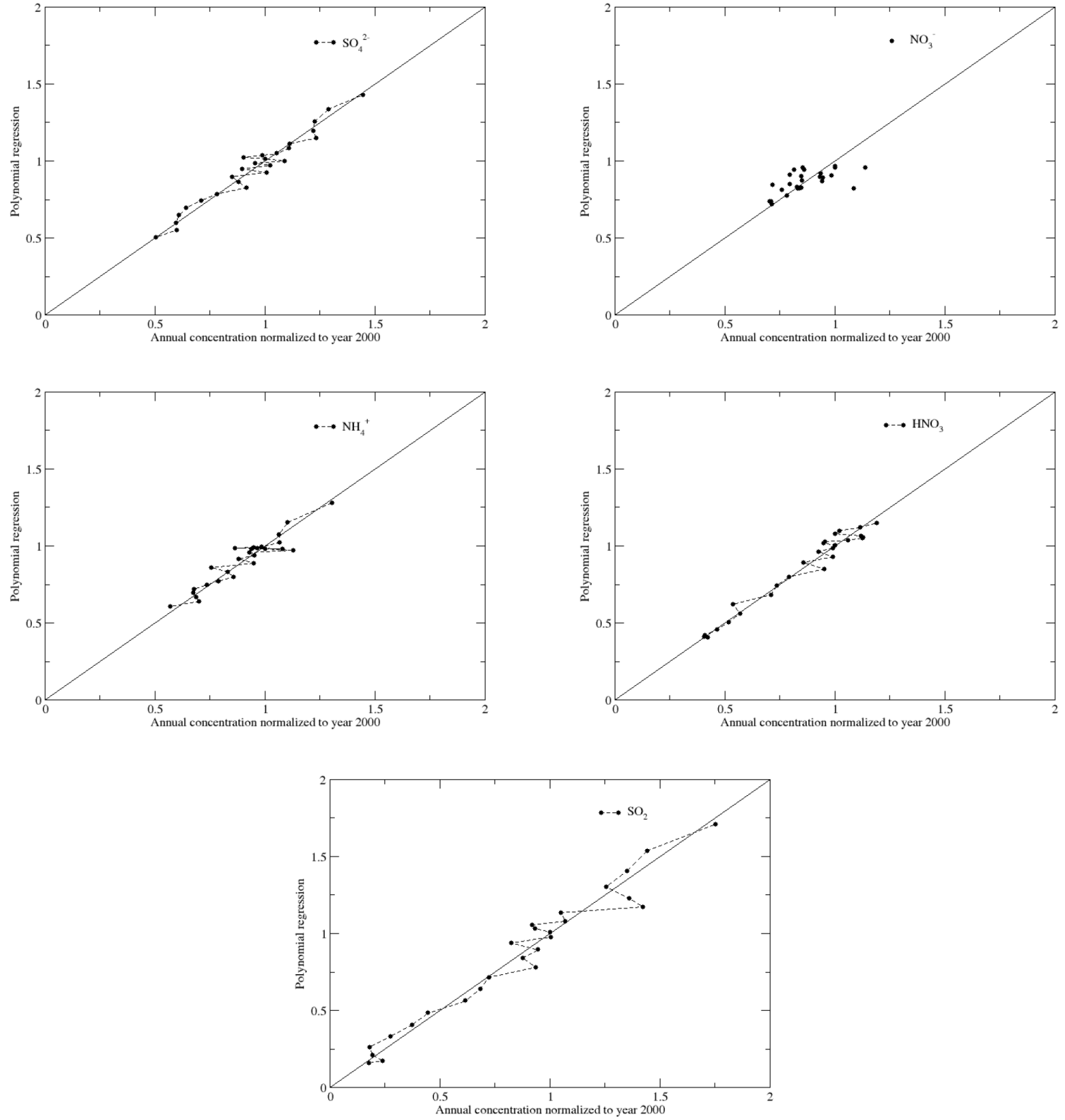

Figure 5. Comparisons of the normalized seasonal mean concentrations with the ones regressed with polynomial regressions for $\mathrm{SO}_{4}^{2-}, \mathrm{SO}_{2}$, $\mathrm{NH}_{4}^{+}, \mathrm{NO}_{3}^{-}$, and $\mathrm{HNO}_{3}$ for region 3 during the cold season. The dotted lines link the seasonal mean concentrations from 1990 to 2016 for species except for $\mathrm{NO}_{3}^{-}$to show the temporal trends.

at which it increased by $18.7 \%$. During the warm season, $\mathrm{RSO}_{4}$ increased at all sites except for VPI120, ASH135, and WST109, at which it decreased by $25.0 \%, 12.5 \%$, and $3.9 \%$, respectively. The most significant increase in $\mathrm{RSO}_{4}$ was in region 3 during the cold season, with a regional average of $166.3 \%$.

Figure 7 shows that $\mathrm{RSO}_{4}$ increased linearly with the year for region 1 and quadratically for regions $2-4$ for both sea- sons. $\mathrm{RSO}_{4}$ increased significantly after 2005 in regions 2 4. Figure 8 shows the correlations of $\mathrm{RSO}_{4}$ vs. $\mathrm{SO}_{2}$ for regions $2-4$, and it is clear that $\mathrm{RSO}_{4}$ increased with the decrease in $\mathrm{SO}_{2}$. The increase in $\mathrm{RSO}_{4}$ was relatively slow when the concentration of $\mathrm{SO}_{2}$ was greater than $5 \mu \mathrm{g} \mathrm{m}{ }^{-3}$ in the cold season and $7.5 \mu \mathrm{g} \mathrm{m}^{-3}$ in the warm season. $\mathrm{RSO}_{4}$ soared when $\mathrm{SO}_{2}$ was less than $5 \mu \mathrm{g} \mathrm{m}^{-3}$ in the cold season in regions $2-4$ and less than $3 \mu \mathrm{g} \mathrm{m}^{-3}$ in the warm season 
Cold season
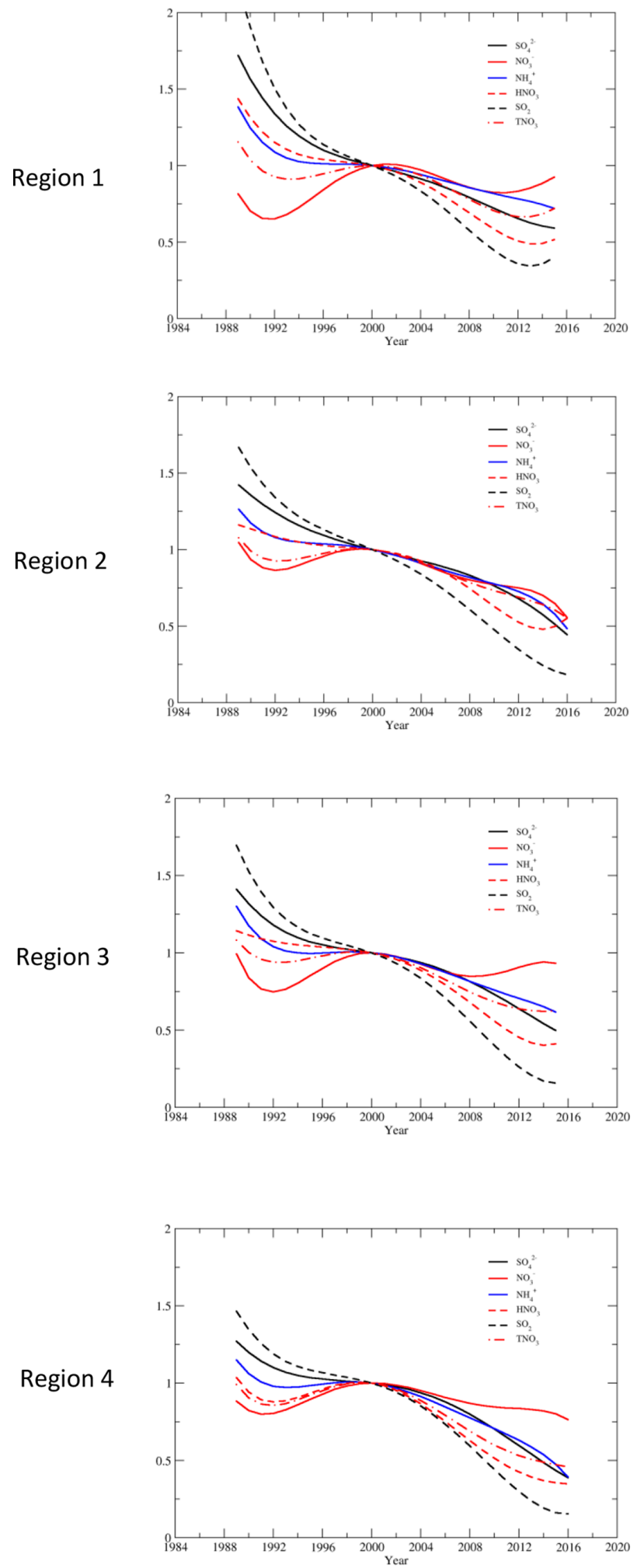

Warm season
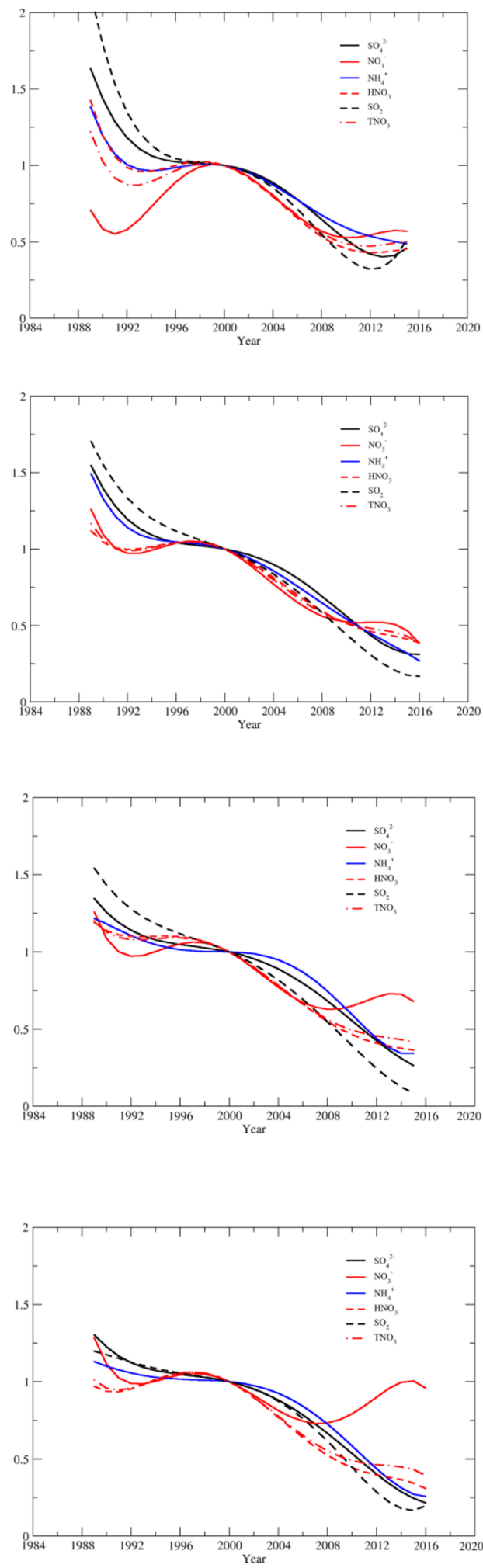

(a) Long-term trends for different species in each region

Figure 6. 
Cold season
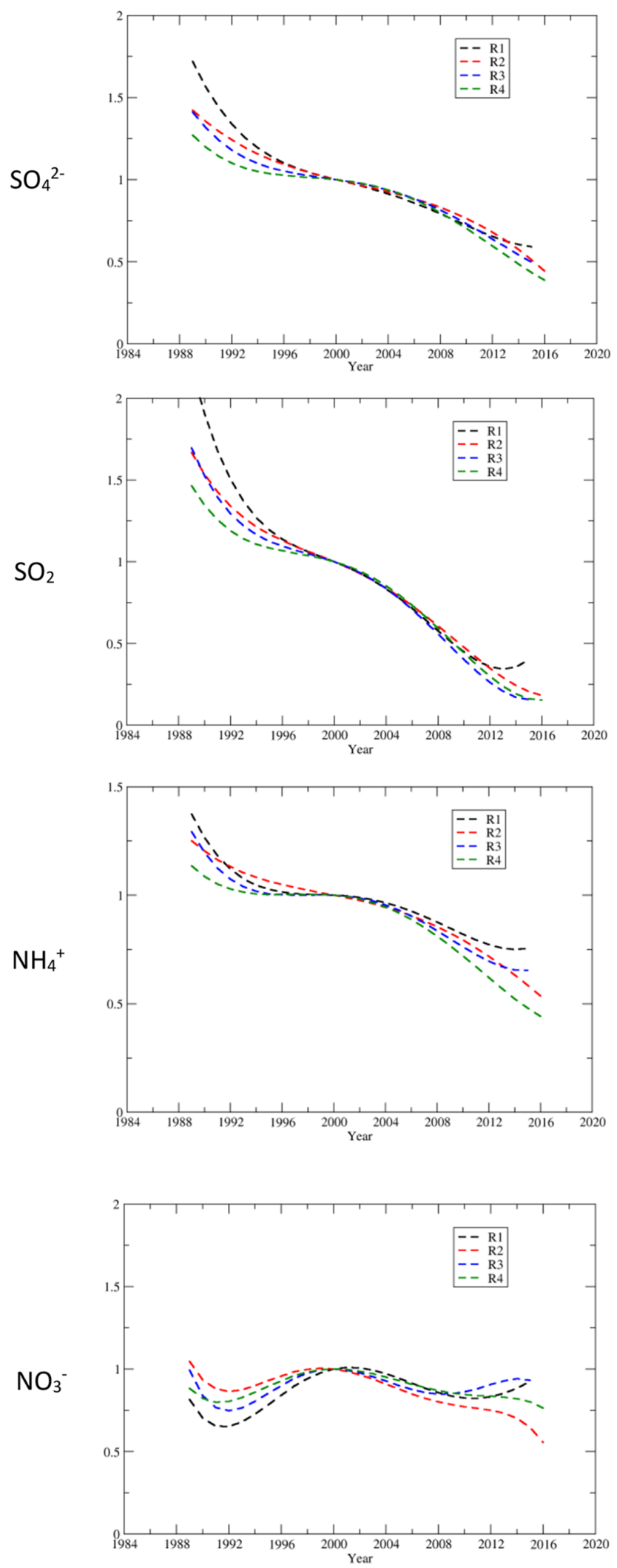

Warm season
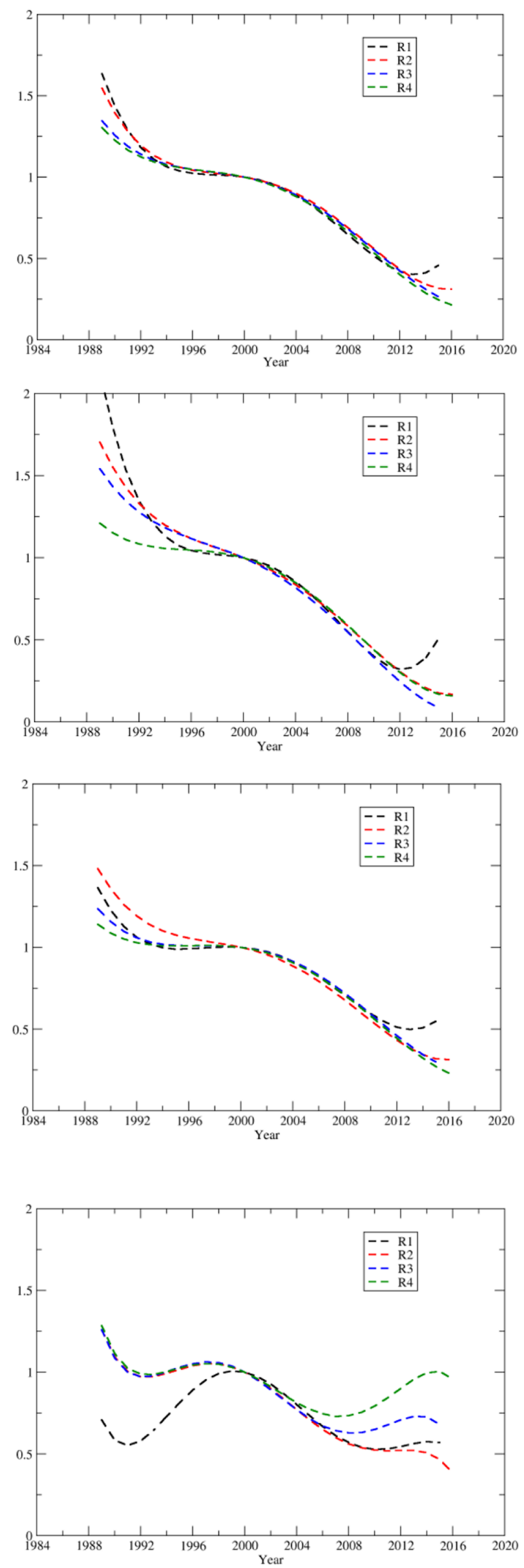

Figure 6. 

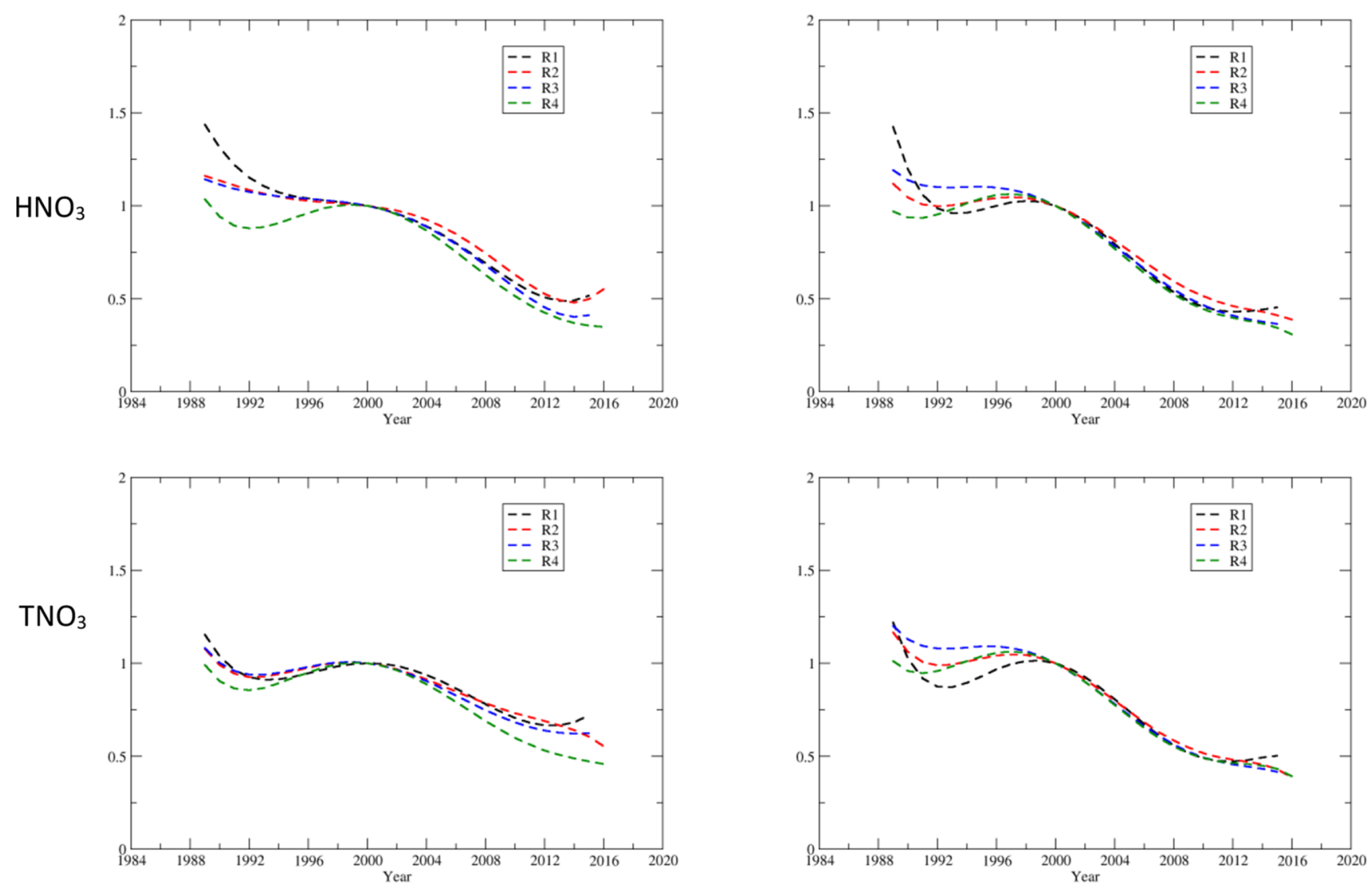

(b) Long-term trends for different regions and each species

Figure 6. Long-term trends derived with fourth-order polynomial regressions for $\mathrm{SO}_{4}^{2-}, \mathrm{SO}_{2}$, and $\mathrm{NH}_{4}^{+}$and fifth-order polynomial regressions for $\mathrm{NO}_{3}^{-}, \mathrm{HNO}_{3}$, and $\mathrm{TNO}_{3}$ during the warm and cold seasons.

in regions 2 and 3. The increase in $\mathrm{RSO}_{4}$ with the decrease in $\mathrm{SO}_{2}$ can be explained as follows: (1) the atmospheric oxidants did not decrease as much as $\mathrm{SO}_{2}$ emissions did. For example, the daily maximum $8 \mathrm{~h}$ average $\mathrm{O}_{3}$ only decreased by $14 \%$ for the EUS during the May-September ozone season from 1997 to 2008 (Butler et al., 2011), and it decreased by $4 \%-15 \%$ during 1997-2006 for regions 2, 3, and 4 (Chan, 2009). No decreasing trend was found for the EUS during the cold season for 1997-2006 (Chan, 2009). Sickles II and Shadwick (2015) found that $\mathrm{O}_{3}$ in the EUS increased during the cold season for 1990-2010. $\mathrm{O}_{3}$ is an atmospheric oxidant and is a precursor to the formation of other atmospheric oxidants, such as $\mathrm{OH}$ and $\mathrm{H}_{2} \mathrm{O}_{2}$. Therefore, relative to the significantly reduced $\mathrm{SO}_{2}$, more atmospheric oxidants were available to oxidize $\mathrm{SO}_{2}$, and $\mathrm{RSO}_{4}$ increased significantly during the period. (2) $\mathrm{NH}_{3}$ was relatively unchanged during the period and even increased in some regions (Yao and Zhang, 2016). The decrease in $\mathrm{SO}_{2}$ caused the decrease in $\mathrm{H}_{2} \mathrm{SO}_{4}$ formation. Together this made cloud or rain droplets or snow particles less acidic, which was beneficial for the ox- idation of $\mathrm{SO}_{2}$ by $\mathrm{H}_{2} \mathrm{O}_{2}$ in the aqueous phase (Makar et al., 2009; Jones and Harrison, 2011).

The disparity in the reduction of $\mathrm{SO}_{2}$ and $\mathrm{SO}_{4}^{2-}$ in response to emission reductions of $\mathrm{SO}_{2}$, namely the fact that the reduction rate of $\mathrm{SO}_{2}$ was faster than $\mathrm{SO}_{4}^{2-}$, has been reported and discussed in some previous studies (Lövblad et al., 2004; Reid et al., 2001; Sickles II and Shadwick, 2015; Shah et al., 2018; Aas et al., 2019). The time series of the normalized regional concentrations of $\mathrm{SO}_{4}^{2-}$ and $\mathrm{SO}_{2}$ in Fig. 3 clearly show the disparity during the period of 1990-2015. The significant increase in $\mathrm{RSO}_{4}$ during the period, especially during the cold season, explains why the reduction rate of $\mathrm{SO}_{2}$ was much higher than that of $\mathrm{SO}_{4}^{2-}$. The reduction of $\mathrm{SO}_{2}$ was not only due to the emission reductions, but also to the fact that a higher fraction of $\mathrm{SO}_{2}$ was converted to $\mathrm{SO}_{4}^{2-}$. A faster reduction of $\mathrm{SO}_{2}$ was observed for all four regions during the cold season, both before and after the year 2000, and it was more significant after 2000. This can be explained by the fact that the increase in $\mathrm{RSO}_{4}$ with time was nonlinear. As shown in Table 2, in the first 10 years of the study period, the increase in $\mathrm{RSO}_{4}$ was relatively limited. During 


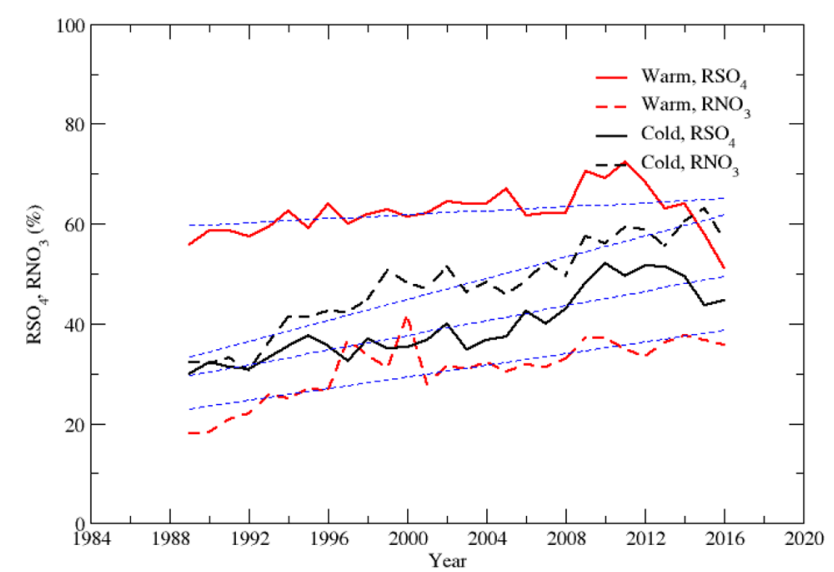

Region 1

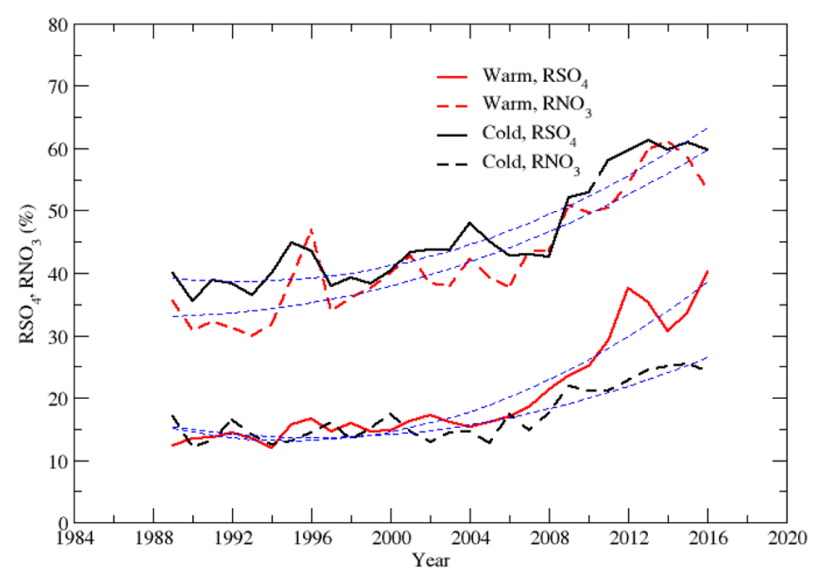

Region 3

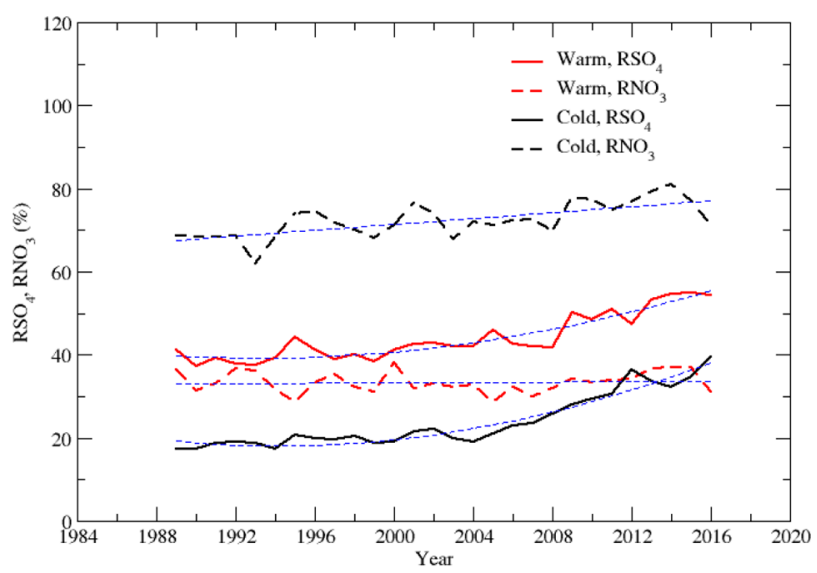

Region 2

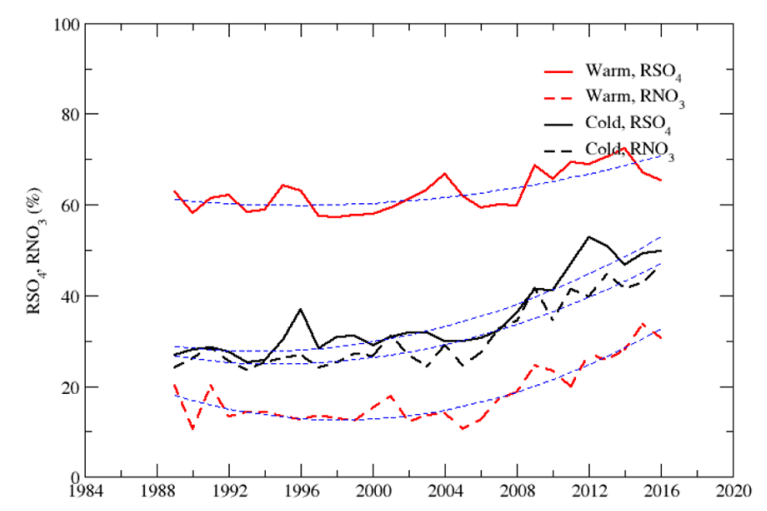

Region 4

Figure 7. Time series of $\mathrm{RSO}_{4}$ and $\mathrm{RNO}_{3}$ for regions 1-4 during the cold and warm seasons.

the cold season, it only increased by $7.3 \%$ in region 4 to $16.5 \%$ in region 3 . It was in the last 10 years from 2005 to 2015 when $\mathrm{SO}_{2}$ was further reduced so that $\mathrm{RSO}_{4}$ increased dramatically. As shown in Tables 2 and 3, during the cold season in region $3, \mathrm{RSO}_{4}$ only increased by $16.5 \%$ in the first 10 years, 1990-2000, but it increased by $149.8 \%$ for the last 15 years of 2000-2015. During the warm season, the disparity in the reduction between $\mathrm{SO}_{2}$ and $\mathrm{SO}_{4}^{2-}$ was much lower, as clearly shown in Fig. 3. This is because the increase in $\mathrm{RSO}_{4}$ during the warm season was much less significant than during the cold season (Table 4). In the first 10 years, $\mathrm{RSO}_{4}$ changed from $-4.1 \%$ in region 4 to $7.7 \%$ in region 1 . For the period of $1990-2015, \mathrm{RSO}_{4}$ only increased by $0.6 \%$ and $12.4 \%$ in regions 1 and 4 . The disparity in the reduction rate of $\mathrm{SO}_{2}$ vs. $\mathrm{SO}_{4}^{2-}$ for these two regions was only $1.7 \%$ and $5.2 \%$ during the warm season, respectively. This is expected and can be explained as follows: (1) in the warm season more atmospheric oxidants are produced due to more solar photons being available than in the cold season, so the oxidation of $\mathrm{SO}_{2}$ is less limited by the availability of atmospheric oxidants in the warm season; (2) in the cold season, limited atmospheric oxidants are available for the oxidation of $\mathrm{SO}_{2}$. The reduction of $\mathrm{SO}_{2}$ emissions to the air will make more atmospheric oxidants available to each $\mathrm{SO}_{2}$ molecule, increase the oxidation rate of $\mathrm{SO}_{2}$, and result in an increase in $\mathrm{RSO}_{4}$; (3) furthermore, in the EUS, the seasonal mean $\mathrm{O}_{3}$ concentration decreased in the warm season and increased in the cold season for the study period (Sickles II and Shadwick; 2015). This made the overall oxidation capacity of the lower atmosphere in the EUS higher in the cold season and lower in the warm season. 


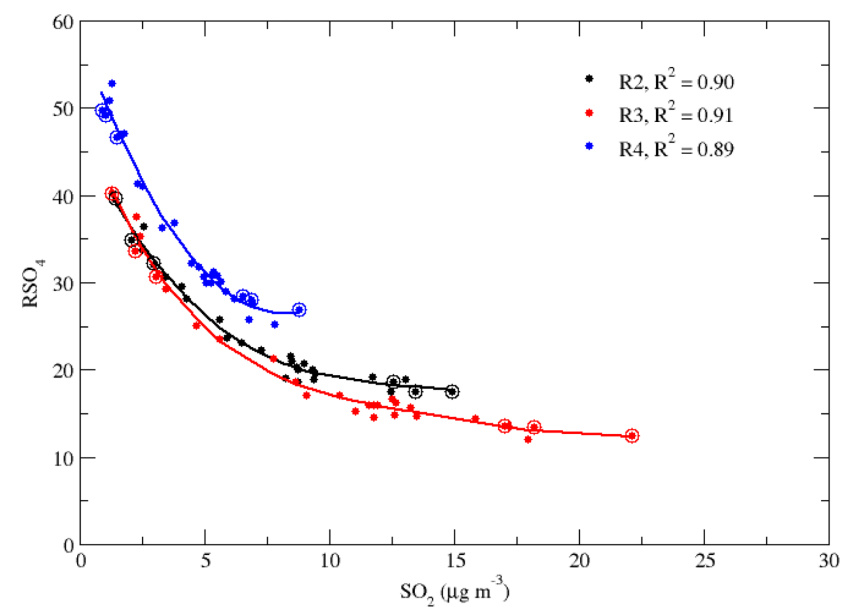

(a) Cold season

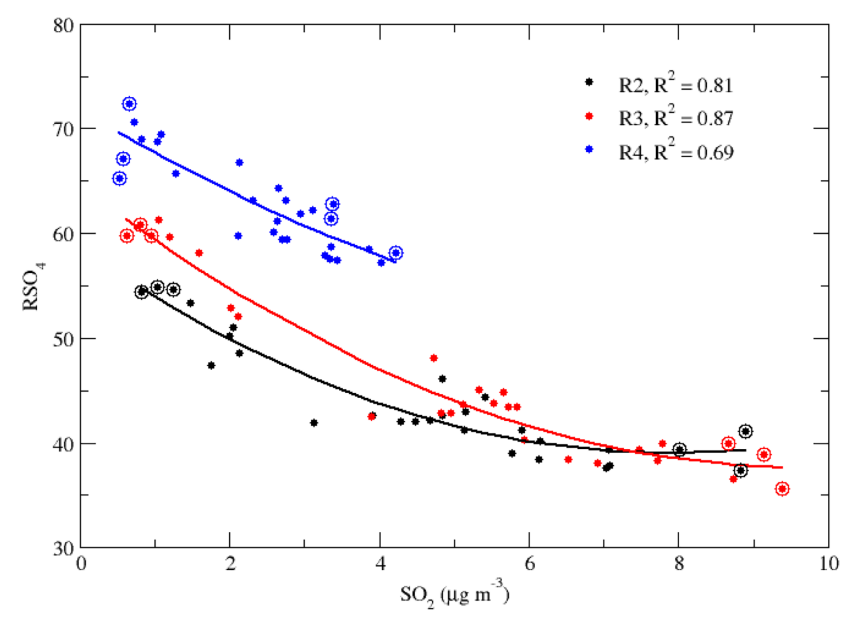

(b) Warm season

Figure 8. Correlations of the seasonal means during the cold and warm seasons: $\mathrm{RSO}_{4}$ vs. $\mathrm{SO}_{2}$ for regions $2-4$. Fourth-order polynomial and quadratic regressions were applied for the cold and warm seasons, respectively. R2, 3, and 4 refer to regions $2-4$. The dots with circles represent the seasonal means in the first and last 3 years.

\subsection{Correlations of $\mathrm{SO}_{4}^{2-}$ vs. $\mathrm{SO}_{2}$}

Correlations between $\mathrm{SO}_{4}^{2-}$ and $\mathrm{SO}_{2}$ are presented in Fig. 9 for regions 1-4 and for the warm and cold seasons. The $\mathrm{SO}_{4}^{2-}-\mathrm{SO}_{2}$ relationships for the period of 1990-2010 can be described by linear regressions (not shown in the graph), with $R=0.87-0.98$ during the warm season and $R=0.96-0.99$ during the cold season. During the cold season, region 1 had the highest slope, and it was followed by regions 4,2 , and 3 . During the warm season, the slopes for regions 1 and 4 were similar and were higher than the slopes for regions 2 and 3 . A linear relationship between the seasonal mean concentrations of $\mathrm{SO}_{4}^{2-}$ and $\mathrm{SO}_{2}$ indicates that there is a linear relationship between the concentration of $\mathrm{SO}_{4}^{2-}$ and the emission

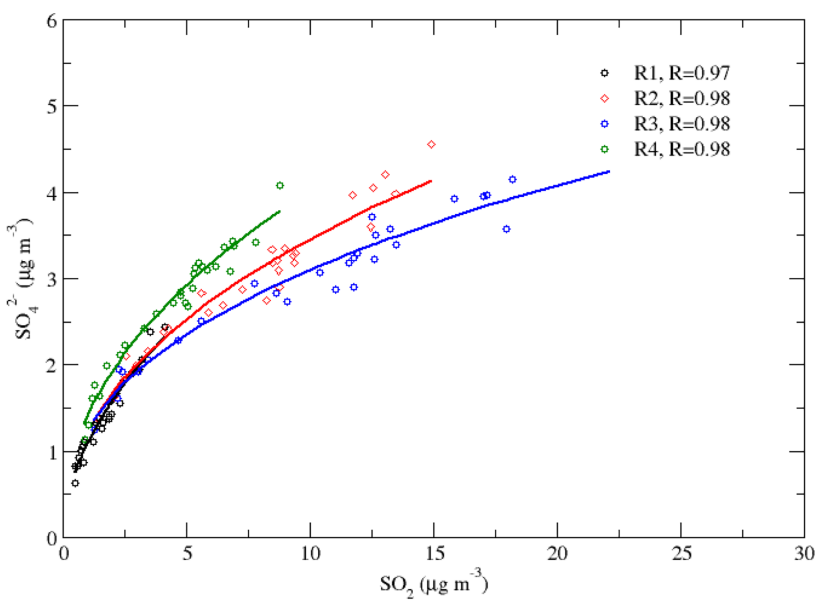

(a) Cold season

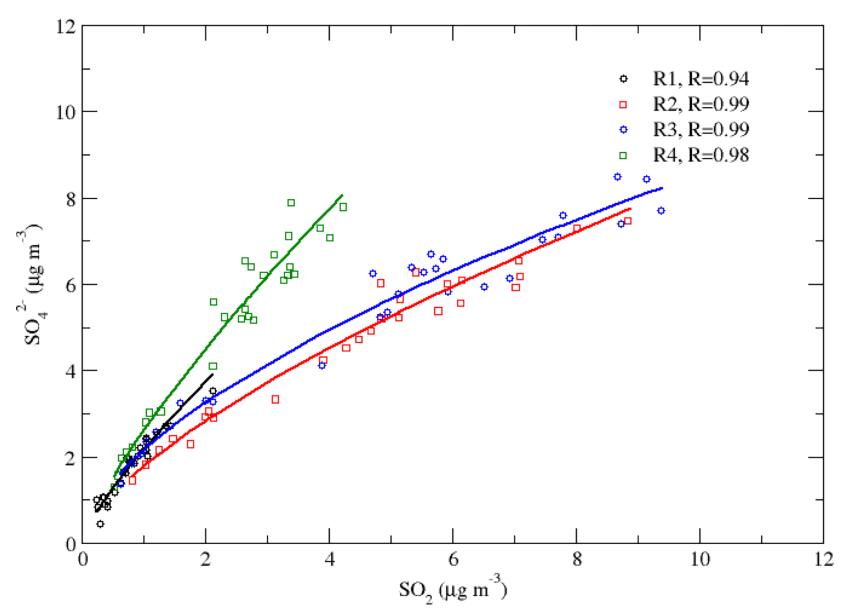

(b) Warm season

Figure 9. Correlations of the seasonal means during the cold and warm seasons: $\mathrm{SO}_{4}^{2-}$ vs. $\mathrm{SO}_{2}$ for regions 1-4. R1, 2, 3, and 4 refer to regions $1-4$.

of $\mathrm{SO}_{2}$. This is consistent with the relationship of the $\mathrm{SO}_{4}^{2-}$ concentration and the $\mathrm{SO}_{2}$ emission rate from the early $1990 \mathrm{~s}$ through 2010 revealed in the study of Hand et al. (2012). As $\mathrm{RSO}_{4}$ significantly increased when $\mathrm{SO}_{2}$ was further reduced during 2010-2016, as seen in Fig. 8, the slopes of the linear regression for 2010-2016 were much higher than those for 1990-2010. A power-law regression, which bends a linear regression with a gentle slope to a linear regression with a steep slope, described the $\mathrm{SO}_{4}^{2-}-\mathrm{SO}_{2}$ relationships very well, with $R=0.97-0.98$ during the cold season and $R=0.94$ 0.99 during the warm season, as shown in Fig. 9. In some previous studies (e.g., Jones and Harrison, 2011), nonlinear power-law relationships have been found for observations at different sites for different seasons and periods. Our results indicate that a linear relationship between $\mathrm{SO}_{4}^{2-}$ and $\mathrm{SO}_{2} \mathrm{ex}-$ 
ists for a subperiod of a long-term period, but generally the correlation of $\mathrm{SO}_{4}^{2-}$ vs. $\mathrm{SO}_{2}$ is a power-law relationship.

\section{$4.3 \quad \mathrm{RNO}_{3}$}

Similar to $\mathrm{RSO}_{4}$ being a gas-particle partition indicator for sulfur in the air, $\mathrm{RNO}_{3}$ is a metric indicating the fraction of gas $\mathrm{HNO}_{3}$ that is aerosolized (Sickles II and Shadwick, 2015). In the air, the emitted $\mathrm{NO}_{x}$ is oxidized to gas $\mathrm{HNO}_{3}$, which can be aerosolized through two paths: (1) reaction with $\mathrm{NH}_{3}$ to form $\mathrm{NH}_{4} \mathrm{NO}_{3}$ and (2) reaction with existing aerosols such as sea salts and crustal materials to form $\mathrm{NaNO}_{3}, \mathrm{Ca}\left(\mathrm{NO}_{3}\right)_{2}$, and $\mathrm{Mg}\left(\mathrm{NO}_{3}\right)_{2}$. The ratio is significantly sensitive to the air temperature, as $\mathrm{NH}_{4} \mathrm{NO}_{3}, \mathrm{NH}_{3}$, and $\mathrm{HNO}_{3}$ in the air are in equilibrium and temperature changes can affect the partitioning between gas and particle phases (Doyle et al., 1979; Harrison and Pio, 1982).

$\mathrm{RNO}_{3}$ for 1989-1991 and 2014-2016, as well as the change in $\mathrm{RNO}_{3}$ between the two periods are shown in Fig. S5. At the beginning of the period, (1) $\mathrm{RNO}_{3}$ in the cold season was much higher than the warm season for all regions. $\mathrm{RNO}_{3}$ in the cold season in regions 2 and 3 was more than double that for the warm season; (2) $\mathrm{RNO}_{3}$ in region 2 was much higher than other regions and was more than double that in regions 3 and 4 . For the 25-year period of 1990-2015, $\mathrm{RNO}_{3}$ significantly increased by more than $70 \%$ in regions 1,3 , and 4 during both seasons. In region 2 , $\mathrm{RNO}_{3}$ only increased by $12.8 \%$ and $8.0 \%$ during the cold and warm seasons, respectively. The significant increase in $\mathrm{RNO}_{3}$ in regions 1,3 , and 4 can be attributed to the significant reduction of $\mathrm{SO}_{4}^{2-}$ during the period, as is explained in Sect. 4.4.

Figure 7 shows that $\mathrm{RNO}_{3}$ had an increasing trend with the year for all regions and both seasons except for region 2 during the warm season. The trends can be described well by linear regressions in regions 1 and 2 and by quadratic regressions in regions 3 and 4 . The linear regression shows that $\mathrm{RNO}_{3}$ in region 2 had a decreasing trend for 1990-2010 during the warm season. The exact reason for this is unknown. One hypothesis is that due to the global warming trend in recent years and the significant reductions of sulfate and nitrate aerosols (which cool the atmosphere by reflecting more solar radiation back to space), the near-surface temperature in the Midwest had an increasing trend during the period of 19902010 (National Climate Assessment, 2014). As region 2 is rich in $\mathrm{NH}_{3}, \mathrm{RNO}_{3}$ is more sensitive to the air temperature than to the availability of $\mathrm{NH}_{3}$. An increasing trend of air temperature in the warm season can cause a decreasing trend of $\mathrm{RNO}_{3}$.

\subsection{Correlations of $\mathrm{RNO}_{3}$ vs. $\mathrm{SO}_{4}^{2-}$}

Correlations between the seasonal mean $\mathrm{RNO}_{3}$ and the seasonal mean concentration of $\mathrm{SO}_{4}^{2-}$ for regions 2-4 and for the warm and cold seasons are presented in Fig. 10. For

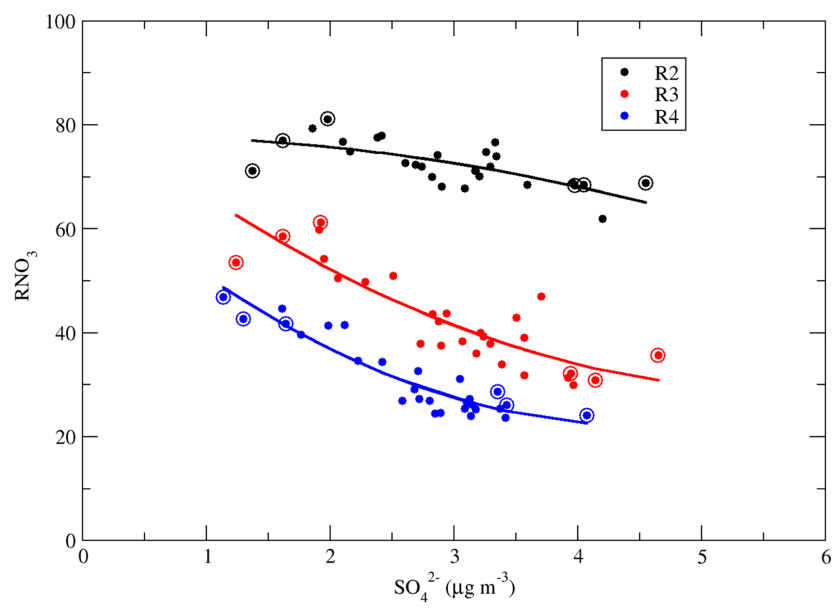

(a) Cold season

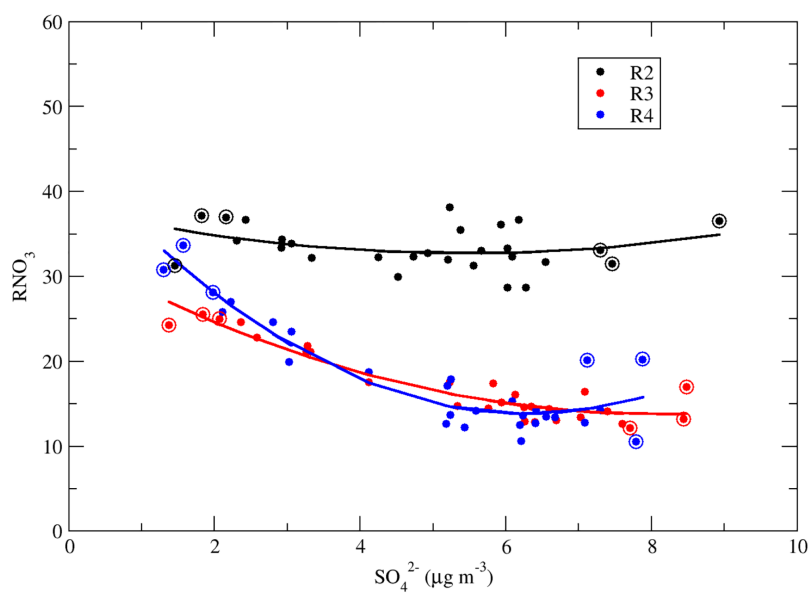

(b) Warm season

Figure 10. Correlations of the seasonal means during the cold and warm seasons: $\mathrm{RNO}_{3}$ vs. $\mathrm{SO}_{4}^{2-}$ for regions $2-4$. The dots with circles represent the seasonal means in the first and last 3 years.

$\mathrm{NH}_{3}$-rich region $2, \mathrm{RNO}_{3}$ increased slightly with the decrease in $\mathrm{SO}_{4}^{2-}$ during the cold season, and there was no obvious trend during the warm season. For regions 3 and 4, which were $\mathrm{NH}_{3}$-limited, $\mathrm{RNO}_{3}$ increased with the decrease in $\mathrm{SO}_{4}^{2-}$. $\mathrm{RNO}_{3}$ increased steeply when the seasonal mean concentration of $\mathrm{SO}_{4}^{2-}$ was less than $4 \mu \mathrm{g} \mathrm{m}^{-3}$ during the warm season and less than $3 \mu \mathrm{g} \mathrm{m}^{-3}$ during the cold season. The increase in $\mathrm{RNO}_{3}$ with the decrease in $\mathrm{SO}_{4}^{2-}$ can be explained as follows: (1) in regions 3 and 4, the formation of $\mathrm{NH}_{4} \mathrm{NO}_{3}$ was limited by the availability of $\mathrm{NH}_{3}$; (2) as $\mathrm{SO}_{4}^{2-}$ decreased, some of the $\mathrm{NH}_{3}$ previously forming $\left(\mathrm{NH}_{4}\right)_{2} \mathrm{SO}_{4} / \mathrm{NH}_{4} \mathrm{HSO}_{4}$ was released and was available to react with $\mathrm{HNO}_{3}$ to form $\mathrm{NH}_{4} \mathrm{NO}_{3}$. In contrast, $\mathrm{RNO}_{3}$ was much less sensitive to the $\mathrm{SO}_{4}^{2-}$ reduction in region 2 as the emissions of $\mathrm{NH}_{3}$ there were much higher than in regions 3 and 4, as seen in Fig. S6. Thus, in general there was always 
excess $\mathrm{NH}_{3}$ available to react with $\mathrm{HNO}_{3}$ to form $\mathrm{NH}_{4} \mathrm{NO}_{3}$ in region 2, which resulted in a lack of trends in $\mathrm{RNO}_{3}$. This also explains why $\mathrm{TNO}_{3}$ decreased by $40.1 \%$ and $46.4 \%$, respectively, during the cold season in regions 3 and 4, while the change in $\mathrm{NO}_{3}^{-}$was negligible in these two regions.

\subsection{Correlations of $\mathrm{NH}_{4}^{+}$vs. $\mathrm{SO}_{4}^{2-}$ and $\mathrm{NO}_{3}^{-}$}

Correlations of $\mathrm{NH}_{4}^{+}$vs. $\mathrm{SO}_{4}^{2-}$ and $\mathrm{NH}_{4}^{+}$vs. $\mathrm{NO}_{3}^{-}$are shown in Fig. 11 for regions 2-4 and for the cold and warm seasons. During the warm season, $\mathrm{NO}_{3}^{-}$in regions 3 and 4 changed little in value during 1990-2015, while $\mathrm{NH}_{4}^{+}$changed significantly, and this change was mostly linearly associated with the change in $\mathrm{SO}_{4}^{2-}$. In region 2, the change in $\mathrm{NH}_{4}^{+}$was also mostly associated with the change in $\mathrm{SO}_{4}^{2-}$, but the change in $\mathrm{NO}_{3}^{-}$also made a contribution to it. During the cold season, $\mathrm{NH}_{4}^{+}$correlated with $\mathrm{SO}_{4}^{2-}$ linearly very well in regions 24. In region $2, \mathrm{NO}_{3}^{-}$also changed significantly during the period, and the variation of $\mathrm{NO}_{3}^{-}$correlated well with the variation of $\mathrm{NH}_{4}^{+}$with $R=0.87$, indicating that some of the reduction of $\mathrm{NH}_{4}^{+}$in region 2 was associated with the reduction of $\mathrm{NO}_{3}^{-}$during the period. The variations of $\mathrm{NO}_{3}^{-}$in regions 3 and 4 were relatively small, and the correlations between $\mathrm{NH}_{4}^{+}$and $\mathrm{NO}_{3}^{-}$, with $R=0.42$ and 0.40 , respectively, were much less significant than those for $\mathrm{NH}_{4}^{+}$vs. $\mathrm{SO}_{4}^{2-}$. Figure 11 shows that in the EUS and EC, the reduction of $\mathrm{NH}_{4}^{+}$during 1990-2015 was mainly due to the reduction of $\mathrm{SO}_{4}^{2-}$ in regions $2-4$, but in region 2 the reduction of $\mathrm{NO}_{3}^{-}$ also made a substantial contribution to it.

\subsection{Sulfate-nitrate-ammonium (SNA) aerosols}

Sulfate, nitrate, and ammonium are the major components of the secondary aerosols in the atmosphere in the EUS and EC (Bell et al., 2007; Dabek-Zlotorzynska et al., 2011). Time series of the seasonal means of the total mass of sulfatenitrate-ammonium aerosols during the warm and cold seasons are shown in Fig. 12. During the cold season, mainly due to the concentrations of $\mathrm{NO}_{3}^{-}$and $\mathrm{NH}_{4}^{+}$, SNA had the highest and second-highest seasonal mean concentrations in region 4 and region 3, respectively, and the lowest seasonal mean concentration in region 1 . During the warm season, SNA in regions 2 and 3 was comparable and a little higher than that in region 4 . The trends in regions $2-4$ are similar during the warm season, and the SNA in regions 2-4 is much higher than that in region 1. Figure 13 shows that SNA in region 1 during the warm season was higher than that during the cold season until 2007, and the trend was reversed after that. In region 2, SNA was generally higher during the warm season until 2005, and it was opposite thereafter. SNA in region 3 was significantly higher during the warm season than the cold season until 2007, and the trend was opposite after 2012. Similarly, SNA in region 4 was much higher in the warm season until 2008 and was comparable between the

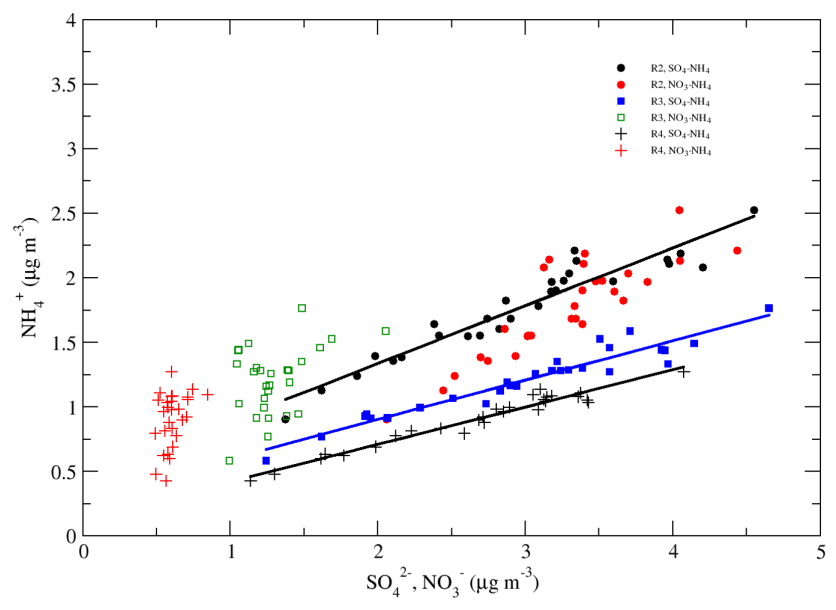

(a) Cold season

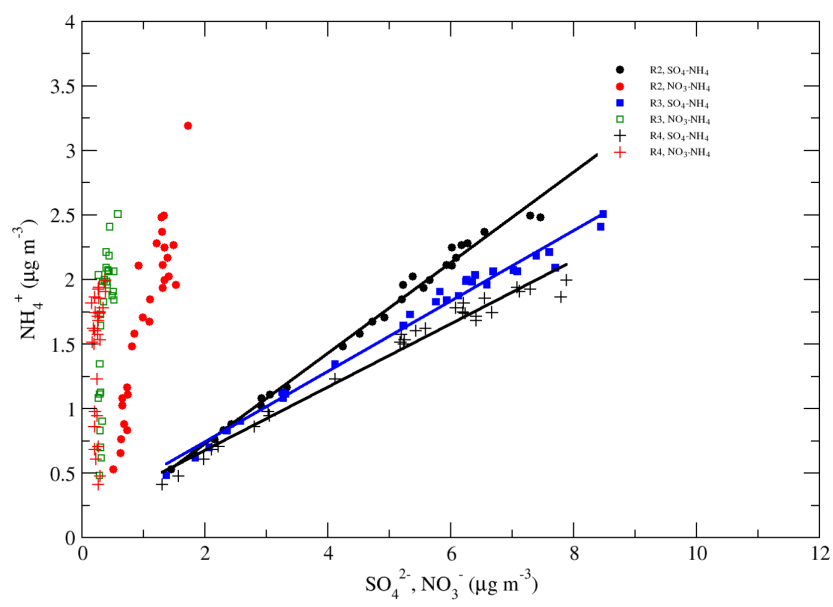

(b) Warm season

Figure 11. Correlations of $\mathrm{NH}_{4}^{+}$vs. $\mathrm{SO}_{4}^{2-}$ and $\mathrm{NH}_{4}^{+}$vs. $\mathrm{NO}_{3}^{-}$during the cold and warm seasons. R2, 3, and 4 refer to regions $2-4$.

warm and cold seasons after 2012. Two points can be derived from the above trends: (1) in the EUS and EC, SNA during the warm season was mainly due to $\left(\mathrm{NH}_{4}\right)_{2} \mathrm{SO}_{4} / \mathrm{NH}_{4} \mathrm{HSO}_{4}$. When the emission of $\mathrm{SO}_{2}$ over the region decreased significantly, SNA followed the decreasing trend of $\mathrm{SO}_{4}^{2-}$ even though the reduction in $\mathrm{NO}_{3}^{-}$was not significant; (2) during the cold season, besides $\left(\mathrm{NH}_{4}\right)_{2} \mathrm{SO}_{4} / \mathrm{NH}_{4} \mathrm{HSO}_{4}, \mathrm{NH}_{4} \mathrm{NO}_{3}$ also made a considerable contribution to SNA. As $\mathrm{SO}_{4}^{2-}$ decreased significantly in both the warm and cold seasons, but $\mathrm{NO}_{3}^{-}$changed little during the cold season except in region 2, the SNA during the cold season became comparable or even higher than the SNA during the warm season. SNA pollution in regions 2 and 3 was more of an issue during the cold season than during the warm season when the emissions of $\mathrm{SO}_{2}$ were further reduced during 2006-2015. 


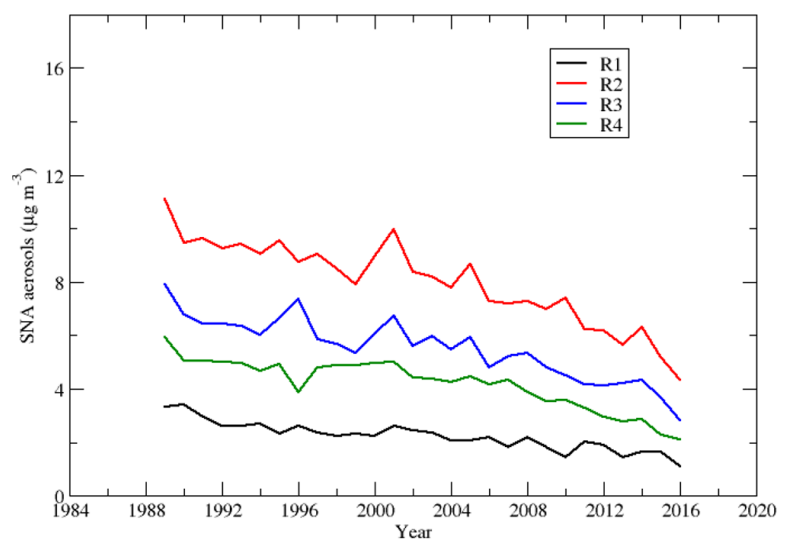

(a) Cold season

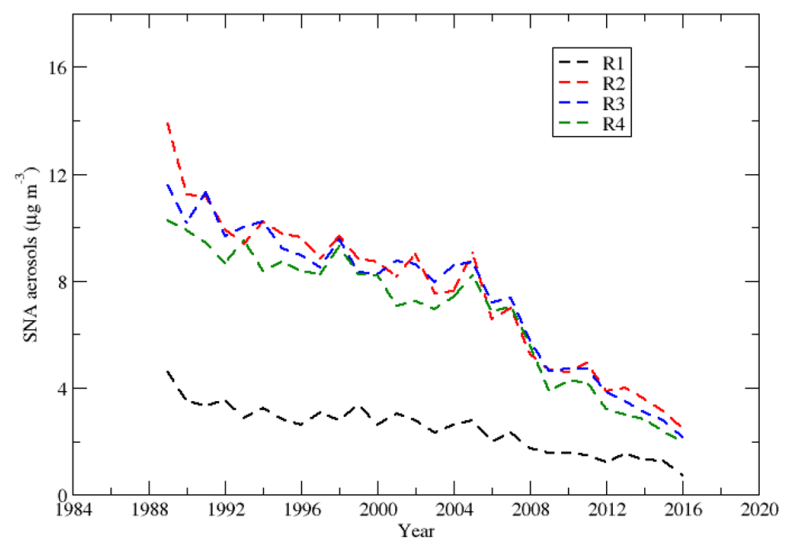

(b) Warm season

Figure 12. Time series of the seasonal means of sulfate-nitrate-ammonium aerosols during the cold and warm seasons.
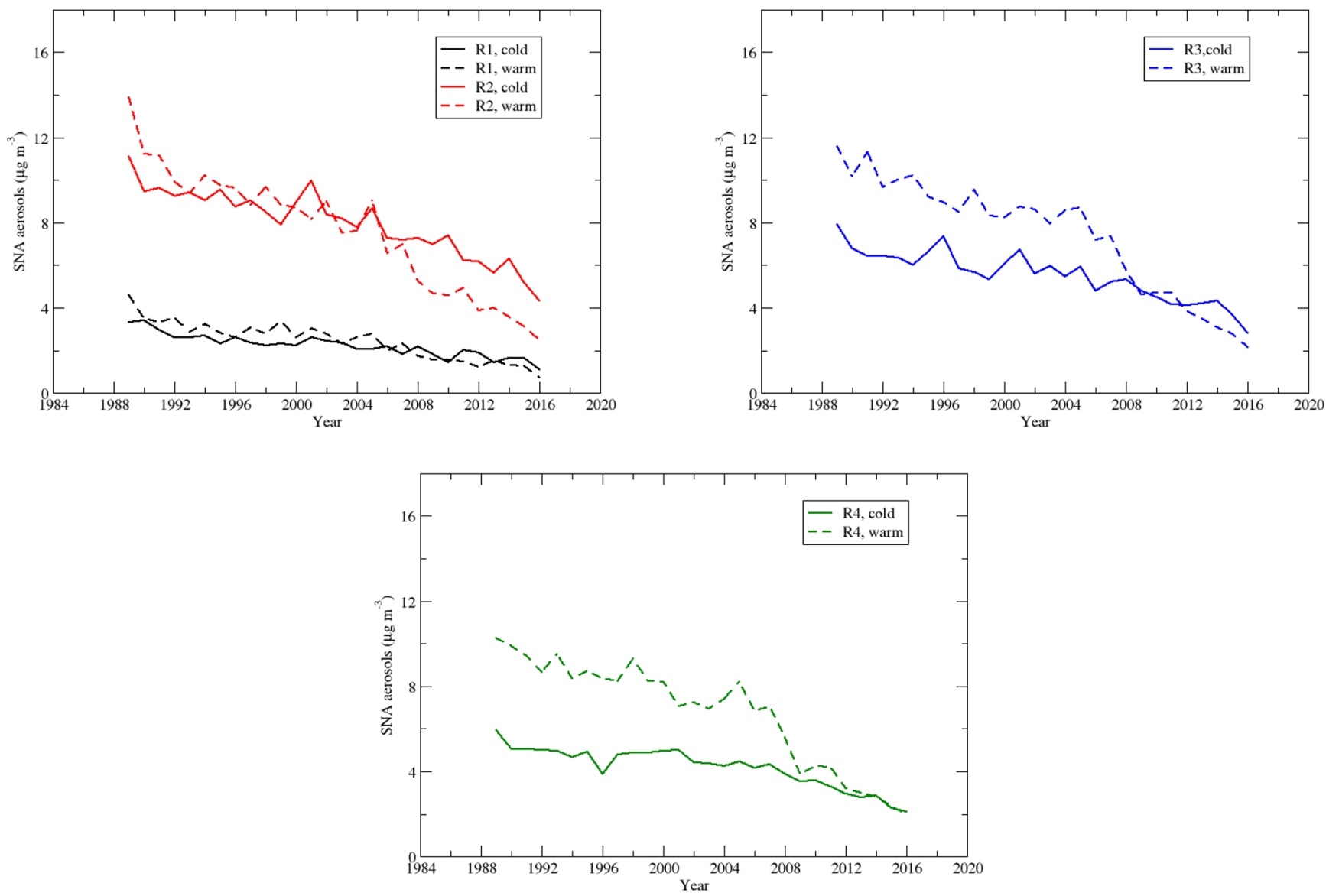

Figure 13. Time series of the seasonal means of sulfate-nitrate-ammonium aerosols in regions $1-4$.

\section{Summary and conclusion}

With the implementation of the Title IV of the 1990 amendments to the CAA in the US in the 1990s, the emissions of $\mathrm{SO}_{2}$ and $\mathrm{NO}_{x}$ in the US were reduced from 23.1 million to 3.7 million $\mathrm{t} \mathrm{yr}^{-1}$ for $\mathrm{SO}_{2}$ and from 25.2 million to 11.5 mil- lion $\mathrm{tyr}^{-1}$ for $\mathrm{NO}_{x}$ from 1990 to 2015. In Canada, compared to the emission level in $1990, \mathrm{SO}_{2}$ and $\mathrm{NO}_{x}$ emissions in 2015 were reduced by $65 \%$ and $25 \%$, respectively. In both the US and Canada, the reduction of emissions was mainly in the eastern regions of the countries. The air concentrations of gases $\mathrm{SO}_{2}$ and $\mathrm{HNO}_{3}$, as well as particles $\mathrm{SO}_{4}^{2-}, \mathrm{NO}_{3}^{-}$, and 
$\mathrm{NH}_{4}^{+}$, had a very different nonlinear response, both spatially and temporally, to the significant reductions of $\mathrm{SO}_{2}$ and $\mathrm{NO}_{x}$ emissions.

In this study, we analyzed the air concentrations of $\mathrm{SO}_{4}^{2-}$, $\mathrm{NO}_{3}^{-}, \mathrm{NH}_{4}^{+}, \mathrm{HNO}_{3}$, and $\mathrm{SO}_{2}$ measured weekly by the CASTNET network in the US and daily by the CAPMoN network in Canada from 1990 to 2015 to reveal the temporal and spatial changes during the period. Four distinct regions, each with a characteristic pattern of air quality in the EUS and EC, were identified: the northeastern US and Eastern Canada (region 1), the Midwest (region 2), the Mid-Atlantic (region 3), and the southeastern US (region 4). In the first 10-year period of 1990-2000, $\mathrm{SO}_{2}$ and $\mathrm{SO}_{4}^{2-}$ decreased by more than $20 \%$ except for $\mathrm{SO}_{4}^{2-}$ in region 4 during the cold season and $\mathrm{SO}_{2}$ in region 4 during the warm season. $\mathrm{NH}_{4}^{+}$declined by $12 \%$ to $29.8 \%$ during both seasons except that region 4 during the cold season had a negligible change. $\mathrm{NO}_{3}^{-}$increased in regions 1-4 during the cold season and changed little during the warm season. $\mathrm{HNO}_{3}$ was reduced in regions $1-3$ by more than $9 \%$ during both seasons and increased in region 4 by $5 \%$ and $5.7 \%$ during the cold and warm seasons, respectively. In a 25-year period of 1990-2015, the reduction of $\mathrm{SO}_{4}^{2-}$ ranged from $60.1 \%$ in region 2 to $62.5 \%$ in region 3 during the cold season and from $72.7 \%$ in region 1 to $78.7 \%$ in region 4 during the warm season. The reduction of $\mathrm{SO}_{2}$ was the most significant among all species, ranging from $83.9 \%$ during the warm season in region 4 to $91.2 \%$ during the warm season for region 3 . During the warm season, the reduction of $\mathrm{NO}_{3}^{-}$was seen in all regions, ranging from $14.3 \%$ in region 1 to $57.5 \%$ in region 2 . However, during the cold season, the reduction of $\mathrm{NO}_{3}^{-}$was only seen in region 2 , and it was reduced by $30.4 \%$. The change in $\mathrm{NO}_{3}^{-}$was negligible in regions 3 and 4 during the cold season. The reduction of $\mathrm{HNO}_{3}$ during the warm season was relatively uniform in terms of percentage, ranging from $63.1 \%$ to $68.8 \%$. During the cold season, region 2 had the lowest percentage of reduction at $56.0 \%$, and region 1 had the highest at $63.5 \%$. The reduction of $\mathrm{NH}_{4}^{+}$was the most significant during the warm season in terms of both percentage and absolute value. The reduction ranged from $74.0 \%$ to $75.7 \%$ in regions $2-4$ during the warm season, which was $20 \%$ more than the corresponding reduction during the cold season. The time series of the seasonal mean concentrations during the warm and cold seasons show that the reduction of each species was not even in time during the period. The reductions of $\mathrm{SO}_{4}^{2-}$ and $\mathrm{SO}_{2}$ mainly occurred during 1990-1995 and 2007-2016 for the warm season and during 1990-1995 and 2005-2016 for the cold season. The reduction of $\mathrm{NO}_{3}^{-}$was mainly after the year 2000.

$\mathrm{RSO}_{4}$ is a metric indicating the gas-aerosol partitioning of sulfur in the air, and $\mathrm{RNO}_{3}$ is an indicator of the fraction of $\mathrm{HNO}_{3}$ being aerosolized. $\mathrm{RSO}_{4}$ increased by $48.6 \%$ to $166.3 \%$ during the cold season and by $0.6 \%$ to $58.4 \%$ during the warm season. $\mathrm{RSO}_{4}$ was found to increase quadrat- ically with the decrease in $\mathrm{SO}_{2}$ for regions $2-4$ and the two seasons. The significant increase in $\mathrm{RSO}_{4}$ during the cold season explains why the reduction rate of $\mathrm{SO}_{2}$ was much higher than that of $\mathrm{SO}_{4}^{2-}$ during the period, as the reduction of $\mathrm{SO}_{2}$ was not only due to the emission reduction, but also more $\mathrm{SO}_{2}$ being converted to $\mathrm{SO}_{4}^{2-}$. A faster reduction of $\mathrm{SO}_{2}$ was observed for all four regions during the cold season, both before and after the year 2000, and it was more significant after 2000. During the warm season, the difference in the reduction rate between $\mathrm{SO}_{2}$ and $\mathrm{SO}_{4}^{2-}$ was much lower. This is because the increase in $\mathrm{RSO}_{4}$ during the warm season was much less significant than during the cold season. In regions 1 and 4, $\mathrm{RSO}_{4}$ only increased by $0.6 \%$ and $12.4 \%$ during the warm season. Differences in the reduction rate between $\mathrm{SO}_{2}$ and $\mathrm{SO}_{4}^{2-}$ for these two regions during the warm season were only $1.7 \%$ and $5.2 \%$, respectively. For regions 1,3 , and $4, \mathrm{RNO}_{3}$ increased between $79.2 \%$ and $94.9 \%$ during the warm season and between $73.9 \%$ and $92.3 \%$ during the cold season. For region $2, \mathrm{RNO}_{3}$ for the warm and cold seasons only increased by $8.0 \%$ and $12.8 \%$, respectively, as $\mathrm{NH}_{3}$ in the region was in excess to neutralize $\mathrm{HNO}_{3} . \mathrm{RNO}_{3}$ was found to increase quadratically with the decrease in $\mathrm{SO}_{4}^{2-}$ in regions 3 and 4.

In summary, with the significant reductions of $\mathrm{SO}_{2}$ and $\mathrm{NO}_{x}$ emissions in the EUS and EC during 1990-2015, $\mathrm{SO}_{4}^{2-}$, $\mathrm{SO}_{2}, \mathrm{NH}_{4}^{+}$, and $\mathrm{HNO}_{3}$ were reduced significantly by $73.3 \%$, $87.6 \%, 67.4 \%$, and $65.8 \%$ for the whole region. The reduction of $\mathrm{NO}_{3}^{-}$was relatively less significant at $29.1 \%$, and it mainly occurred (1) after the year 2000, (2) in regions 1-4 during the warm season, and (3) in region 2 only during the cold season.

Data availability. The CASTNET data used in this study can be downloaded from the website of the U.S. Environmental Protection Agency at https://java.epa.gov/castnet/clearsession.do (EPA, 2020). The CAPMoN data used in this study can be accessed through the Open Government Portal of Canada at https://open.canada.ca/data/ en/dataset?keywords $=\mathrm{CAPMoN}$ (ECCC, 2020$)$ or by contacting the corresponding author.

Supplement. The supplement related to this article is available online at: https://doi.org/10.5194/acp-20-3107-2020-supplement.

Author contributions. JF carried out the overall analysis and interpretation of the data as well as writing the paper. EC did the initial data and trend analysis. RV provided supervision for the study and discussed the results.

Competing interests. The authors declare that they have no conflict of interest. 
Acknowledgements. We would like to thank Tom Butler and the anonymous reviewer. Their detailed, insightful, and constructive suggestions and comments greatly improved the quality of the paper. We also thank Irene Cheng for the internal review. The CASTNET and CAPMoN data used in this study were provided by Environment and Climate Change Canada (ECCC) through the Canadian National Atmospheric Chemistry (NAtChem) Particulate Matter and Precipitation Databases.

Review statement. This paper was edited by Veli-Matti Kerminen and reviewed by two anonymous referees.

\section{References}

Aas, W., Mortier, A., Bowersox, V., Cherian, R., Faluvegi, G., Fagerli, H., Hand, J., Klimont, Z., Galy-Lacaux, C., Lehmann, C. M. B., Myhre, C. L., Myhre, G., Olivié, D., Sato, K., Quaas, J., Rao, P. S. P., Schulz, M., Shindell, D., Skeie, R. B., Stein, A., Takemura, T., Tsyro, S., Vet, R., and Xu, X.: Global and regional trends of atmospheric sulfur, Sci. Rep., 9, 953, https://doi.org/10.1038/s41598-018-37304-0, 2019.

Bell, M. L., Dominici, F., Ebisu, K., Zeger, S. L., and Samet, J. M.: Spatial and temporal variation in $\mathrm{PM}_{2.5}$ chemical composition in the United States for health effects studies, Environ. Health Perspect., 115, 989-995, https://doi.org/10.1289/ehp.9621, 2007.

Bloomer, B. J., Vinnikov, K. Y., Dickerson, R. R.: Changes in seasonal and diurnal cycles of ozone and temperature in the eastern U.S., Atmos. Environ., 44, 2543-2551, https://doi.org/10.1016/j.atmosenv.2010.04.031, 2010.

Butler, T. J., Likens, G. E., Vermeylen, F. M., and Stunder, B. J. B.: The relation between $\mathrm{NO}_{x}$ emissions and precipitation $\mathrm{NO}_{3}^{-}$in the eastern USA, Atmos. Environ., 37, 2093-2104, https://doi.org/10.1016/S1352-2310(03)00103-1, 2003.

Butler, T. J., Vermeylen, F. M., Rury, M., Likens, G. E., Lee, B., Bowker, G. E., and McCluney, L.: Response of ozone and nitrate to stationary source $\mathrm{NO}_{x}$ emission reductions in the eastern USA, Atmos. Environ., 45, 1084-1094, https://doi.org/10.1016/j.atmosenv.2010.11.040, 2011.

CAA - Clean Air Act: The Clean Air Act Highlights of the 1990 Amendments, available at: https://www.epa.gov/clean-air-act-overview/ clean-air-act-highlights-1990-amendments, last access: November 2019 .

Chan, E.: Regional ground-level ozone trends in the context of meteorological influences across Canada and the eastern United States from 1997 to 2006, J. Geophys. Res., 114, D05301, https://doi.org/10.1029/2008JD010090, 2009.

Chan, E. and Vet, R. J.: Baseline levels and trends of ground level ozone in Canada and the United States, Atmos. Chem. Phys., 10, 8629-8647, https://doi.org/10.5194/acp-10-8629-2010, 2010.

Cheng, I., and Zhang, L.: Long-term air concentrations, wet deposition, and scavenging ratios of inorganic ions, $\mathrm{HNO}_{3}$, and $\mathrm{SO}_{2}$ and assessment of aerosol and precipitation acidity at Canadian rural locations, Atmos. Chem. Phys., 17, 4711-4730, https://doi.org/10.5194/acp-17-4711-2017, 2017.

Clarke, J.-F., Edgerton, E. S., Martin, B. E.: Dry deposition calculations for the clear air status and trends network, Atmos. Environ.,
31, 3667-3678, https://doi.org/10.1016/S1352-2310(97)001416, 1997.

Dabek-Zlotorzynska, E., Dann, T. F., Martinelango, P. K., Celo, V., Brook, J. R., Mathieu, D., Ding, L., and Austin, C. C.: Canadian National Air Pollution Surveillance (NAPS) $\mathrm{PM}_{2.5}$ speciation program: Metholodology and $\mathrm{PM}_{2.5}$ chemical composition for the years 2003-2008, Atmos. Environ., 45, 673-686, https://doi.org/10.1016/j.atmosenv.2010.10.024, 2011.

Doyle, G. J., Tuazon, E. C., Graham, R. A., Mischke, T. M, Winer, A. M., and Pitts Jr., J. N.: Simultaneous concentrations of ammonia and nitric acid in a polluted atmosphere and their equilibrium relationship to particulate ammonium nitrate, Environ. Sci. Technol., 13, 1416-1419, https://doi.org/10.1021/es60159a010, 1979.

Du, E., de Vires, W., Galloway, J. N., Hu., X., and Fang, J.: Changes in wet nitrogen deposition in the United States between 1985 and 2012, Environ. Res. Lett., 9, 095004, https://doi.org/10.1088/1748-9326/9/9/095004, 2014.

ECCC - Environment and Climate Change Canada: Canadian Environmental Sustainability Indicators: Air pollutant emissions,available at: https://www.canada.ca/en/ environment-climate-change/services/environmental-indicators/ air-pollutant-emissions.html, last access: 13 November 2019.

ECCC - Environment and Climate Change Canada: Canadian Air and Precipitation Monitoring Network (CAPMoN) datasets, available at: https://open.canada.ca/data/en/dataset?keywords= CAPMoN, last access: 11 March 2020.

EPA: Our Nation's Air: Status and Trends through 2015, available at: https://gispub.epa.gov/air/trendsreport/2016/ (last access: 13 November 2019), 2016.

EPA: Air Emissions Inventories, available at: https://www.epa.gov/ air-emissions-inventories/air-pollutant-emissions-trends-data, last access: 13 November 2019.

EPA: Clean Air Status Trends Network (CASTNET) - Filter Pack Concentrations, available at: https://java.epa.gov/castnet/ clearsession.do, last access: 11 March 2020.

Hand, J. L., Schichtel, B. A., Malm, W. C., and Pitchford, M. L.: Particulate sulfate ion concentration and $\mathrm{SO}_{2}$ emission trends in the United States from the early 1990s through 2010, Atmos. Chem. Phys., 12, 10353-10365, https://doi.org/10.5194/acp-1210353-2012, 2012.

Harrison, R. M. and Pio, C. A.: An investigation of the atmospheric $\mathrm{HNO}_{3}-\mathrm{NH}_{3}-\mathrm{NH}_{4} \mathrm{NO}_{3}$ equilibrium relationship in a cool, humid climate, Tellus B, 35, 155-159, https://doi.org/10.3402/tellusb.v35i2.14795, 1982.

Haywood, J. M. and Shine, K. P.: The effect of anthropogenic sulfate and soot aerosol on the clear sky planetary radiation budget, Geophys. Res. Lett., 22, 603-606, https://doi.org/10.1029/95GL00075, 1995.

Heroux, M.-E., Anderson, H. R., Atkinson, R., Brunekreef, B., Cohen, A., Forastiere, F., Hurley, F., Katsouyanni, K., Krewski, D., Krzyanowski, M., Kunzli, N., Mills, I., Querol, X., Ostro, B., and Walton, H.: Quantifying the health impacts of ambient air pollutants: recommendations of a WHO/Europe project, Int. J. Publ. Health, 60, 619-627, https://doi.org/10.1007/s00038-015-0690$\mathrm{y}, 2015$.

Jones, A. M. and Harrison, R. M.: Temporal trends in sulphate concentrations at European sites and relation- 
ships to sulphur dioxide, Atmos. Environ., 45, 873-882, https://doi.org/10.1016/j.atmosenv.2010.11.020, 2011.

Kajino, M., Ueda, H., Han, Z., Kudo, R., Inomata, Y., and Kaku, H.: Synergy between air pollution and urban meteorological changes through aerosol-radiation-diffusion feedback - A case study of Beijing in January 2013, Atmos. Environ., 171, 98-110, https://doi.org/10.1016/j.atmosenv.2017.10.018, 2017.

Kuklinska, K., Wolska, L., and Namiesnik, J.: Air quality policy in the U.S. and the EU - a review, Atmos. Poll. Res., 6, 129-137, https://doi.org/10.5094/APR.2015.015, 2015.

Kunzli, N., Kaiser, R., Medina, S., Studnicka, M., Chanel, O., Filiger, P., Herry, M., Horak Jr., F., Puybonnieux-Texier, V., Quenel, P., Schneider, J., Seethaler, R., Vergnaud, J.-C., and Sommer, H.: Public-health imact of outdoor and traffic-related air pollution: A European assessment, Lancet, 356, 795-801, https://doi.org/10.1016/S0140-6736(00)02653-2, 2000.

Lee, B.: Highlights of the Clean Air Act Amendments of 1990, J. Air Waste Manage. Assoc., 41, 16-19, https://doi.org/10.1080/10473289.1991.10466820, 1991.

Lee C., Martin, R. V., van Donkellar, A., Lee, H., Dickerson, R. R., Hains, J. C., Krotkov, N., Richter, A., Vinnikov, K., and Schwab, J. J.: $\mathrm{SO}_{2}$ emissions and lifetimes: Estimates from inverse modeling using in situ and global, space-based (SCIAMACHY and OMI) observations, J. Geophys. Res., 116, D06304, https://doi.org/10.1029/2010JD014758, 2011.

Lövblad, G., Tarrason, L., Tørseth, K., and Dutchak, S.: EMEP Assessment, Part I, European Perspective, Norwegian Meterological Institute, Oslo, Norway, available at: http://emep.int/publ/ reports/2004/assessment_2004.html (last access: 13 November 2019), 2004.

Makar, P. A., Moran, M. D., Zheng, Q., Cousineau, S., Sassi, M., Duhamel, A., Besner, M., Davignon, D., Crevier, L.-P., and Bouchet, V. S.: Modelling the impacts of ammonia emissions reductions on North America air quality, Atmos. Chem. Phys., 9, 7183-7212, https://doi.org/10.5194/acp-9-7183-2009, 2009.

Mann, H. B.: Non-parametric tests against trend, Econometrica, 13, 245-59, https://doi.org/10.2307/1907187, 1945.

Napolitano, S., Stevens, G., Schreifels, J., and Culigan, K.: The NOx Budget Trading Program: A collaborative, innovative approach to solving a regional air pollution problem, Elec. J., 20, 65-76, https://doi.org/10.1016/j.tej.2007.09.005, 2007.

National Climate Assessment: U.S. Global Change Research Program, available at: https://nca2014.globalchange.gov/report/ regions/midwest/graphics/temperatures-are-rising-midwest (last access: 13 November 2019), 2014.

Penner, J., Hegg, D., Andreae, M., Leaitch, D., Pitari, G., Annegarn, H., Murphy, D., Nganga, J., Barrie, L., Feichter, H: IPCC, Climate Change 2001: Aerosols and Indirect Cloud Effects, IPCC Third Assessment Report, Cambridge University Press, Cambridge, UK, 289-348, 2001.

Pitari, G., Visioni, D., Mancini, E., Cionni, I., Di Genova, G., and Gandolfi, I.: Sulfate aerosols from nonexplosive volcanoes: Chemical-radiative effects in the troposphere and lower stratosphere, Atmosphere, 7, 85, https://doi.org/10.3390/atmos7070085, 2016.
Reid, N., Misra, P. K., Bloxam, R., Yap, D., Rao, S. T., Civerolo, K., Brankov, E., and Vet, R. J.: Do We Understand Trends in Atmospheric Sulfur Species?, J. Air. Waste. Manage., 51, 15611567, https://doi.org/10.1080/10473289.2001.10464384, 2001.

Shah, V., Jaeglé, L., Thornton, J. A., Lopez-Hilfiker, F. D., Lee, B. H., Schroder, J. C., Campuzano-Jost, P., Jimenez, J. L., Guo, H., Sullivan, A. P., Weber, R. J., Green, J. R., Fiddler, M. N., Bililign, S., Campos, T. L., Stell, M., Weinheimer, A. J., Montzka, D. D., and Brown, S. S.: Chemical feedbacks weaken the wintertime response of particulate sulfate and nitrate to emissions reductions over the eastern United States, P. Natl. Acad. Sci. USA, 115, 8110-8115, https://doi.org/10.1073/pnas.1803295115, 2018.

Sickles II, J. E. and Shadwick, D. S.: Changes in air quality and atmospheric deposition in the eastern United States: 1990-2004, J. Geophys. Res., 112, D17301, https://doi.org/10.1029/2006JD007843, 2007.

Sickles II, J. E. and Shadwick, D. S.: Air quality and atmospheric deposition in the eastern US: 20 years of change, Atmos. Chem. Phys., 15, 173-197, https://doi.org/10.5194/acp-15-1732015, 2015.

WHO - World Health Organization: WHO Air quality guidelines for particulate matter, ozone, nitrogen dioxide and sulfur dioxide, Global update 2005, Summary of risk assessment, Geneva, p. 22, 2006.

Yao, X. and Zhang, L.: Trends in atmospheric ammonia at urban, rural, and remote sites across North America, Atmos. Chem. Phys., 16, 11465-11475, https://doi.org/10.5194/acp-16-114652016, 2016.

Yoshizumi, K. and Hoshi, A.: Size distributions of ammonium nitrate and sodium nitrate in atmospheric aerosols, Environ. Sci. Technol., 19, 258-261, https://doi.org/10.1021/es00133a007, 1985.

Yu, H., Kaufman, Y. K., Chin, M., Feingold, G., Remer, L. A., Anderson, T. L., Balkanski, Y., Bellouin, N., Boucher, O., Christopher, S., DeCola, P., Kahn, R., Koch, D., Loeb, N., Reddy, M. S., Schulz, M., Takemura, T., and Zhou, M.: A review of measurement-based assessments of the aerosol direct radiative effect and forcing, Atmos. Chem. Phys., 6, 613-666, https://doi.org/10.5194/acp-6-613-2006, 2006.

Zhang, L., Vet, R., Wiebe, A., Mihele, C., Sukloff, B., Chan, E., Moran, M. D., and Iqbal, S.: Characterization of the size-segregated water-soluble inorganic ions at eight Canadian rural sites, Atmos. Chem. Phys., 8, 7133-7151, https://doi.org/10.5194/acp-8-7133-2008, 2008.

Zhang, Y., West, J. J., Mathur, R., Xing, J., Hogrefe, C., Roselle, S. J., Bash, J. O., Pleim, J. E., Gan, C.-M., and Wong, D. C.: Long-term trends in the ambient $\mathrm{PM}_{2.5^{-}}$and $\mathrm{O}_{3}$-related mortality burdens in the United States under emission reductions from 1990 to 2010, Atmos. Chem. Phys., 18, 15003-15016, https://doi.org/10.5194/acp-18-15003-2018, 2018.

Zhuang, H., Chan, C. K., Fang, M., and Wexler, A. S.: Size distributions of particulate sulfate, nitrate, and ammonium at a coastal site in Hong Kong, Atmos. Environ., 33, 843-853, https://doi.org/10.1016/S1352-2310(98)00305-7, 1999. 